\title{
I. Die Vorgeschichte
}

\section{Die Ermordung Matthias Erzbergers am 26. August 1921}

Terror und Bürgerkrieg hatten die Gründung der ersten Republik begleitet, doch die Ermordung des früheren Reichsfinanzministers Erzberger, die die Attentatsserie von 1921/ 22 eröffnete, fiel in eine Zeit sichtbarer Konsolidierung und traf einen Mann, der zu den profiliertesten Repräsentanten des Weimarer Staates gehörte. Der während des Ersten Weltkrieges vom Propagandisten des Siegfriedens zum Vorkämpfer der Verständigung gewandelte Zentrumspolitiker, dessen Unterschrift unter der Kapitulation von Compiègne stand, war schon lange einer der bestgehaßten deutschen Politiker geworden, bevor die von Karl Helfferich geführte Rechtsopposition ihn mit einer erbarmungslosen Hetzkampagne überzogen hatte, deren Schlachtruf „Fort mit Erzberger" auf die Republik selbst zielte und den Zentrumspolitiker zur Zielscheibe schärfster Angriffe gemacht hatte ${ }^{1}$. Der demagogische Feldzug hatte Erfolg gehabt: Erzberger war im März 1920 in einem von ihm selbst angestrengten Gerichtsverfahren gegen Helfferich der Verquickung von Politik und persönlichen Geldinteressen für überführt befunden worden und sofort zurückgetreten, nachdem das Gericht die Anschuldigungen seines deutschnationalen Widersachers nur mit einer lächerlich geringen Geldstrafe geahndet hatte. Anschließend jedoch war es Erzberger gelungen, den auf ihm lastenden Verdacht der Steuerhinterziehung und des Meineides restlos zu entkräften. Trotz der haßerfüllten Feindschaft, die ihm in Deutschland entgegenschlug, war er gewillt, Ende August 1921 in die Politik zurückzukehren².

Der Mordanschlag, der dieser Absicht zuvorkam, ereilte ihn nicht unvorbereitet. Erzberger soll seiner Tochter gegenüber geäußert haben, die für ihn bestimmte Kugel sei bereits gegossen, und von der Polizci war er gewarnt worden, die Gefahr steige, je näher seine Rückkehr in die Politik bevorstünde ${ }^{3}$. Im Mai 1920 hatte auf einer Wahlversammlung ein Attentäter eine Handgranate auf ihn geworfen ${ }^{4}$, und bereits einige Monate zuvor war er bei einem Anschlag erheblich verletzt worden, den ein zwanzigjähriger Fähnrich namens Oltwig von Hirschfeld auf ihn verübt hatte ${ }^{5}$. Hirschfeld hatte sein Opfer während des Beleidigungs-

1 Nicht nur konnten Blätter wie der Miesbacher Anzeiger Erzberger ungestraft als „f cistgefressene[n] Lumpen, das Urbild schmutziger Käuflichkeit“ beschimpfen (Hoegner, Verratene Republik, S. 100); auch deutschnationale Politiker wie der Reichstagsabgeordnete Dr. Bang brandmarkten ihn öffentlich als „fleischgewordene Sünde“, die „der Zorn Gottes dem deutschen Volk als Zuchtrute auf den Leib gebunden habe" (ebenda, S. 62).

2 Die Zentrumsfraktion schob zu diesem Zeitpunkt die leidige „Erzbergerfrage“ allerdings noch vor sich her; ein Fraktionsausschluß Erzbergers hätte zur Spaltung der Partei führen können, seine Rückkehr aber nicht weniger als Sprengpulver gewirkt. Vgl. Morscy, Zentrumspartei, S. 397.

3 Vgl. Epstein, Erzberger, S. 429.

4 Vgl. Hocgner, Verratene Republik, S. 83.

5 Dazu eingehend Langemann, Attentat, S. 128 ff.; daneben Epstein, Erzberger, S. 400 ff.; Hannover/ Hannover-Drück, Politische Justiz, S. 108; Gumbel, Verräter, S. 54. 
prozesses Erzberger-Helfferich am 26. Januar 1920 an einem Seitenausgang des Berliner Gerichtsgebäudes abgepaßt und zwei Kugeln abgefeuert, deren eine die Schulter des Ministers durchbohrte und in der Lunge steckenblieb. Erzberger erholte sich schnell von den Folgen des Anschlags, so daß der Prozeß ohne Unterbrechung weitergeführt werden konnte, und auch gegen den wegen versuchten Mordes angeklagten Attentäter verhandelte das Schwurgericht des Landgerichts I in Berlin bereits am 21. Februar 1920. Der Angeklagte versicherte glaubhaft, in niemandes Auftrag gehandelt zu haben, sondern nach der Lektüre von Helfferichs Broschüre „Fort mit Erzberger“ den Entschluß zur Tat gefaßt zu haben, weil „er meinte, Helfferichs Aufforderung, Erzberger zu entfernen, müsse wörtlich genommen werden “6. Hirschfeld genoß die Sympathien des Gerichts und wurde wegen gefährlicher Körperverletzung unter Zubilligung mildernder Umstände zu einer Gefängnisstrafe von nur 18 Monaten verurteilt. Denn, so das Gericht in der Urteilsbegründung, der Angeklagte habe den Minister zwar „mit der Schußwaffe auf Monate arbeitsunfähig und damit vorerst unschädlich machen“ wollen, strafmildernd sei aber in Betracht zu ziehen, daß er durch „die Lektüre von Zeitungen, Broschüren und durch den persönlichen Eindruck, den der Reichsminister Erzberger in dem Beleidigungsprozeß gegen den Staatsminister a.D. Dr. Helferich [sic!] auf ihn [...] machte, [...] so gegen den Reichsminister beeinflußt worden [sei], daß er zu

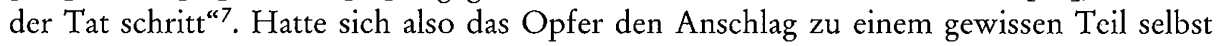
zuzuschreiben, so wußte das Gericht auf der anderen Seite zugunsten des Angeklagten zu sagen, daß er „sonst von idealer Gesinnung“ sei, und wies darauf hin, daß „zahlreiche Personen aus den verschiedensten Kreisen die Tat des Angeklagten gebilligt und ihn beglückwünscht haben“. Wie sehr die Öffentlichkeit gegen Erzberger eingestellt war, zeigte sich am deutlichsten darin, daß in konservativen Kreisen auch dieses Tendenzurteil noch als zu hart empfunden wurde, wie ein Gnadengesuch vom 9. September 1920 unterstrich, das den Hinweis auf Erzbergers „unheilvolle“ Tätigkeit nicht vergaß $\beta^{8}$. Zwar wurde dem Gesuch mit Rücksicht auf den nur zufällig glimpflichen Ausgang des Überfalls nicht stattgegeben; Hirschfeld erhielt später gleichwohl bedingten Strafaufschub?

Das tödliche Attentat wurde bei Bad Griesbach im Schwarzwald verübt, wo Erzberger am 26. August 1921 in Begleitung des Zentrumsabgeordneten Karl Diez einen Spaziergang unternahm, der ihn vom Kurhaus die sich durch den Wald zum Kniebis hochziehende Straße hinaufführte ${ }^{10}$. Unterwegs wurden die beiden von zwei Männern überholt, ohne ihnen weiter Beachtung zu schenken. Auf dem Rückweg aber, noch im bewaldeten Teil der Kniebisstraße, „bemerkte Diez plötzlich, daß die beiden jungen Männer, von denen sie auf dem Weg bergwärts überholt worden waren, wieder hinter ihm und Erzberger standen" ${ }^{11}$. Ehe dic Politiker reagieren konnten, hatten beide Verfolger ihre Revolver gezogen und feuerten auf sie. Diez stürzte, in Oberarm und Brust getroffen und kurzzeitig gelähmt, zu Boden; Erzberger hingegen versuchte, obwohl durch zwei Schüsse verwundet, seitabwärts durch ein Waldstück zu entkommen, und rutschte in Todesnot einen steilen Hang hinab, während unablässig weiter auf ihn geschossen wurde. Das wohl schon tödlich getroffene Opfer blieb

${ }^{6}$ Epstein, Erzberger, S. 401.

${ }^{7}$ Landesarchiv Berlin, Rep 58, Generalstaatsanwalt 1919-1933/45, Urteil gegen Oltwig von Hirschfeld, 21. 2. 1920.

${ }^{8}$ Ebenda, Gnadengesuch vom 9. 11. 1920 an den Beauftragten für Gnadensachen beim Landgericht I in Berlin.

9 Vgl. Langemann, Attentat, S. 129.

${ }^{10}$ Die Wiedergabe des Tathergangs folgt dem Anklageentwurf gegen Manfred von Killinger wegen Beihilfe zum Erzbergermord, S. 8 ff., in: StAF, Nr. 15.

11 Ebenda, S. 11. 
schließlich am Fuß einer Tanne liegen; einer der Attentäter sprang hinterher und brachte dem Hilflosen mehrere Kopfschüsse bei. Als es Diez gelang, sich wieder zu erheben und die Fahrstraße bergab zu gehen, sah er unten am Hang Erzberger tot liegen und die Täter sich in schnellem Schritt entfernen. Der Tatort zeugte vom verzweifelten Kampf des wehrlosen Opfers um sein Überleben; die von Kugeln zerfetzten Kleider des Ermordeten trugen Erdschürfspuren, seine aus der Tasche gerutschte Uhr war zur Tatzeit, um 11 Uhr 05, stehengeblieben. In Griesbach wurde das Verbrechen eine halbe Stunde später durch Diez bckannt, der sich aus eigener Kraft in den Ort hatte schleppen können. Die polizeilichen Nachforschungen setzten erst um 3 Uhr nachmittags ein, als die Täter natürlich längst verschwunden waren.

Der Mord erregte in ganz Deutschland anhaltendes Aufsehen, wobei vielfach nicht Abscheu, sondern offen zur Schau getragene Befriedigung zu spüren war, daß der verhaßte Politiker aus dem Weg geräumt war ${ }^{12}$. An seiner Beisetzung im schwäbischen Biberach, Erzbergers Reichstagswahlkreis seit 1903, nahmen 30000 Menschen teil. Reichskanzler Wirth erklärte den Ermordeten zum Märtyrer für die Sache der deutschen Republik und forderte den Zusammenschluß der Anhänger der Demokratie und des Christentums ${ }^{13}$. Die Reichsregierung lobte eine Belohnung von 100000 Mark für die Ermittlung der Täter aus ${ }^{14}$; SPD, USPD und Gewerkschaften forderten die „Anwendung aller staatlichen Mittel zur Bekämpfung der rechtsbolschewistischen Mordhetze"15. Die sozialdemokratische Linke war des Lavierens überdrüssig und verlangte, der sich ankündigenden Gegenrevolution mit „brutaler Rücksichtslosigkeit" ${ }^{\prime 16}$ entgegenzutreten. Die Reaktionen auf der Rechten schienen die Härte des verlangten Vorgehens zu bestätigen. Nachdrücklich wies Helfferich den von Scheidemann im Reichstag erhobenen Vorwurf zurück, Erzberger moralisch gemeuchelt und so die Mordatmosphäre maßgeblich geschaffen zu haben; namens der DNVP protestierte Herzgt gegen den "ungeheuerlichen Vorwurf“, daß die Deutschnationalen Urheber des Mordes gewesen seien, und sagte der Regierung allerschärfsten Kampf an ${ }^{17}$. Gleich in ihren ersten Kommentaren fand die nationalistische Presse eine willkommene Rückzugslinie in der Ablehnung, über Motive und politische Heimat der nicht ergriffenen Täter zu spekulieren, oder gab gar der Überlegung Ausdruck, Erzberger sei von Mitgliedern der eigenen Partei umgebracht worden, die ihn als Belastung empfunden hätten ${ }^{18}$. Durchgängig versuchte man auf der Rechten, die Fluchwürdigkeit des Verbrechens an Erzberger mit dem Hinweis auf den durch ihn dem Vaterland zugefügten Schaden zu relativieren oder zu entschuldigen ${ }^{19}$. Damit traf die rechtsstehende Presse ein in „nationalen Kreisen“ vorherrschendes Gefühl. Daß der Witwe Erzbergers roheste, den Mord verherrlichende Schmähbriefe zugesandt wurden, mag als Tun von Außenseitern abgetan werden. Aber auch ciner der beiden flüchtigen Mörder beschrieb stolz in einem von der badischen Staatsanwaltschaft abgefangenen Brief an seine Mutter, wie „sie Beide auf der Flucht unterstützt [worden seien], sogar von Frauen, auch arme

12 Vgl. die Anthologie entsprechender Äußerungen in: Der Erzberger-Mord, S. 62 ff. Aus Bcrlin wurde bekannt, daß Studenten in einem Demonstrationszug Unter den Linden Spottverse auf den Ermordeten sangen; Erman, Berliner Geschichten, S. 427.

13 Wirth, Reden während der Kanzlerschaft, S. 169 ff.

14 Schulthess' Geschichtskalender, Jg. 1921, S. 253.

${ }^{15}$ Horkenbach, Das Deutsche Reich, S. 130.

16 So Otto Braun in einer Reichstagsrede; Verhandlungen des Deutschen Reichstages, 1. Wahlperiode, Bd. 356, S. 8330.

17 Vgl. Horkenbach, Das Deutsche Reich, S. 133.

18 Vyl. etwa den Artikel „Cui bono?" der Deutschen Zeitung vom 13. 9. 1921.

19 Vgl. z. B. Neue Preußische Zcitung - Krcuzzeitung vom 28. 8. 1921. 
Frauen hätten geholfen dabei und sie beschenkt" ${ }^{20}$. Noch zu Beginn der Schwurgerichtsverhandlung im Juni $1922 \mathrm{kam}$ der Widerstreit zwischen Abscheu vor der Tat und Abneigung gegenüber dem Opfer deutlich zum Ausdruck, als der Vorsitzende sich an die Geschworenen wandte: „Wir alle, die wir im öffentlichen Leben stehen, haben [...] bei seinem [Erzbergers] Tode uns Gedanken darüber gemacht, ob dieser dem öffentlichen Wohl günstig oder ungünstig sei. Solche Gedanken müssen jetzt unbedingt weit hinter uns bleiben. Jetzt handelt es sich nur um die Frage, ob der heutige Angeklagte der Beihilfe zum Morde schuldig ist." 21

Angesichts dieser Situation entschloß sich die Reichsregierung zu drastischen Einschränkungen der liberalen Freiheitsrechte. Am 29. August 1921 erließ der Reichspräsident cine vom Kabinett beschlossene Republikschutzverordnung nach Art. 48 der Reichsverfassung, die „in erster Linie gegen den Rechtsbolschewismus sich richtet“, aber „trotzdem auch gegen kommunistische Verhetzung Anwendung finden soll“ ${ }^{22}$. Diese Verordnung ermächtigte den Reichsinnenminister, periodische Druckschriften zu verbieten, die zur Gewalt gegen die Verfassung oder Vertreter der republikanischen Staatsform aufriefen oder Verfassungsorgane und Staatseinrichtungen verächtlich machten. Versammlungen, bei denen die begründete Besorgnis bestand, daß in ihnen entsprechende Delikte propagiert würden, sollten gleichfalls untersagt werden können. Eine weitere, tags darauf erlassene Verordnung beschränkte das Recht zum Tragen der Militäruniform auf Angehörige der Reichswehr ${ }^{23}$.

Entstehungsgeschichte und Schicksale dieser Verordnungen zeigen die Grenzen eines wirksamen Republikschutzes in einem Staatswesen, das sich nicht nur einer erstarkenden Rechten erwehren mußte, sondern auch durch föderativen Aufbau und inneren Gegensatz der republikanischen Parteien in seiner Durchsetzungskraft behindert war. Während das sozialdemokratische Lager die Gelegenheit zur Entmachtung der alten Herrschaftseliten und damit zur Nachbesserung der Revolutionsergebnisse nutzen wollte ${ }^{24}$, standen die bürgerlichen Parteien der Weimarer Koalition gegen zwei Seiten. Dies zeigte sich unmittelbar im Charakter der Verordnung, die im ganzen kaum weniger durch den Mord als durch dic befürchteten Reaktionen auf ihn veranlaßt wurde. Zwar führten Ebert und Wirth in der Kabinettssitzung vom 29. August 1921 aus, mit der Verordnung müsse der Hetze der Rechtsradikalen endlich entgegengetreten werden ${ }^{25}$. Wirth gab aber wenige Tage später in einer Besprechung mit deutschnationalen Parteiführern deutlich zu erkennen, man habc die Verordnung als „Blitzableiter zur Abwehr gegen die Auswüchse von rechts“ beschließen müssen ${ }^{26}$, und beteuerte im Reichstag wie anderswo, es sei Aufgabe der Regierung gewesen, die große Bewegung im werktätigen Volk in geordneten Bahnen zu halten ${ }^{27}$. Ebenso sah Scheidemann in derselben Debatte die Regierung gedrängt, entweder den Kampf gegen die

${ }^{20}$ StAF, Nr. 15, Anklageentwurf gegen Manfred von Killinger, S. 60.

${ }^{21}$ Schweder, Erzberger-Mord-Prozeß, S. 59.

${ }^{22}$ Akten der Reichskanzlei, Die Kabinette Wirth I und II, Nr. 76, Ministerratssitzung vom 29. 8. 1921, S. 217, Anm. 5.

${ }^{23}$ Reichsgesetzblatt 1921, Teil 1, S. 1239 bzw. S. 1251.

${ }^{24}$ Vgl. Jasper, Schutz der Republik, S. 38.

${ }^{25}$ Akten der Reichskanzlei, Die Kabinette Wirth I und II, S. 216.

${ }^{26}$ Besprechung mit Parteiführern der Deutsch-Nationalen Volkspartei, 6. 9. 1921, S. 222, in: Ebenda, Nr. 79.

${ }^{27}$ Schulthess' Geschichtskalender, S. 272; vgl. Wirths Rede vom 31.8.1921 am Grabe Erzbergers: „Hcute sind nach Tausenden zählende Arbeitermassen in der Hauptstadt des Deutschen Reiches in Bewegung. Die Welle kann ganz Deutschland durchziehen. Mancherlei Gefahren können durchaus entstehen. [...] Aufs Neuc kann das Chaos über Deutschland heraufbeschworen werden." (Ebenda, S. 257). 
politischen Mörder selbst in die Hand zu nehmen oder aber den eigenen Sturz und den Bürgerkrieg zu riskieren ${ }^{28}$.

Die Strategie der Regierung zur Sicherung der Republik gegen den Umsturz von links ging auf. Die Massendemonstrationen vom 30. August 1921 führten nur zu vereinzelten Ausschreitungen ${ }^{29}$, der befürchtete Bürgerkrieg blieb aus. Wirksamer Widerstand gegen die Schutzverordnung allerdings ging von dem Land aus, in das die Spur der flüchtigen Mörder Erzbergers weisen sollte: Bayern. Hier regierte das Kabinett Kahr mit Hilfe eines am 4. November 1919 nach Art. 48 der Reichsverfassung verhängten Ausnahmezustandes, der nun durch einen gegen rechts gerichteten Reichsausnahmezustand aufgehoben zu werden drohte. Nachdem Kahr in einer Sitzung des Bayerischen Staatsministeriums seinen entschiedenen Widerstand gegen die Schutzverordnung bekräftigt hatte ${ }^{30}$, kam es zu Verhandlungen zwischen bayerischer und Reichsregierung, die dadurch erschwert wurden, daß Kahr den Konflikt nutzen wollte, um im Lager der bayerischen Rechtsverbände verlorenes Terrain wiederzuerobern ${ }^{31}$. Er weigerte sich daher, den schließlich gefundenen Kompromiß mitzutragen, der die Zuständigkeit für Druckschriften- und Versammlungsverbote den jeweiligen Landesbehörden übertrug, die politische Verantwortung aber beim Reichsinnenministerium beließ. Obwohl Bayern zudem durchgesetzt hatte, daß der Kreis der zu Schützenden nicht mehrals „Vertreter der republikanisch-demokratischen Staatsform“, sondern wertneutral als „Personen des öffentlichen Lebens" gefaßt wurde ${ }^{32}$ und damit die Verordnung gänzlich ihrer ursprünglichen Stoßrichtung entkleidet war, strebte Kahr den offenen Bruch an. Da die BVP ihm hierfür die Unterstützung versagte, demissionierte er und mit ihm am 12. September 1921 das ganze Kabinett. Die so geschwächte baycrische Abwehr gegen die Durchsetzungsbemühungen des Reichs wurde unhaltbar, als am 15. September Wirth im Überwachungsausschuß einen Bericht des preußischen Staatskommissars Weismann verlas, demzufolge die per Haftbefehl gesuchten Kapp-Putschisten Hermann Ehrhardt, Waldemar Pabst und Max Bauer sich bei München aufhielten. Zwei von ihm nach Bayern entsandte Kommissare hätten ihren Auftrag, Genaueres festzustellen, nicht ausführen können, „weil jeder, der sich nähere, mit Feuer empfangen würde", denn die Gesuchten würden von ihren Gefolgschaften, darunter aktiven Polizeieinheiten, wirksam geschützt. Es habe sich aber sicher ermitteln lassen, daß Ehrhardt im Münchener Polizeipräsidium ein- und ausgehe ${ }^{33}$. Die neue bayerische Regierung Lerchenfeld, der auch der mit Kahr zurückgetretene bisherige Justizminister und maßgebliche Förderer rechtsradikaler Bestrebungen in Bayern, Christian Roth, nicht

28 Vgl. ebenda, S. $277 \mathrm{f}$.

29 Näheres bei Jasper, Schutz der Republik, S. 37 f.

30 Akten der Reichskanzlei, Die Kabinette Wirth I und II, S. 224, Anm. 2.

${ }^{31}$ Schwend, Bayern zwischen Monarchie und Diktatur, S. 173.

${ }^{32}$ Akten der Reichskanzlei, Die Kabinette Wirth I und II, Nr. 83, Verhandlungen mit der bayerischen Sonderkommission am 8. 9. 1921, S. 242 bzw. S. 246.

33 In einer Regierungserklärung vor dem bayerischen Landtag dementierte der bayerische Staatssekretär und zukünftige Innenminister Schweyer die „ungeheuerlichen Beschuldigungen“: „Der Haftbefehl gegen Ehrhardt stammt vom 15. Mai 1920. Der bisherige Nichtvollzug des Haftbefehls ist so ausgelegt worden, daß unbedingt die böse Hand der bayerischen Behörden mit im Spiele sein müsse. Es wird dabei übersehen, daß auch sonstige Haftbefehle schon seit längerer Zeit nicht vollzogen werden können. Mit Vorwürfen allein ist es nicht getan. Das gilt auch für den Vorwurf, daß Ehrhardt immer noch beim Polizeipräsidenten Pöhner cin- und ausgehe, eine Behauptung, der der Polizeipräsident widerspricht und die für jeden unbefangenen Beurteiler den Stempel der Erfindung an der Stirne trägt." (Schulthess' Geschichtskalender, S. 266 f.) 
mehr angehörte ${ }^{34}$, zeigte sich den Reichsinteressen gegenüber wesentlich aufgeschlossener und hob den bayerischen Ausnahmezustand auf, nachdem der Reichspräsident am 28. September in einer entsprechend abgewandelten Verordnung ${ }^{35}$ den bayerischen Wünschen entgegengekommen war.

In der Zwischenzeit hatten auch die polizeilichen Ermittlungen im Mordfall Erzberger zu ersten Ergebnissen geführt. Zwar blieben die Täter selbst vorerst unauffindbar, aber es stellte sich schnell heraus, daß im Gasthof „Hirschen“ des Nachbarorts Oppenau in den Tagen vor dem Anschlag zwei Studenten im fraglichen Alter unter den Namen „Riese“ und „Bergen“ logiert hatten ${ }^{36}$. Sie waren am 21. August eingetroffen, hatten ihr Zimmer für drei Tage bestellt und ihr Gepäck - drei auffällig schwere Koffer - vom Bahnhof Oppenau abholen lassen. Nachdem sie die folgenden Tage außerhalb Oppenaus, vorgeblich auf Spaziergängen, verbracht hatten, kehrten sie am Mordtag um vier Uhr nachmittags, vom Regen stark durchnäßt, zurück und reisten kurz darauf mit dem Zug Richtung Offenburg ab. Es erwies sich bei näherer Untersuchung des Zimmers im Gasthof „Hirschen“, daß aus seinem rückwärtigen Fenster Papierschnitzel in einen am Haus entlangfließenden Bach geworfen worden waren, von denen einige geborgen werden konnten. Sie waren mit Telefonnummern beschrieben, die den Verdacht erhärteten, daß die beiden seit Wochen die Spur Erzbergers nach Berlin, Stuttgart, Biberach und Ulm verfolgt hatten. Es gelang der Polizei, aus weiteren hinter dem Haus gefundenen Fetzen von Briefumschlägen die Namen „Schulz" und „Tillessen“ sowic die Adresse „München, Maximilianstraße“ zu rekonstruieren ${ }^{37}$.

Am 15. September konnten die Zeitungen die Identität der mutmaßlichen Mörder Heinrich Schulz, geboren am 20. Juli 1893 in Saalfeld, und Heinrich Tillessen, geboren am 27. November 1894 in Köln, melden. Beide seien in München, Maximilianstraße 33, wohnhaft, aber offenbar entkommen. Eine von der badischen Staatsanwaltschaft mit Unterstützung der Münchener Behörden durchgeführte Haussuchung habe erhebliches Bclastungsmaterial erbracht $^{38}$. Was die Presse zu diesem Zeitpunkt noch nicht wußte: Die Untersuchungsbehörde war auf die Spur einer weitverzweigten Geheimorganisation gestoßen, die mit dem Mord an Erzberger in engster Verbindung zu stehen schien - die O.C. Der in der Maximilianstraße eingesetzte Beamte hatte den Bescheid erhalten, „Schulz sei vielleicht bei Kapitänleutnant von Killinger in der Leopoldstraße 62. Dort wurde von Killinger zwar nicht angetroffen, aber eine ziemliche Zahl von Schriftstücken vorgefunden, die Angelegenheiten der O.C. behandelten und auf Kapitänleutnant Hoffmann in der Franz-Josef-Straße 23 hinwiesen. " ${ }^{39}$ Dort konnte

${ }^{34}$ Ohne Roths Deckung konnte sich auch der Münchener Polizcipräsident Pöhner, unter dessen Ägide München zum Tummelplatz der illegalen Bestrebungen der Rechten und Aufenthaltsort Ehrhardts wie Ludendorffs geworden war, nicht länger halten; er trat im Oktober 1921 zurück. Zu den Umständen vgl. Benz, Politik in Bayern, S. 87 f.

${ }^{35}$ Reichsgesetzblatt 1921, Teil 1, S. $1271 \mathrm{f}$.

${ }^{36}$ Diese und die folgenden Angaben nach: StAF, Nr. 15, Anklageentwurf gegen Manfred von Killinger, S. $23 \mathrm{ff}$.

${ }^{37}$ Auf den Namen „Tillessen“ führte ein ungewöhnlicher Zufall: „Auf dem weißen Schnitzel war nur das Wortende ,lessen` erhalten. Als die für die Münchner Maximilianstraße zuständigen Briefträger darüber gehört wurden, ob ihnen dort eine Person bekannt sei, deren Namen mit ,lessen' endige, entsann sich einer von ihnen aus seiner Mannheimer Dienstzeit an den dort mehrfach vertretenen Namen ,Tillessen'. Auf Erwähnung dieses Namens wiederum meldeten sich vier andere Briefträger, die mehrfach Post an einen Herrn Tillessen als Untermieter in der Maximilianstraße abgegeben hätten." Ebenda, S. 50; vgl. Stern, Political Crime, S. 252.

38 Bayerischer Kurier vom 14. 9. 1921.

${ }^{39}$ StAF, Nr. 147, Anklageschrift gegen Alfred Hoffmann u. Gen., 16. 5. 1924. 
fast die gesamte Führungsspitze der Gehcimorganisation festgesetzt werden, die sich offenbar bei Hoffmann verabredet hatte, um ein neues Organisationsstatut zu beraten und eine Tagung der regionalen Führer vorzubereiten. Im Laufe desselben Tages zeigte sich, daß die in vier Abteilungen gegliederte Geheimorganisation unter ebenso vielen Adressen arbeitetc und daß in einer von ihnen, nämlich der Abteilung (b), Schulz und Tillessen als Mitarbeiter Killingers tätig gewesen waren. Das unauffällig als „Bayerische Holzverwertungsgesellschaft m.b.H." getarnte Büro der Abteilung (b) in der Trautenwolfstraße 8 wurde tags darauf durchsucht ${ }^{40}$. Die Räumc, dic den Eindruck erweckten, „die Zentrale der geheimen Organisation zu sein“, waren offenbar in größter Hast von belastendem Matcrial gesäubert worden; das Durchsuchungsprotokoll hiclt fest, „daß alle Korrespondenzen und andere wichtige Beweisstücke beseitigt worden sind. [...] In den Öfen war eine Mengc Papier verbrannt worden. " ${ }^{41}$ Immerhin ging auch aus den in der Wohnung verbliebenen Sachen deutlich genug hervor, daß hier eine recht betriebsame Tätigkeit stattgefunden haben mußte, wenn auch nicht unbedingt die einer Holzverwertungsfirma. Ein Hausmädchen des ahnungslosen Vermieters gab an, daß Schulz und Tillessen bis vor einigen Wochen täglich in der Wohnung anwesend waren ${ }^{42}$.

Im Zuge ihrer Ermittlungen gelang es der Offenburger Staatsanwaltschaft, Manfred von Killingers habhaft zu werden, der als Abteilungschef von Tillessen und Schulz der Beihilfe, wenn nicht der Anstiftung, zum Erzbergermord verdächtig war, in Frankfurt a.M. und Halle andere O.C.-Funktionäre besucht hatte und bei seiner Rückkehr noch im Zug identifiziert und verhaftet werden konnte ${ }^{43}$. Killinger verweigerte über die O.C. jede Aussage, gab aber zu, Schulz und Tillessen kurz vor seiner eigenen Abreise am 9. September zur Bahn gebracht zu haben. Auch gestand er, „daß wir in München über Erzberger geschimpft haben. Unwahr ist aber sicher, daß irgendein Plan besprochen wurde, den Erzberger zu beseitigen "44. Insbesondere beharrte er darauf, daß auch Ehrhardt, der mittlerweile als der „Consul“ und eigentliche Leiter der O.C. festgestellt worden, aber nach vorzeitiger Warnung entkommen war $^{45}$, nicht in die Mordsache verwickelt sei. Seine Aussage wirkte in diesem Punkt allerdings eher wie ein durchsichtiger Versuch, die Wahrheit zu verschweigen, ohne direkt zu lügen ${ }^{46}$.

${ }^{40}$ Eine genaue Darstellung bei Schweder, Erzberger-Mord-Prozeß, S. 56.

${ }^{41}$ StAF, Nr. 108, Durchsuchungsprotokoll, 14. 9.1921.

42 Ebenda.

${ }^{43}$ Ebenda, Nr. 88, Aktenvermerk betr. Festnahme des Manfred von Killinger, 13. 9. 21. Der schnelle Zugriff erwies sich als berechtigt - tatsächlich wartete ein anderes O.C.-Mitglicd auf dem Münchener Hauptbahnhof, um Killinger bei sciner Ankunft zu warnen.

${ }^{44}$ Ebenda, Aussage Manfred von Killinger, 5. 12. 1921.

${ }^{45}$ Ebenda, Nr. 31, Mitteilung des Untersuchungsrichters am LG Offenburg an den ORA, 2. 12. 1926.

${ }^{46}$ Ebenda, Nr. 88, Aussagen Manfred von Killinger, 14. und 19. 11. 1921. Auch Ehrhardts Adjutant Alfred Hoffmann gab zu, „daß sehr wohl [...] von uns darüber gesprochen worden ist, daß Erzberger gewaltsam beiseite geschafft werden müßte. [...] Es herrschte im Winter und Frühjahr d. Js. in diesen Kreisen allgemein eine Stimmung, die ich zusammenfassen möchtc in dem Wort ,Schlagt den Erzberger tot'. In diese Stimmung bin auch ich mit hineingerissen worden, und sicher habe auch ich bei irgendwelchen Gelegenheiten [...] den Ausdruck gebraucht, Erzberger müsse beseitigt werden, denn er sei der Urheber der jetzigen hoffnungslosen Lage. Ich gebe zu, daß über diescs Thema vielleich: in einer Form gesprochen worden ist, die dem Zuhörer den Eindruck erweckt hat, daß ich mich ernstlich mit dem Gedanken trügc, diesem Wunsche auch die Tat folgen zu lassen." Ebenda, Nr. 105, Aussage vom 1.12.1921. 
Die auffällige Tatsache, daß die am Tatort gefundenen Patronenhülsen teilweise die gleiche Bezeichnung trugen wie die in dem Büro gefundene Munition, konnte er nicht erklären ${ }^{47}$.

Bei dieser Sachlage war der badische Staatsanwalt überzeugt, die für den Mord verantwortliche Verschwörung aufgedeckt zu haben. Die beschlagnahmten Listen legten die Bezirkseinteilung der O.C. offen, so daß in den folgenden Wochen weitere Verhaftungen im ganzen Reich vorgenommen wurden, bis insgesamt 34 Angehörige des Geheimbundes in Untersuchungshaft saßen. Als sich allerdings der Verdacht nicht erhärten ließ, daß die O.C. als Organisation den Anschlag auf Erzberger vorbereitet habe, wurde im Herbst 1921 ein Großteil der Beschuldigten wieder auf freien Fuß gesetzt, bei anderen der auf Mordbeteiligung lautende Haftbefehl durch einen neuen wegen Verdachts der Geheimbündelei ersetzt ${ }^{48}$. Zum Jahreswechsel 1921/22 befanden sich nur mehr Killinger und dessen Mitarbeiter in der Abteilung (b), Herbert Müller, in Untersuchungshaft.

Die eigentlichen Täter, Schulz und Tillessen, hatten sich ins Ausland absetzen können. Immerhin gelang es der Staatsanwaltschaft, ihren Fluchtweg detailliert zu rekonstruieren. Noch am Tag des Attentates hatten sie auf Umwegen per Bahn die Rückfahrt nach München angetreten und waren dort am 27. August morgens angekommen ${ }^{49}$. Tags darauf trafen sie sich mit Killinger im Englischen Garten zum Kaffeetrinken und holten am 30. August sogar ihre nach der Rückkehr bei Killinger untergestellten Koffer wieder ab. Anschließend aber verließen sie überraschend München. Als Erklärung für ihr Verschwinden konnte nur die öffentliche Verbreitung eines ersten Ermittlungserfolges in Frage kommen: Am 31. August war nämlich durch Presseberichte das bisher von den Fahndungsbehörden gehütete Geheimnis über die mutmaßliche Identität der Studenten „Riese“ und „Bergen“ publik geworden, so daß sich Schulz und Tillessen in München nicht mehr sicher wähnen konnten. Tatsächlich teilte Schulz kurz darauf in einem Brief an seine Mutter mit ${ }^{50}$, daß er fortan andauernd auf Reisen sei und bitte, seinen Koffer und alle Post an Manfred von Killinger zu schicken. Läßt sich schon aus diesen Zeilen entnehmen, daß Schulz und Tillessen bei ihrer Flucht von Dritten unterstützt wurden, so erhärtete ein wenig später bei der Offenburger Staatsanwaltschaft eingehender, offenbar von Tillessen aufgesetzter Brief diesen Verdacht noch. Darin gestanden die beiden eine gewisse Beteiligung an der Ermordung Erzbergers, wollten aber nur zugunsten der wirklichen Täter Fluchthilfe geleistet haben und versuchten, durch falsche Orts- und Datumsangaben die Behörden in die Irre zu führen. Da zwischen dem Briefdatum und der Abstempelung in Emden sechs Tage lagen, drängte sich der Verdacht auf, daß das Schreiben zwar in Emden zur Post gegeben, aber dort nicht verfaßt worden war. Dies wertete die Staatsanwaltschaft Offenburg als Indiz für eine mögliche O.C.-Beteiligung, denn gerade Emden und andere nahegelegene Nordseestädte bildeten einen Schwerpunkt der Aktivitäten der O.C. Daß Schulz und Tillessen sich auch weiterhin vertrauter Mittelsmänner bedienen konnten, wurde aus einem Brief der Mutter von Schulz an ihre Tochter deutlich. In ihm schilderte sie, daß ihr ein Kontaktmann unter konspirativen Umständen einen Brief ihres Sohnes am 6. November 1921 zur Kenntnis gebracht habe ${ }^{51}$.

${ }^{47}$ Ebenda, Nr. 88, Aussage vom 5. 12. 1921.

${ }^{48}$ Ebenda, Nr. 147, Anklageschrift gegen Hoffmann u. Gen., S. 40 f.

${ }^{49}$ Diese und die folgenden Angaben nach dem Anklageentwurf gegen Killinger, S. 101 ff., sowie nach der Druckfassung der Anklage, in: Ebenda, Nr. 15 bzw. Nr. 167, S. 27 ff.

50 Das von der Polizei abgefangene Schreiben trägt den Poststempel „München 45 - 12. Sep. 21 - 6-7 N“, also das Datum des Tages, an dem um sieben Uhr morgens die Münchener Haussuchungen zur Enttarnung der „Bayerischen Holzverwertungsgesellschaft" eingesetzt hatten, was darauf deuten läßt, daß Schulz sich möglicherweise auch noch nach dem 9. 9. versteckt in München aufgehalten hatte; Anklageentwurf gegen von Killinger, S. 106, in: Ebenda.

${ }^{51}$ Ebenda, Nr. 167, Anklage gegen Killinger, S. 17 f. 
Der tatsächliche Aufenthaltsort der Flüchtlinge blieb den Ermittlungsbehörden ein Rätsel, bis Ende Dezember eine Anzeige einlief, daß Schulz und Tillessen in Budapest gesehen worden seien. Nachforschungen bestätigten diesen Verdacht: Am 8. November 1921 waren die beiden in der Stadt eingetroffen und lebten seitdem in den vornehmsten Hotels auf großem Fuße. Auch hierin deutete sich wieder die Unterstützung durch Dritte an, denn Schulz war vor seiner Flucht ohne Vermögen gewesen und Tillessens seit Juli 1921 unberührtes Bankkonto bereits im September 1921 gesperrt worden. Tatsächlich ergaben die Nachforschungen der Offenburger Kriminalisten, daß häufig ein dritter Mann in Begleitung von Tillessen und Schulz aufgetreten sei, der sich mit ihnen zu langen Konferenzen im Hotelzimmer zurückgezogen habe. Auch konnte festgestellt werden, daß Tillessen aus Budapest ein Telegramm an einen Dr. Müller in München gesandt hatte ${ }^{52}$. Der Adrcssat des Telegramms und damit mutmaßliche Mittelsmann der Mörder Erzbergers war Adolf Müller, Rechtsberater und Verbindungsmann Otto Pittingers, des Leiters der mit der baycrischen Regicrung in Verbindung stehenden Vereinigten Vaterländischen Verbände ${ }^{53}$. Angespornt durch eine - falsche Mitteilung des preußischen Staatskommissars Weismann, nach der Pittinger der eigentliche Leiter der O.C. in Bayern sei und seine Münchener Adresse, Möhlstraße 10, das Zentralbüro Südbayern der O.C. sowie deren Nachrichtenabteilung und Kurierdienst beherberge ${ }^{54}$, sondierte der Offenburger Staatsanwalt beim neuen Münchener Polizeipräsidenten Nortz die Möglichkeit eines Vorgehens gegen die Möhlstraße ${ }^{55}$. Mit dessen Einverständnis wurde am 22. Februar 1922 in der Wohnung Pittingers Haussuchung gehalten, die immerhin soviel Material erbrachte, daß gegen diesen Voruntersuchung beantragt und Adolf Müller wegen des Verdachts der Begünstigung von Tillessen und Schulz verhaftet wurde ${ }^{56}$. Müller konnte zusätzlich anhand eines Hotelmeldezettels überführt werden, sich vom 17. bis zum 20. Dezember in Budapest aufgehalten und dort Tillessen getroffen zu haben ${ }^{57}$.

Für die Staatsanwaltschaft stand damit fest, daß der persönlich mittellose Müller, der bei seiner Festnahme 164000 Mark bei sich trug ${ }^{58}$, Tillessen und Schulz mit von Pittinger stammenden Geldern unterstützt hatte. Da nun aber Pittingers Anstrengungen zur Sammlung des rechten Lagers in Bayern von der Regierung Kahr kräftig gefördert worden waren ${ }^{59}$, drohten die Ermittlungen der badischen Staatsanwaltschaft in einen politischen Skandal zu münden. In Bayern war mittlerweile cine erhebliche Erregung über die angebliche Bespitzelung vaterländischer Männer durch den preußischen Staatskommissar und die badische

52 Vgl. Schweder, Erzberger-Mord-Prozeß, S. 67 ff.

${ }^{53}$ Dies bestätigt implicite auch ein Schreiben des badischen Oberstaatsanwaltes Link an den Münchener Polizeipräsidenten Nortz, 21. 3. 1921, in: StAF, Nr. 183.

${ }^{54}$ Ebenda, Vermerk vom 9. 3. 1921. Auf diese Angabe Weismanns stützt sich offenbar Schulz in seiner irrigen Auffassung, daß das wirkliche Haupt der O.C. Pittinger und nicht Ehrhardt sei; vgl. Schulz, Zwischen Demokratie und Diktatur, S. 364, Anm. 2.

55 StAF, Nr. 183, Die Offenburger Staatsanwaltschaft an den Münchener Polizeipräsident, 21. 3. 1923.

56 Dieses Material bezog sich auf eine finanzielle Unterstützung der O.C. durch Pittinger: Bei der Haussuchung fiel der Staatsanwaltschaft ein Bricf Ehrhardts in die Hände, in dem dieser sich bei Pittinger für die Finanzierung bedankte; Vernehmung Killinger, 25. 2. 1922, und Bericht der Badischen Staatsanwaltschaft, 9. 3. 1922, in: Ebenda, Nr. 86; Augsburger Postzeitung vom 8. 3. 1922.

57 StAF, Nr. 86, Bericht der Badischen Staatsanwaltschaft an den Untersuchungsrichter, 2. 3. 1922.

58 Ebenda. Sicher nicht zu Unrecht erschien dem Staatsanwalt in diesem Zusammenhang auch auffällig, daß bei der oben erwähnten Haussuchung in der Wohnung Pittingers auch ein Budapester Mittelsmann der Organisation Pittingers angetroffen wurde.

59 Thoß, Ludendorff-Kreis, S. 176. 
Staatsanwaltschaft entstanden. Geschickt verband Innenminister Schweyer im bayerischen Landtag das Eingeständnis, daß die badischen Behörden ihre Zuständigkeit in keiner Weise überschritten hätten, mit der unüberhörbaren Feststellung, daß die mit Adolf Müller Festgenommenen „sich alle hohe vaterländische Verdienste erworben“ hätten und der ganze Vorfall „tief bedauerlich sei“60. Deutlicher noch wies der Münchener Polizeipräsident Nortz auf die Unterstützung hin, die Müller ungeachtet des auf ihm lastenden Verdachts in Bayern genoß: „Daß Rechtsanwalt Müller in Haft bleiben muß, wird hicr von vielen Seiten aus sehr beachtenswerten Erwägungen bedauert [...]. Der etwaige Abtransport Müller's nach Offenburg wird in weiten Kreisen Stimmungen auslösen, welche die Polizeidirektion zumal angesichts der für Ende des Monats vielleicht zu erwartenden Unruhen nicht ohne Sorge betrachten kann." 61

Nachdem die badischen Ermittlungsbehörden der mutmaßlichen Mörder bis zu diesem Zeitpunkt nicht hatten habhaft werden können, griffen sie nun zu unkonventionellen Methoden und versicherten sich der Dienste eines zwielichtigen Mannes aus dem Dunstkreis der Rechtsverbände namens Ernst Krull. Krull war selbst für dic O.C. tätig und auch in die Ermordung Rosa Luxemburgs und Ernst Liebknechts verwickelt gewesen, galt aber in den eigenen Reihen als notorischer Aufschneider ${ }^{62}$. Er bot in der verfahrenen Situation der badischen Staatsanwaltschaft gegen Bezahlung an, einen Kontakt zu Tillessen und Schulz herzustellen. Die Ermittlungsbehörden sahen durchaus die Gefahr, daß Krull für die Gegenseite arbeitete und, statt die Verhaftung der Erzbergermörder zu ermöglichen, vielmchr der O.C. präzise Erkenntnisse über den Ermittlungsstand liefern würde. Dennoch glaubte die Staatsanwaltschaft dieses Risiko eingehen zu müssen, weil Krull die Polizei schon Anfang Oktober 1921 auf Budapest als vermutlichen Aufenthaltsort der Mörder hingewiesen und einige interessante und offensichtlich zutreffende Details über die Arbeit der O.C. und ihren $\mathrm{Haß}$ auf Erzberger geliefert hatte. Nach Budapest geschickt, wollte Krull tatsächlich auch bald mit Schulz und Tillessen in Kontakt getreten sein, kündigte dann aber die Zusammenarbeit auf, als er erkannte, daß die badische Staatsanwaltschaft insgeheim auch ihn überwachte. Es ließ sich nie feststellen, ob Krull wirklich zur Ergreifung der Erzbergermörder hätte beitragen können oder ob er nicht vielmehr in ihrem Auftrag die Ermittlungsbehörden auf eine falsche Spur zu locken versucht hatte ${ }^{63}$.

Am Ende der Ermittlungen stand ein höchst unbefriedigendes Ergebnis: Die durch die Schwere der Indizien für überführt geltenden Mörder Tillessen und Schulz waren entkommen; die meisten der im Zusammenhang mit der Aufdeckung der O.C. Verhafteten hatten Ende 1921 aus der Untersuchungshaft entlassen werden müssen und sahen nun einem Verfahren wegen Mitgliedschaft in eincm Geheimbund entgegen, über dessen Struktur und politische Absichten keine rechte Klarheit zu gewinnen war. Infolge dieser Entwicklung war auch das Verfahren gegen die noch in Offenburger Untersuchungshaft verbliebenen Killinger und Herbert Müller gefährdet: Für eine Anklage wegen Beihilfe zum Mord an Matthias Erzberger schien die Beweislage zu dürftig; ein Verfahren wegen bloßer Begünstigung der Täter hätte nach der geltenden Rechtslage aber keinen Offenburger Gerichtsstand mehr begründen können und so die Abgabe auch dieser Untersuchung nach München zwingend erforderlich gemacht. Dagegen aber wehrte sich der Staatsanwalt Burger aus der Überlegung heraus, daß ein Münchner Gericht „vielleicht subjektive Gründe dafür findet, den v. Killinger

60 Augsburger Postzcitung vom 8. 3. 1922.

${ }^{61}$ StAF, Nr. 168/178, Polizeipräsident Nortz an den badischen Oberstaatsanwalt Burger, 16. 3. 1922.

62 Vgl. zu Krull: Gumbel, Verräter, S. 44 und S. 49 f.

${ }^{63}$ Aussage Krull, 3. 10. 1921, und Gemcinsamcr Bericht von Untersuchungsrichter und Staatsanwalt beim Landgericht Offenburg, 22. 6. 1922, in: StAF, Nr. 50 und Nr. 13. 
freizusprechen "64, und erwog sogar die zeitweilige Außcrverfolgungsetzung Killingers, um sich für den Fall der immer noch erhofften Ergreifung Tillessens und Schulz' nicht den Weg zu dessen möglicher Verurteilung wegen Beihilfe oder sogar Anstiftung zu verstellen ${ }^{65}$.

Man behalf sich mit einem Kompromiß: Herbert Müller wurde außer Verfolgung gesetzt, Killinger hingegen in Offenburg am 11. Mai 1922 angeklagt, Schulz und Heinrich Tillessen Beihilfe zum Mord geleistet zu haben. Da der Tatbestand der Beihilfe aber natürlich nur als crfüllt angesehen werden konnte, wenn Schulz und Tillessen in absentia ihrer Tat zu überführen waren, befaßte sich die Verhandlung vom 7. bis 13. Juni 1922 mehr mit den flüchtigen Haupttätern als mit dem Angeklagten selbst, was immerhin zum Ergebnis hatte, daß neben der Schuld von Tillessen und Schulz auch die Tatsache, daß Hintermänner die beiden unterstützt hatten, eindeutig festgestellt werden konnte. Dennoch wurde allen Indizien zum Trotz Killinger am 13. Juni 1922 durch die Geschworenen von dem Vorwurf freigesprochen, Schulz und Tillessen Beistand zu ihrer Flucht geleistet zu haben ${ }^{66}$. Damit war die Wendung eingetreten, die dic Offenburger Staatsanwaltschaft besonders bei Durchführung des Verfahrens in München befürchtet hatte. Das Urteil wurde in der demokratischen Presse als Fehlurteil gebrandmarkt, in „nationalen" Zeitungen hingegen befriedigt kommentiert.

Der Freispruch war cin Justizirrtum. Nach dem Zweiten Weltkrieg vor Gericht gestellt ${ }^{67}$, gestanden Tillessen und Schulz, daß sie beide zusammen mit Killinger „innerhalb der Organisation C eine[r] extrem radikale[n] Sonderklique“ angchört hätten: dem Germanenorden. Drei Wochen vor der Tat habe ein Abgesandter dieser Geheimverbindung ihnen im Bciscin Killingers den Befehl erteilt, Erzberger zu töten. Daraufhin hätten dic beiden sich auf Erzbergers Fährtc gesetzt „im Bewußtsein, daß sie zur Ausführung ihres Vorhabens Förderung jeder Art und Schutz vor Verfolgung nach verübter Tat durch ihre Auftraggeber, insbesondere auch Manfred v. Killinger und die ihm verfügbaren Mittel der Organisation C erwarten durften " ${ }^{68}$. Bestätigten die Geständnisse von Schulz und Tillessen so die 1922 gegen Killinger erhobene Anklage, so schufen sie mit der überraschenden Zuschreibung des Mordauftrags an einen bislang öffentlich nicht in Erscheinung getretenen Bund, der nicht mit der O.C. identisch sein sollte, ein neues Rätscl. Um den Wahrheitsgehalt dieser Behauptung zu prüfen, soll im weiteren zunächst dic Geschichte beider Geheimorganisationen und ihr Verhältnis zueinander beleuchtet werden.

\section{Die Organisation „Consul“}

Mit Untersuchungen im Milieu konspirativer Geheimorganisationen der deutschen Rechten zu Anfang der Wcimarer Republik wird ein unübersichtliches Gelände betreten, dessen Begehung auch dadurch crschwert wird, daß staatliche Erhcbungen über solche Vereinigungen an einem grundlegenden Mangel litten: Der Weimarer Republik stand kein mit entspre-

${ }^{64}$ Vermerk vom 29. 11. 1921, in: Ebenda, Nr. 13.

65 „Wird v. Killinger in München angeklagt und abgeurteilt, so wird durch das Urteil ein ne bis in idem geschaffen [...]. Wenn dann spätere Feststellungen, etwa im Fall der Ergreifung der Haupttäter, ergeben, daß v. Killinger nicht nur Begünstigter, sondern Gehilfe oder gar Anstifter ist, so wäre jedes weitere Verfahren gegen v. Killinger abgeschnitten“ (ebenda).

${ }^{66} \mathrm{Vgl}$. Schweder, Erzberger-Mord-Prozeß, S. $79 \mathrm{ff}$.

${ }^{67}$ Heinrich Tillessen wurde am 28. 2. 1947 vom Landgericht Konstanz wegen Mordes zu 15, Heinrich Schulz am 19.7. 1950 vom Landgericht Offenburg wegen Totschlags zu zwölf Jahren Zuchthaus verurteilt; StAF, Nr. 6 bzw. 7.

${ }^{68}$ Urteil gegen H. Tillessen, 28. 2. 1947, S. 6, in: Ebenda, Nr. 6. 
chenden Befugnissen ausgestatteter Verfassungsschutz zur Verfügung, und die informatorische Sammeltätigkeit des Reichskommissars für Überwachung der öffentlichen Ordnung konnte diesen Mangel nur unvollkommen kompensieren. Kaum ergiebiger sind hier die späteren Erinnungsschriften von Ehrhardt-Leuten: „Die schärfste Waffe in der Hand der O.C. aber und die ungeheuerlichste Gefahr, die aus ihr erwuchs, war die Tatsache, daß sie niemals bestand“, versicherte Salomon $1930^{1}$. Zwanzig Jahre später präsentierte er allerdings eine andere Version, derzufolge die „sagenhafte“ O.C. zwar als Organisation nie bestanden, wohl aber Ehrhardt sich 1920 nach Bayern „eine Art Hausmacht" mitgebracht habe. Dieser Verband „war ein überaus loser Zusammenschluß ehemaliger Soldaten und Offiziere der Marine-Brigade, die [...] weiterhin gute Kameradschaft untereinander hielten und in persönlicher Anhänglichkeit an ihren alten, Chef' [...] gelegentlich Aufgaben erfüllten, die ihnen von des Kapitäns ,Zentrale in München zudiktiert wurden. "2 Was dies für Aufgaben waren, wollte Salomon von Ehrhardt selbst erfahren haben: Letzten Endes sei die O.C. aus der durch den Versailler Vertrag erzwungenen Beschränkung der deutschen Armee entstanden. Nach den Vertragsbestimmungen durfte die Reichswehr keinen militärischen Nachrichtendienst unterhalten; diesen Aufgabenbereich habe - verdeckt - die Reichsmarine übernommen und sei dabei von den Männern aus Ehrhardts Marinebrigade unterstützt worden: „Die O.C. war nichts weiter als ein Teil der im Neuaufbau begriffenen ,Abwehr. "3

Nicht weniger verschwommen ist das Bild, das die Forschung von Ehrhardts geheimnisumwobener Untergrundvereinigung zeichnete. Eine Reihe von Historikern folgt Stern, der die O.C. als Freikorps im Wartestand zur Bekämpfung innerer und äußerer Feinde beschreibt und sie nicht mit einer politischen Mordorganisation verwechselt wissen will ${ }^{4}$. Aber auch innerhalb dieser Gruppe reichen die Einschätzungen von der Bewertung des Geheimbundes als Teil der Schwarzen Reichswehr ${ }^{5}$ bis hin zu der Auffassung, daß Charakter und Ziele der O.C. viel zu verschwommen seien, um eine einheitliche Zuordnung zu erlauben ${ }^{6}$. Eine andere Auffassung schließlich folgt der Sicht Gumbels, der 1924 plakatierte: „Es dürfte wohl keinen politischen Mord der letzten Zeit in Deutschland geben, bei dem nicht die Organisation C unmittelbar oder mittelbar beteiligt gewesen wäre."7 Von den jüngeren Autoren hat sich besonders Waite Gumbels Urteil zu eigen gemacht und die O.C. als eine Mordorganisation beschrieben, die die Todesstrafe an Verrätern nach mittelalterlichem Vorbild vollzog8. Denselben Standpunkt nahm die in der DDR veröffentlichte Literatur ein ${ }^{9}$.

1 Die Geächteten, S. 299; vgl. Heinz, Nation, S. 135.

2 Fragebogen, S. 394.

3 Ebenda, S. 399. Diese These ist in der Sekundärliteratur verschiedentlich aufgegriffen worden; vgl. Langemann, Attentat, S. 146, Anm. 109; Sauer, Mobilmachung, S. 131; Koch, Bürgerkrieg, S. 308; Fenske, Konservativismus, S. 157.

4 Stern, Organisation Consul, S. 20; vgl. Meinl, Revolutionär, S. 91.

5 Vgl. Jasper, Aus den Akten, S. 433.

6 Vgl. Krüger, Brigade Ehrhardt, S. 79.

7 Verschwörer, S. 114. Ebenso urteilte die Weltbühne auch nach dem Prozeß gegen die O.C.: „Die Geschichte der politischen Morde in Deutschland ist die Geschichte der Organisation C." (Lania, Organisation Consul, S. 665). Andere Urteile der republikanischen Publizistik dicser Zeit waren nicht weniger bündig: „Die Attentate auf Gareis, Erzberger, Rathenau, Harden, von Gerlach sind von Mitgliedern der O.C. ausgeführt resp. versucht worden. Verräter verfielen der Feme. Man hat daher mit Recht von einer Mörderorganisation gesprochen." Deutschvölkischer Katechismus, S. 131.

8 Waite, Vanguard of Nazism, S. 203 und 213.

9 Mahlke, Organisation Consul, S. 456. 
Um den Charakter der O.C. und ihr Verhältnis zum politischen Terrorismus zu erhellen, bedarf es eines Blicks auf ihre bis in den Sommer 1920 zurückreichende Entstehungsgeschichte. Wohl schon während der Auflösung der Brigade Ehrhardt nach dem gescheiterten KappLüttwitz-Putsch war der Gedanke aufgetaucht, den Zusammenhalt zu wahren, um den Entlassenen beim Aufbau einer wirtschaftlichen Existenz bchilflich zu sein und sie gleichzeitig als Reservoir für künftige militärische Einsätze zu behalten ${ }^{10}$. Neben einem vor allem der Traditionspflege dienenden „Verein der ehemaligen Angehörigen der 2. und 3. Marinebrigade" entstanden zwei Verbindungen, die direkte Vorläufer der O.C. bildeten: Der EhrhardtOffizier Manfred von Killinger sammelte seit Juli 1920 in der „Vereinigung ehemaliger Sturmsoldaten " Männer, „die sich im Falle höchster Not zur Verfügung zu stellen" hätten, und stellte die Bildung von Ortsgruppen in Aussicht. Am 11. September 1920, dem Vorabend der endgültigen Auflösung, wurde außerdem in Munsterlager ein „Bund ehemaliger Ehrhardt-Offiziere" (BEEO) gegründet, dessen Ehrenvorsitz dem seit Mai flüchtigen Ehrhardt angetragen wurde. Sein Vorstand setztc sich mit Alfred Hoffmann (Erster Vorsitzender), Friedrich von Abendroth (Zweiter Vorsitzender), Eberhard Kautter (Schriftführer) und Herbert Müller (Schatzmeister) aus eben den Marineoffizicren der alten Brigade zusammen, dic dann auch in der O.C. führende Funktionen einnehmen sollten ${ }^{11}$.

Fast noch bedeutsamer für die Vorgeschichte der O.C. war, daß die Marinedienstfähigen der bisherigen Brigade zu einem großen Teil in die Reichsmarine übernommen wurden und dort die neugeschaffene Schiffsstammdivision Nordsee bildeten. Andere Mannschaften und Offiziere schlossen sich zu „Arbeitsgemeinschaften“ zusammen, die gemeinsame Beschäftigung vor allem auf dem Land suchten, um als intakte Zellen der Ehrhardt-Organisation bis zu einem erneuten Ruf ihres Führers zu überwintern. Während sich die Grundbesitzer in Norddeutschland eher reserviert zeigten, waren die infolge des Kapp-Putsches gewandelten politischen Verhältnisse in Bayern den Interessen der Brigade-Angehörigen günstiger, so daß dort seit Herbst 1920 eine ganze Reihe von Arbeitsgemeinschaften, die 35 bis 120 Mann umfaßten, zur Moorkultivierung am Ammersee oder zur Holzrodung am Tegernsee eingesetzt wurden ${ }^{12}$. Diese Arbeitsgemeinschaften bestanden auch nach Gründung der O.C. fort und bildeten eines der Reservoirs, aus denen die Führung geeignete Männer für die Arbeit in der Zentrale oder besondere Einsätze auswählte ${ }^{13}$.

Aus den persönlichen Aufzeichnungen von Hartmut Plaas, der im Juni 1922 an der Ermordung Rathenaus beteiligt war und dann nach seiner Haftentlassung Ehrhardts Adjutant wurde, wird deutlich, daß die Arbeitsgemeinschaften sich selbst durchaus nicht als wirtschaftliche Versorgungseinrichtung für alte Brigadeangehörige ansahen, wie später be-

${ }^{10}$ StAF, Nr. 179, Entwurf der Geheimbündelei-Anklage gegen Hoffmann u. Gen., S. 10; vgl. Wette, Noske, S. 685.

${ }^{11}$ StAF, Nr. 147, Anklageschrift gegen Hoffmann u. Gen., S. 17 f.

${ }^{12}$ Der Pommersche Landbund allerdings vermittelte Brigadeangehörige in kleineren Gruppen zum Einsatz gegen streikende Landarbeiter auf Güter in Pommern; etwa 600 Mann der Brigade sollen dicsem Aufruf gefolgt scin. Entwurf der Geheimbündelei-Anklage, S. 11 und 20, Aussage Hoffmann vom 24. 9. 1921, in: Ebenda, Nr. 179 bzw. 105.

${ }^{13}$ Ebenda, Nr. 113, Bcricht Kriminalkommissar Reidler, 15. 9. 1921. Zwar behaupteten die befragten O.C.-Funktionäre gegenüber dem Staatsanwalt, daß die Arbeitsgemeinschaften an die O.C. nur „lose angehängt“ seien (ebenda, Nr. 105, Aussage Hoffmann, 24. 9. 1921). Plaas' Tagebucheintragungen, der 1920/21 der Arbeitsgemeinschaft Schmidt bei Wcilheim angehörtc, belegen aber intensivc Kontakte zwischen den Arbeitsgemeinschaften und der Münchener Zentrale. 
hauptet wurde ${ }^{14}$. Von den eigentlichen Informationen und Planungen abgeschnitten, begriffen sie ihr Tun als ein Opfer für Erhardt und sie vertrauten darauf, daß cs bald "losgehen" werde. Je länger allerdings das angekündigte bewaffnete Handeln verschoben wurde, desto perspektivärmer gestaltete sich dieSituation der sich als „eine Art Mobilmachung “ verstehenden Arbeitsgemeinschaften auf dem Land, die mit wirtschaftlichen Problemen zu kämpfen hatten und offenbar auch in der Planung Ehrhardts eine immer geringere Rolle spielten, so $\mathrm{daß}$ zunehmend mehr Männer absprangen ${ }^{15}$.

Auch die andere Bastion der Ehrhardt-Leute an der Nordsee bröckelte 1921. Nach den Tätigkeitsberichten des in der O.C. für die Brigademänner in der Reichsmarine zuständigen Korvettenkapitäns Paul Werber bestanden zwar zusätzlich zur Schiffsstammdivision Nordsee auch bei der Küstenwehrabteilung 6 in Borkum, Emden und Wilhelmshaven sowie an der Marineschule Mürwik bei Flensburg Ortsgruppen mit jewcils etwa 50 Mann. Doch drohten sie der Autorität ihres Führers zu entgleiten, nachdem sich ihre Hoffnung auf einen Einsatz in Oberschlesien zerschlagen hatte. Schwerer noch wog, daß es nach Ansicht der EhrhardtOffiziere unmöglich schien, den gesamten Verband im Eventualfall geschlossen „nach unten ", also nach Bayern, zu bringen. Besonders bei einem im Mai 1921 erwarteten kommunistischen Aufstand in Mitteldeutschland und Thüringen wäre die im Norden abgeschnittene Marineformation nahezu wertlos gewesen. Damit aber verlor der Stützpunkt im Norden entscheidend an Gewicht; zunehmend wurde München zum einzigen Kristallisationspunkt des ursprünglich aus der Marine entstandenen Freikorps Ehrhardt. Im Frühsommer 1921 lösten sich erst die Borkumer und kurz darauf die Wilhelmshavener Ortsgruppe ganz auf, nachdem mit den alsbald in der O.C. in Erscheinung tretenden Klintzsch, Schüder und Baldenius auch noch andere Offiziere der alten Marinebrigade ihren Abschied genommen hatten. Die Ausscheidenden stellten sich sämtlich „unserer Organisation“ zur Verfügung, wurden aber verpflichtet, über „ihre Anstellungsmöglichkeit nicht zu sprechen“16.

Die Münchener Zentrale, die diese Aktionen koordinierte, hatte sich schon längere Zeit zuvor konstituiert, nachdem bereits im September 1920 ein erster Teil der Ehrhardt-Offiziere die Reichsmarine nach kurzem Gastspiel wieder verlassen hatte ${ }^{17}$. Hoffmann, die treibende Kraft bei der Gründung der O.C., ging noch Ende September 1920 nach München und traf nach eigener Aussage im Oktober mit den Ehrhardt-Offizieren Kautter, Henrich, von Prince und Müller zusammen. Am 1. November 1920 wurde über den Kaufmann Wilhelm Bollinger, früher Zahlmeister in der Marinebrigade, eine Wohnung in der Trautenwolfstraße

14 Vgl. z. B. BA, NL 150, 110, Aussage Werber vom 2. 12. 1921, und das Urteil des Staatsgerichtshofs gegen Hoffmann u. Gen. vom 26. 10. 1924, in: BA/P, 30. 3.-12J190/22.

15 NL Plaas, Tagebuch, Eintrag vom 18.1. und 11. 9. 1921. Plaas erwog sein Ausscheiden bereits im April 1921 (Eintrag vom 5. 4. 1921).

16 StAF, Nr. 168/178, Tätigkeitsberichte Werber vom 29. 10., 12. 11., 23.11. 1920, 9. 5. 1921 („Mannschaften: Stimmung ziemlich gereizt. Wenn nach O.S. [Obcrschlesien] gerufen wird, wird eine ziemliche Menge einfach abhauen.“) und 10.5.1921 („Ich halte es daher für dringend notwendig, wenn irgend angängig, die Verlegung unseres Standpunktes nach dem Süden und das Sammeln unserer Kräfte am besprochenen Ort möglichst bald anzuordnen. Eine Schwierigkeit wird ja im Hinunterbringen der Kräfte liegen."); NL Plaas, Tagebuch, Eintrag vom 9. 6. 1921; BA/P, 15.07-341, „Ludwig" [Paul Werber] an Hoffmann, 25. 5. 1921.

17 Es handelt sich unter anderen um dic Korvettenkapitänc Wilhelm Ehrentraut und Paul Werber sowic die Kapitänleutnants Alfred Hoffmann, Eberhard Kautter und Karl Tillessen, die sämtlich in der späteren O.C. Schlüssclpositionen einnahmen. Kurz darauf, im November 1920, verließ auch Plaas die Marine, um zur „Reserve Ehrhardt“ zu gehen, und schloß sich der Arbeitsgemeinschaft Schmidt in Bayern an (Mitteilung Karl-Arnd Plaas an den Verf., 1. 6. 1993); vgl. Krüger, Brigade Ehrhardt, S. 71. 
gemietet, in die die am 10. Dezember 1920 gegründete „Bayerische Holzverwertungsgesellschaft $\mathrm{mbH}^{\text {" }}$ einzog ${ }^{18}$. Die Tarnbezcichnung war geschickt gewählt, da die bisher in der Moorkultivierung eingesetzten Arbeitsgemeinschaften mit Beginn der kalten Jahreszeit bei der Bereitung von Stockholz eingesetzt wurden ${ }^{19}$; tatsächlich aber entfaltete die neue $\mathrm{GmbH}$ zu keiner Zeit geschäftliche Tätigkeit. Vielmehr hatte Bollinger bei Abschluß des Mietvertrages durchblicken lassen, daß er die Wohnung für eine politische Organisation benötigte ${ }^{20}$.

Es ist nicht auszuschließen, daß der sich nun zielstrebig entwickelnden Organisation anfänglich der spätere Anschluß an dic Orgesch vorgeschwebt hatte, wie Hoffmann später behauptete; jedenfalls aber bestand seit Spätherbst 1920 eine reichsweit operierende Geheimorganisation, dic die in Ortsgruppen zusammengeschlossenen Ehrhardt-Männer mit Richtlinien versorgte und deren Vorstände in regelmäßigen Abständen nach München beorderte, um besonders die Werbung neuer Mitglieder zu besprechen ${ }^{21}$.

Spätestens mit dem Eintritt Killingers in die Zentrale im Januar 1921 erweiterte die Organisation ihr Tätigkcitsgebiet. Killinger übernahm die militärische Leitung des Bundes und plante die Herausgabe einer eigenen Zeitschrift „Wiking“, deren erste Nummer im Juni 1921 erschien $^{22}$. Eine besondere Unterabteilung der Zentrale in München war für Mobilmachungsvorbercitungen, Alarmierung und Einberufung der erfaßten Freiwilligen zuständig und hielt die Einsatzbereitschaft für einen künftigen Ernstfall aufrecht. Die erwartete Situation trat ein, nachdem das nicht eindeutige Ergebnis der Volksabstimmung über den Verbleib Oberschlesiens beim Deutschen Reich am 2. Mai 1921 zum Einfall polnischer Insurgenten geführt hatte, die unter der Leitung Wojciech Korfantys nach wenigen Tagen das Gebiet westlich bis zur Oder in ihre Gewalt gebracht hatten. Zu Hunderten eilten Freiwillige aus dem ganzen Reich ins Kampfgebiet, um die schwachen Kräfte des Oberschlesischen Selbstschutzes aufzufüllen. Auch Ehrhardt-Leute machten sich spontan nach Oberschlesien auf; in Breslau stellten Zedlitz-Neukirch und Koppe eine kleine Formation als Kristallisationspunkt der Hinzukommenden auf, die unter dem Namen "Sturmkompanie Koppe“ nördlich Annabergs kämpfte. Killinger, der unterdessen in Breslau mit der Führung des Oberschlesischen Selbstschutzes über die Stellung von Truppen verhandelt hatte, übernahm Mitte Mai die Führung der auf etwa 200 Mann angewachsenen Sturmkompanie, die zum Zeichen ihrer Zugehörigkeit zu Ehrhardt das Wiking-Emblem am Ärmel trug ${ }^{23}$.

Infolge des Anfang Juni geschlossenen Waffenstillstandes fand der Einsatz der Freikorps sein Ende, ohne daß sich die angestrcbte Gelegenheit zum innenpolitischen Eingreifen geboten hätte. Dennoch hatte die Niederschlagung des Polenaufstandes die Organisation, die

18 Aussage Hoffmann, 23. 9. 1921, und Entwurf der Geheimbündelei-Anklage, S. 20 f., in: StAF, Nr. 105 bzw. 179.

19 Denn zumindest cin bayerisches Blatt war offenbar bald auf die getarnte Sammlungsbewegung der Ehrhardtleute aufmerksam geworden und veröffentlichte im Januar 1921 einen Artikel unter der Überschrift „Die Holzhacker der Brigade Ehrhardt“, der den Strohmännergeschäften eines bayerischen Holzhändlers mit einer von Kapitänleutnant Hoffmann in München geführten „MarincArbeitsgemeinschaft" nachging und hellsichtig warnte: „Der cigentliche Zweck der Marine-Arbeitsgemeinschaft und des Vertrages mit dem Holzhändler ist natürlich der, die Ehrhardtleute [...] für die Zwecke eines Rechtsputsches zusammenzuhalten." Der Kampf, 5. 1. 1921.

20 Aussage Böckel, o. D., in: StAF, Nr. 105.

21 BA, NL 150, 110, Aussage vom 31. 10. 1921.

${ }^{22}$ Aussage Killinger, 10.4 1922, und Entwurf der Geheimbündelei-Anklage, S. 22, in: StAF, Nr. 88 bzw. 179; Krüger, Brigade Ehrhardt, S. 75.

${ }^{23}$ Aussage Killinger, 10. 4. 1922, und Entwurf der Geheimbündelci-Anklage, S. 23 f., in StAF, Nr. 88 bzw. 179. 
sich seit Mai desselben Jahres nach dem Decknamen ihres Führers Ehrhardt „Consul“ nannte ${ }^{24}$, erheblich gestärkt und führte ihr, obwohl sie in Oberschlesien nicht unter eigenem Namen gekämpft hatte, laufend neue Mitglieder zu, die vor allem mit dem Hinweis auf einen drohenden abermaligen Polenaufstand geworben wurden ${ }^{25}$. Im Juli kehrte auch Killinger nach München zurück und nahm seine Tätigkeit als Leiter der militärischen Abteilung der O.C. wieder auf. Ein kleinerer Teil seiner Leute war in Oberschlesien geblieben und sollte als Stamm zur Aufstellung einer Truppe für den erwarteten vierten Polenaufstand dienen. Killinger vereinbarte mit der Leitung des Oberschlesischen Selbstschutzes die Aufstellung einer eigenen, als „Regiment Süd“ bezeichneten Formation von nahezu 2000 Mann, die im Bedarfsfalle auf die Stärke einer Division ausgebaut werden sollte, und arbeitete einen Mobilmachungsplan aus ${ }^{26}$. Jede Ortsgruppe hatte 25 Mann zu stellen und die Garantie zu geben, daß die aufgerufene Mannschaft innerhalb von drei Tagen nach Alarmierung am Sammelplatz eintreffe ${ }^{27}$. Bewaffnung, Einkleidung und Unterhalt waren vom Oberschlesischen Selbstschutz zu übernehmen.

Tatsächlich erhielt Killinger vom Heimatschutz Schlesien auf ein Konto bei einer Schlesischen Bank eine erste Zahlung von 300000 Mark für Verpflegungs- und Marschgelder ${ }^{28}$, die ihren Empfänger aber erst erreichten, als dieser sich bereits wegen des Erzbergermordes in Untersuchungshaft befand. Offenbar war die Aufstellung des Regiments bereits bis ins kleinste vorbereitet; der Polizei fielen in München auch Befehlsentwürfe und Autzeichnungen in die Hände, die sich mit der detaillierten Aufteilung neugeworbener Mitglieder auf Waffengattungen und Kompanien befaßten. Gleichzeitig hatte die O.C.-Führung Kontakte zu anderen Freikorps geknüpft, um sie für den Fall eines vierten polnischen Aufstandes zum Anschluß an die O.C. zu bewegen, und eine eigene Wiener Organisation geschaffen, die eine entsprechende Sammlungstätigkeit in Österreich entfaltete ${ }^{29}$.

Nicht zuletzt dieses rasante Wachstum der Ehrhardt-Organisation führte im Sommer 1921 zu einem Ausbau auch der inneren Organisationsstruktur. Die Münchener Zentrale war schon im Laufe des ersten Halbjahres auf vier Büroadressen verteilt worden, in denen täglich zu festgesetzten Dienstzeiten "viele junge Leute, die den Eindruck entlassener Offiziere machten, teils paarweise, teils gruppenweise, zum Teil mit Mappen, regelmäßig ein- und ausgingen "30. Die Zentrale beschäftigte „ungefähr 30 bei uns beamtete Offiziere“, wie ihr Leiter Alfred Hoffmann eingestand, der militärische Befehlsgewalt über seine Mitarbeiter besaß und als der eigentliche Stellvertreter des „Chefs" Ehrhardt angesehen wurde ${ }^{31}$.

Die von Hoffmann selbst geleitete Abteilung (a) (auch „allgemeine Abteilung“) unterhielt eine Nachrichtensammelstelle, wahrte die Verbindungen zu anderen rechtsgerichteten Orga-

${ }^{24}$ Bis zu diesem Zeitpunkt wurde intern die Bezeichnung „Früheres Freikorps Ehrhardt" verwendet (ebenda, S. 18).

25 Vgl. Krüger, Brigade Ehrhardt, S. 77.

${ }^{26}$ Aussage Killinger, 10. 4. 1922, und Befehl der Zentrale vom 19. 7. 1921, in: StAF, Nr. 88 bzw. 150.

${ }^{27}$ Vgl. Stern, Organisation Consul, S. 23.

${ }^{28}$ StAF, Nr. 183, Aussage des Provinzialgeschäftsführers des Heimatverbandes Schlesien, Hepke, 14. 11. 1921.

${ }^{29}$ Ebenda, Nr. 179, Entwurf der Geheimbündelei-Anklage, S. 32 f. Es handelt sich vor allem um die in Oberschlesien eingesetzten Freikorps Roßbach, von Aulock, Bergerhoff, von Heydebreck und von Lützow.

${ }^{30}$ Ebenda, Nr. 105, Aussage Böckel, o. D.

${ }^{31}$ Ebenda, Nr. 108, Aussage Hoffmann, 2. 11. 1921. Daß Ehrhardt der eigentliche Leiter der O.C. war, crklärte Hoffmann unumwunden selbst: „Chef der Organisation ist der frühere Kommandeur der II. Marine-Brigade, Korvettenkapitän a.D. Ehrhardt“ (ebenda, Nr. 105, Aussage vom 24. 9. 1921), während ein in der O.C. verfaßtes Papier zur Koordinierung der Aussagen aller der Gcheimbündelei 
nisationen und bemühte sich, neue Kontakte und Bündnisse zu knüpfen. Auch Killinger als Leiter der mit den militärischen Aufgaben betrauten Abteilung (b) war dafür zuständig, Kontakte zu anderen militärischen Formationen zu knüpfen und die Vertrauensleute im Reich zu unterrichten. Die als politische oder Presse-Abteilung firmicrende Abteilung (c), geleitet von Eberhard Kautter, gab die Zeitschrift „Wiking“ heraus, sammelte Zeitungsnachrichten und versuchte auf die Presse Einfluß zu nehmen; von ihr gingen von Zeit zu Zeit verbindliche Richtlinien für die politische Arbeit an die Gefolgsleute im Reich heraus. Schließlich verfügte die O.C. noch über eine Abteilung (z), die die Finanz- und Verwaltungsgeschäfte besorgte. Hiermit war Wilhelm Bollinger beauftragt, der aus einem ihm zur Verfügung gestellten Fonds neben den Büro- und Reisekosten auch dic Gehälter der von der Zentrale beschäftigten Mitarbeiter zu bezahlen hatte und unter Eingeweihten als der Mann galt, „der immer mit einer Aktentasche herumläuft, in der viele Millionen sind“32.

Neben dieser Ressortabgrenzung bestanden für die drei inhaltlich arbeitenden Abteilungen genauere Geschäftsverteilungspläne, die im Falle der Abteilung (b) gemäß einer von Killinger stammenden Diensteinteilung neben dem „Ressortchef“"33 vier Unterabteilungen mit präzise festgelegten Aufgabengebieten vorsahen und nicht zufällig eher an eine staatliche Militärbehörde als an einen Geheimbund erinnerten. So war Killingers Adjutant in der Unterabteilung (b) 2, Herbert Müller, für „1) Organisation, 2) Taktik, 3) Mobilmachungsvorbereitungen, 4) Alarmierung, 5) Einberufung, 6) Stellenbesetzung nach Rücksprache mit A 1 [Ehrhardt]“ zuständig, der spätere Erzbergermörder Heinrich Schulz ${ }^{34}$ hingegen in der Unterabteilung (b) 3 unter anderem für „1) Briefwechsel, 2) Bekanntgabe von Veränderungen an die B.L. [Bezirksleitungen], 3) Geschäftszimmer, 4) Materialbeschaffung, 5) Schreibmaschinen-Arbeiten “35. Die hier verrichtete Arbeit war ebenso effizient wie professionell; sie wurde ausschließlich durch besonders bewährte Offiziere geleistet, die ihre Stellung als „Einberufung“ 36 begriffen und im Verkehr untereinander ihren überkommenen militärischen Verhaltenskodex wahrten, der beispielsweise die Anrede von Vorgesetzten in der dritten Person vorsah ${ }^{37}$.

Ende Mai oder Anfang Juni 1921 zog die Organisation die Konsequenz aus dem wachsenden Zulauf von Anhängern, die bislang nicht in Beziehung zur früheren Marinebrigade gestanden hatten, und ergänzte die bisherige persönliche Bindung an ihren Führer durch ein politisches Programm, auf das sich alle Mitglieder vereidigen lassen mußten. Diese „Satzungen“ definierten den Bund als „Geheimorganisation“ mit dem Namen „Organisation C“, der jedem „nationalgesinnten Deutschen“ offenstand, „Juden und überhaupt jeden Fremdrassigen “ aber ausschloß ${ }^{38}$. Der konspirative Charakter des Bundes erhellt aus der Verpflichtung zu strengstem Stillschweigen über alle Organisationsnachrichten gegenüber Fremden und zu

Beschuldigten dekretierte, daß Ehrhardt nur die Rolle eines Beraters und ideellen Chefs gespielt habe, „ohne jedoch direkt der Leiter zu werden“ (BA, NL 150, 113, Richtlinien zur Verteidigung, S. 12).

${ }^{32}$ StAF, Nr. 180, Aussage Lauch, 1. 10. 1921.

${ }^{33}$ Diesen Terminus verwendete Hoffmann (BA, NL 150, 113, Richtlinien zur Verteidigung, S. 11).

${ }^{34}$ Sein Mittäter H. Tillessen war in der Unterabteilung (b) 4 tätig.

${ }^{35}$ StAF, Nr. 183. Vgl. den kommentierten Teilabdruck dieser Diensteinteilung bei Langemann, Attentat, S. 144.

${ }^{36}$ BA, NL 150, 113, Richtlinien zur Verteidigung, S. 9. Urlaubsgewährung erfolgte in der Zentrale nur auf Antrag: Dienstrcisen und jede Entfernung aus München bedurften der Genehmigung durch den jewciligen Ressortleitcr (StAF, Nr. 109, Aussage Henrich, 27. 9. 1921).

${ }^{37}$ Salomon, Fragebogen, S. 395.

${ }^{38}$ Die Satzungen hier und im folgenden zit. nach: BA, NL 150, 113, Satzungen. Zu ihrer Bewertung vgl. Fenske, Konservativismus, S. 157. 
größter Vorsicht im Schriftverkehr, vor allem aber aus der lapidaren Formulierung des $₫ 11$ seiner Satzung: „Verräter verfallen der Fehme.“ Das Gehorsamsgelöbnis gegenüber den Vorgesetzten und dem obersten Leiter verwandelte jedes neugeworbene Mitglied in ein gefügiges Werkzeug der Bundesführung. In „geistiger" Hinsicht verlangte der Bund die "weiteste Pflege des nationalen Gedankens" und die "Bekämpfung der antinationalen Weimarer Verfassung mit Wort und Schrift", insbesondere der Sozialdemokratie und des Judentums. Zum „materiellen“ Ziel wurde die „Sammlung von entschlossenen nationalen Männern“ erklärt, um „die vollständige Revolutionierung Deutschlands zu verhindern“ und „bei großen inneren Unruhen deren vollständige Niederwerfung zu erzwingen und durch Einsetzung einer nationalen Regierung die Wiederkehr der heutigen Verhältnisse unmöglich zu machen".

Auf dem Weg dahin hatte die O.C. im Zuge ihrer militärischen Sammlungsbewegung ein sich über ganz Deutschland erstreckendes Netz von Bezirksorganisationen gespannt, die von der Zentrale kontrolliert und geführt wurden. Die meisten Bezirke waren in Ortsgruppen untergliedert, denen „Unterführer" oder „Vertrauensleute“ vorstanden, die ihre Anweisungen über die ihnen vorgesetzten Bezirksleiter von der Zentrale erhielten ${ }^{39}$. Die Vertrauensleute mußten zum 1. und 15. jeden Monats Meldung nach München erstatten, die neben der Auflistung von $\mathrm{Zu}$ - und Abgängen auch einen Tätigkeitsbericht über die geleistete Arbeit enthielt ${ }^{40}$.

Doch schien dieses Organisationsschema auf Dauer nicht effizient genug, um angesichts der raschen Ausbreitung des Bundes ein reibungsloses Zusammenspiel von Bezirken und Leitung zu garanticren. Insbesondere der sich ausweitende Schriftverkehr führte dazu, daß die Führung sich trotz aller Vorsichtsmaßnahmen in einem Maße exponierte, das ihre Geheimhaltung gefährdete ${ }^{41}$. Mit einer Reihe von Maßnahmen suchte die O.C. ihre Verratsanfälligkeit zu reduzieren und verständigte sich noch kurz vor der einsetzenden Verhaftungswelle über eine Änderung der Verbindungsstränge. Die Polizei konnte einen auf den 8. September 1921 datierten Organisationsplan beschlagnahmen, der die insgesamt 14 O.C.Bezirke $^{42}$ sieben neuzuschaffenden Oberbezirken zuordnete, über deren Leiter fortan aller Verkehr der Münchener Zentrale mit den Gefolgsleuten im Reich abgewickelt werden sollte, um so den Kopf der Organisation wieder besser gegen Entdeckungsgefahr abzuschirmen. Bevor jedoch diese Neustrukturierung auf einer für den 15. September 1921 anberaumten Vertretertagung beschlossen werden konnte, hatte die badische Staatsanwaltschaft festgestellt, daß Tillessen und Schulz seit Frühjahr 1921 in der Abteilung (b) der Münchener Geheimorganisation tätig waren, und daraufhin die O.C.-Zentrale ausgehoben.

Die beschlagnahmten Organisationspläne schienen darauf hinzudeuten, daß die O.C. im Grunde nur eine in den Untergrund verlegte Fortsetzung der Marinebrigade Ehrhardt

${ }^{39}$ StAF, Nr. 114, Aussage Vornfett, 26. 9. 1921.

${ }^{40}$ Darunter verstand eine Anweisung vom Juli 1921: „a) Werbetätigkeit, b) Ausbildung, c) Beteiligung an öffentlichen Veranstaltungen (Versammlungsschutz, -störung), d) Verhältnis und Verkehr mit anderen nationalen Verbänden." Weiterhin war Meldung zu erstatten über „Neues über andere Bünde" sowie „Volksstimmung in Bezug auf national- und linksradikale Strömungen“ (ebenda, Nr. 150, Befehle der Zentrale).

${ }^{41}$ Die Zentrale führte ein Befehlsbuch, in dem alle ausgehenden Weisungen mit cincr „Befehlsbuchnummer" (BBN) aufgeführt wurden. Bis zur Entdeckung der O.C. waren den BBN zufolge fast 1000 Verfügungen von der Zentrale an die einzelnen Bezirke im Reich übermittelt worden.

42 Es handelte sich um die Bezirke A (Kiel), B (Wilhelmshaven), C (Hamburg), E (Pommern), F (Köln), G (Gießen), H (Halle), I (Berlin), K (Wiesbaden), L (Thüringen), M (Leipzig), N (Breslau), O (Stuttgart). Der 15. Bezirk P (München) wurde von der Abt. B der Zentrale selbst geführt; StAF, Nr. 89 und Nr. 183. 
bildete, die wie die oberschlesischen Freiwilligenverbände angesichts der von den Alliierten erzwungenen Beschränkung der deutschen Verteidigungsmittel eine „merkwürdige Stellung zwischen Legalität und Illegalität" 43 einnahm - offiziell den deutschen Bchörden weder bekannt noch von ihnen geduldet, unter der Hand aber sogar gefördert. Eine Reihe von Indizien bestärkt diese Vermutung: Viele Mitglieder einzelner Ortsgruppen beharrten in ihren Vernehmungen darauf, sich der Organisation nur für einen außenpolitischen Einsatz zur Verfügung gestellt zu haben, und tatsächlich befaßt sich fast ein Drittel aller sichergestellten Befehle der Zentrale mit der Vorbereitung eines Einsatzes in Oberschlesien. O.C.-Funktionäre gingen mit Bezug auf die militärische Ohnmacht des Reiches ohne Scheu Industrielle in Nord- und Süddeutschland um Geld für „unsere Bewegung “44 an; Ehrhardt selbst bekannte bricflich „die Finanzierung meiner Organisation durch die pfälzische Industrie“45.

Schließlich arbeitete die Zentrale unter dem kaum verhüllten Schutz des Münchener Polizeipräsidiums, dessen Leiter Pöhner den steckbrieflich gesuchten Ehrhardt mit falschen Pässen versorgte und ihm einen ungefährdeten Aufenthalt in München ermöglichte ${ }^{46}$. Daß Ehrhardt unbehelligt in den Lokalen der bayerischen Landeshauptstadt verkehrte, war schon Anfang 1921 publik geworden und hatte zu einem vielsagenden Dementi des Bayerischen Innenministeriums geführt: „Eine Kontrolle der Münchener Kaffeehäuser ist nur dann angczcigt, wenn die Richtigkeit der Zeitungsmeldungen, daß Ehrhardt tagtäglich in einem Kaffee zu sprechen sei, einwandfrei feststeht.“ Auch sei die Fahndung "wegen gänzlichen Mangels einer Personalbeschreibung " sehr erschwert! ${ }^{47}$ Noch während der von der badischen Staatsanwaltschaft ausgelösten Verhaftungswelle in München, die praktisch alle hauptamtlichen Mitarbeiter Ehrhardts in Untersuchungshaft brachte, konnte ihr Chef dort eine Besprechung mit O.C.-Vertretern aus Deutschland und Österrcich über die entstandene Lage abhalten ${ }^{48}$.

Als nicht ganz abwegig erwies sich auch die Behauptung der O.C.-Männer, die Reichsregierung habe von ihrer Organisation durchaus Kenntnis gehabt, denn der preußische Staatskommissar Weismann habe cinen Mittelsmann zu Hoffmann geschickt, der erkunden

43 Krüger, Brigade Ehrhardt, S. 76.

${ }^{44}$ StAF, Nr. 183, Bcricht Werber, 11. 8. 1921. Hoffmann schätzte „den Umsatz im Jahr auf ungefähr eine Million“, von der ein Großteil aus Kaufmannskreisen in Bremen stamme und unter Hinweis vor allem auf dic Notlage in den Arbeitsgemeinschaften der Ehrhardt-Truppe eingeworben worden sei. Erhebliche Summen verschlangen allein die Büro- und Reisekosten des O.C.-Apparates, dessen hauptamtliche Funktionäre außerdem ein festes Gehalt bezogen. Auch die Vertrauensleute der Ortsgruppen konnten über einen kleinen, monatlich ausbezahlten Werbeetat verfügen (Aussage Hoffmann, 23. 9. und 2. 11. 1921; in: Ebenda, Nr. 105 bzw. 108).

45 BA/P, 30.03. 12 J 190/22, Bd. 9, Ehrhardt an den Regierungspräsidenten von Regensburg, 26. 11. 1921. Zur Finanzierung der O.C. vgl. Krüger, Brigade Ehrhardt, S. 82 f., und Fenske, der die von Scheidemann in einer Reichstagsrede 1926 geäußerte Behauptung bestätigt, nach der die Marine die O.C. finanziert habe (Konservativismus, S. 157).

46 Der Reichskommissar für Überwachung der öffentlichen Ordnung hielt fest: „Die Münchner CKreise haben [...] gute Beziehungen zur bayerischen Polizei. Von Strafverfolgungen gegen CAngehörige sind sic stets rechtzeitig unterrichtet und werden auch über die Vorgänge bei den Zugkontrollen an der bayerischen Landesgrenze stets unterrichtet. Auch durch die Fremdenkontrolle über die Hotels und Logierhäuser werden sie von der Anwesenheit mißliebiger Personen in Kenntnis gesetzt. " BA/P, 15.07-340, Bcricht des RKO vom 16. 9. 1922; vgl. Freksa, Kapitän Ehrhardt, S. 216 f.; Krüger, Brigade Ehrhardt, S. 78. Pöhner schützte Ehrhardt offenbar sogar vor der Übereifrigkeit seiner eigenen Beamten; vgl. Münchener Post vom 16./17. 12. 1922.

47 Bayerische Staatszeitung vom 1. 3. 1921.

48 StAF, Nr. 179, Entwurf der Gehcimbündelei-Anklage, S. 39. 
sollte, ob Ehrhardt einen neuen Putsch plane ${ }^{49}$. Dieser Mittelsmann bestätigte denn auch, Weismann mitgeteilt zu haben, daß dic O.C. für Oberschlesien ein Freikorps gegründet habe, „mit dem die Regierung arbeite, und daß die Organisation der Ehrhardt-Leute als solche wahrscheinlich auch in Erscheinung treten werde, wenn, ausgehend von linksradikalen Elementen, innere Unruhen entstehen würden, die eine Abwehr durch Nationalgesinnte notwendig machen würden" 50 . Der bei der Bildung des Selbstschutzes selbst maßgeblich beteiligte Weismann erfuhr seinerseits, daß Ehrhardt im Gegensatz zu Ludendorff cin Engagement von Freikorps gegen reguläre polnische Truppen in Oberschlesien ohne Beistand der Reichswehr für sinnlos halte, und schloß daraus, daß Ehrhardt „für eine Sache, bei der er einen praktischen Erfolg nicht sieht, seine Organisation nicht aufzudecken gewillt ist" ${ }^{\text { } 51}$.

Der preußische Staatskommissar war nicht die einzige staatliche Stelle, die Kontakte zur O.C. geknüpft hatte. Im Verlauf der staatsanwaltschaftlichen Ermittlungen stellte sich heraus, daß Killinger in den Verhandlungen mit dem Heimatverband Schlesien indirekt auch von obersten Reichsbehörden unterstützt worden war: Die mit Sperrvermerk ausgezahlten Gelder zur Ausrüstung des Regiments Süd stammten offenkundig vom Auswärtigen Amt, das den Oberschlesischen Selbstschutz verdeckt finanzierte ${ }^{52}$. In einer von Reichsinnenminister Köster anberaumten Besprechung über das Verhältnis von Regierungsstellen und O.C. bestritt der Vertreter des Auswärtigen Amts allerdings, daß scin Ministerium von einer Organisation mit dem Namen „O.C.“ Kenntnis gehabt habe ${ }^{53}$. Tatsächlich war in allen Verhandlungen Killingers über die Aufstellung einer eigenen Truppe von der O.C. selbst niemals die Rede gewesen. Hoffmann mußte immerhin zugeben, „auch der Staatsregierung unser Dasein und den Zweck unseres Daseins nicht mitgeteilt und ihr auch nicht unsere Satzungen vorgelegt ${ }^{\text {"54 }} \mathrm{zu}$ haben. Die aufgefundenen Unterlagen bestätigen das Bild einer O.C., deren Zentrale alle nur erdenkliche Sorgfalt darauf verwandte, Aufbau und Struktur ihrer Untergrundorganisation vor staatlichen Stellen zu verbergen. Schon der Name des Leiters Ehrhardt, der in Briefen als „Fritz“, „Erich“ oder „Wolf“ zu zeichnen pflegte, sollte soweit als möglich verschwiegen werden; selbst neu aufgenommene Mitglieder durften ihn nicht immer sofort erfahren ${ }^{55}$. Andererseits hatte sich Ehrhardt als Chef so stark exponiert, daß die O.C.-Zentrale es als untunlich ansah, seine Beteiligung ganz abzustreiten. Analog zur späteren Taktik der wegen Geheimbündelei angeklagten Funktionäre suchte die Zentrale nach einer glaubwürdigen Linic, die weder das Engagement Ehrhardts gänzlich verleugncte noch seine tatsächliche Rolle eingestand. Als eine Möglichkeit wurde erwogen, das aufge-

49 Ebenda, Nr. 105, Aussage Hoffmann, 2. 11. 1921.

${ }^{50}$ Ebenda, Nr. 179, Entwurf der Geheimbündelei-Anklage, S. 58; BA/P, 15.07-339, Bericht des württembergischen Polizeiamtes, 4. 11. 1921.

51 Aussage Staatskommissar Weismann, 13. 12. 1921, und Bericht des Staatskommissars für Überwachung der öffentlichen Ordnung vom 1. 7. 1921, zit. nach Entwurf der Geheimbündelei-Anklage, S. 59, in: StAF, Nr. 179.

52 Dies behauptete der vernommene Vertreter des Oberschlesischen Heimatschutzes (ebenda, Nr. 183, Aussage Queiß, 14.11. 1921). Der von ihm namhaft gemachte Legationsrat Kessler bestätigte im Auftrag des Auswärtigen Amtes: „Auch die Reichsregicrung hatte keine Veranlassung, ihrerscits diese Bereitwilligkeit weiter Kreise, dem bedrängten Oberschlesien zu helfen, zu unterdrücken." (Ebenda, Aussage Friedrich von Kessler, 17. 11. 1921) Auf die Frage, ob das Reich solche Bestrebungen auch finanziell unterstützt habe, verweigerte er allerdings „aus dienstlichen Gründen“ die Aussage.

53 BA/P, 15.07-339, Besprechung betreffend Geheimorganisationen, 22. 11. 1921.

${ }^{54}$ StAF, Nr. 105, Aussage vom 24. 9. 1921.

55 Entwurf der Geheimbündelei-Anklage, S. 74, und Schreiben der Zentrale, 21. 7. 1921, in: Ebenda, Nr. 179 bzw. 150 . 
kommene Gerücht zu bekräftigen, daß Ehrhardt der stellvertretende Leiter der O.C. in Deutschland sei. Eine andere Argumentation betonte die Eigenständigkeit der Münchener O.C.-Arbeit, da der unter Haftbefehl stehende Ehrhardt sich in Salzburg aufhalte; auf jeden Fall aber sollte in Zukunft auch der Deckname "Consul“ nicht mehr gebraucht werden und statt dessen nur noch von "C" gesprochen werden ${ }^{56}$.

Der Bund führte eine schwarze Liste, auf der die Namen unzuverlässiger und verdächtiger Personen den Bezirksorganisationen mitgeteilt wurden ${ }^{57}$. Die Schreiben zwischen Zentrale und Bezirksleitern wurden chiffriert ${ }^{58}$ und bedurften in der Regel zum Beweis ihrer Authentizität einer besonderen Unterschrift, wenn sie nicht von Ehrhardt selbst stammten ${ }^{59}$. Auch bei der Vorbereitung zur Aufstellung einer eigenen Truppe für Oberschlesien verlangte die Zentrale strikte Geheimhaltung; die zu bildende Formation sollte die neutrale Bezeichnung „Regiment Süd“ tragen und nach außen keinesfalls mit der O.C. in Verbindung gebracht werden: „Sowohl die Vorbereitungen, als auch der Namen unseres Truppenteiles dürfen keinesfalls an die Öffentlichkeit kommen. Vor Abrollen jedes Transportes sind alle Leute nochmals an Geheimhaltung und Vorsicht bei Gesprächen auf der Eisenbahn zu mahnen. Tragen auffälliger Abzeichen, Bemerkungen über Reiseziel müssen vermieden werden. "60

Dennoch kam es anfangs zu manchen Pannen, die der Zentrale jeweils Anlaß zu neuen Richtlinien gaben, bis endlich im Juli 1921 Ehrhardt alias „Herr Wolf [...] allen Bezirkslcitcrn wegen der guten Geheimhaltung seine Anerkennung" aussprach. Diesen Anweisungen zufolge sollten Postkarten vermieden, Zeitungsausschnitte nur in verschlossenen Kuverts und nicht als Drucksachen versandt werden. In bezug auf Telegramme, bei deren Abfassung der sonst verwendete Code zu auffällig gewesen wäre, verlangte die Zentrale statt einer Umschreibung in geschäftlichem T'ext unverfängliche familiäre Ausweichformulierungen zu suchen. Als Postadresse wurden wechselnde Anschriften in München gewählt; nie dic der Ressortbüros, sondern stets die einzelner Mitarbeiter ${ }^{61}$. Den geheimen Charakter der von den

56 „Es ist erneut geboten, darauf aufmerksam zu machen, daß strengste Geheimhaltung über unsere Tätigkeit und vor Allem über unsere Beziehungen zu andern Persönlichkeiten, Behörden und Verbänden allen Mitarbeitern zur Pflicht gemacht wird. Der Herr, Consul' ist in letzter Zeit so in die Öffentlichkeit gekommen, daß bei einem derartigen Mißbrauch auf die Dauer nicht dafür garantiert werden kann, daß Unbefugte Kenntnisse von Dingen erhalten, die lediglich für die eigenen Reihen bestimmt sind. In welcher Richtung wir arbeiten, wird sich nicht verheimlichen lassen; aber es muß immer wieder betont werden, daß alle Arbeit in Abwesenheit des im Salzburgischen weilenden Chefs geschieht. Die etwaige Ableugnung, daß ein Consul nicht bei uns wäre, ist falsch." Ebenda, Nr. 150, Befehl der Zentrale vom 29. 8. 1921.

57 Vgl. Rundschreiben „Bbn. 438“ vom 29. 7. 1921 (ebenda).

${ }^{58}$ Als Chiffriergrundlage diente F. J. Wershoevens Liliput-Wörterbuch Deutsch, Leipzig 1921, um inhaltlich bedeutsame Begriffe durch eine Ziffernangabe zu ersetzen, aus der der genaue Fundort des chiffrierten Ausdrucks in diesem Wörterbuch hervorging. Waren einzelne Buchstaben zu chiffrieren, wurde nur die entsprechende Seite angegeben.

${ }^{59}$ BA, NL 150, 110, Aussage Krebs, 21. 10. 1921. Diese immer aus vier Buchstaben bestehenden Unterschriften bereiteten den Ermittlungsbehörden erhebliches Kopfzerbrechen, weil nie eine der anderen glich. In Wirklichkeit setzten sich die vermeintlichen Namen, mit denen wichtige Mitteilungen unterzeichnet waren, aus den - rückwärts gelesenen - beiden ersten und beiden letzten Buchstaben des Schreibens zusammen.

${ }^{60}$ StAF, Nr. 150, Befehl der Zentrale vom 19. 7. 1921.

${ }^{61}$ Befehle der Zentrale vom 7., 29. und 23.7. 1921. Demnach war auch die Anschrift einer der Erzbergermörder eine solche Postadresse: „Adresse Heinrich Schulz vom 1. August 21 ab: München, Maximilianstraße 33/I (bei Achton). Alle Schreiben der Bezirke A bis $\mathrm{H}$ einschl. sind vom Eintreffen dieses Umlaufes ab an diese neue Adresse zu senden." 
Ermittlungsbehörden enttarnten O.C. unterstrich schließlich im September 1921 augenfällig die fieberhafte Aktivität der - offenbar durch cinen Wink aus dem Münchener Polizeipräsidium alarmierten - Funktionäre in München und in den einzelnen Bezirken, die in den Stunden vor dem staatsanwaltschaftlichen Zugriff alles Belastungsmaterial zu vernichten trachteten. So wurde bei der Aushebung der O.C. auch nur ein Bruchteil der im Befehlsbuch der Führung ausgewiesenen Befehle und Rundschreiben sichergestellt; überall trafen die Fahnder auf mit verkohltem Papier gefüllte Öfen.

Allerdings bewies die Tatsache, daß der Geheimbund seine Struktur und Ausdehnung auch vor staatlichen Stellen sorgfältig verbarg, angesichts der außenpolitischen Rahmenbedingungen dieser Jahre noch nicht zwingend, daß seine Absichten wirklich hochverräterisch waren. Killinger beispielsweise begründete in seinen Vernehmungen die konspirative Struktur des Verbandes mit einer verblüffenden Argumentation: Man habe damit nur auf die Regierung Rücksicht nehmen wollen, da diese eine militärische Organisation wie die O.C. nach den Bestimmungen des Versailler Vertrages hätte verbieten müssen, wäre sie ihr offiziell bekannt geworden ${ }^{62}$. Dic von der O.C. betriebenen Waffengeschäfte schienen diese auch von Salomon verfochtene Behauptung ${ }^{63}$ zu stützen: Ausweislich der Korrespondenz des Ehrhardt-Beauftragten Werber bemühte die Organisation sich nachdrücklich, Zugang zu deutschen Waffen zu erlangen, die nach den Bestimmungen des Versailler Vertrages zu vernichten waren. Am 20. Februar 1921 meldete Werber beispielsweise, daß er mit dem stellvertretenden Kommandanten der Reichsmarine auf Borkum Einvernehmen über eine Waffenübcrnahme hergestellt habe ${ }^{64}$, und Ende April teilte er der Zentrale seine Hoffnung mit, „in Berlin einen größeren Posten Pistolen erfassen zu können "65; in weiteren Berichten ist von Maschinenpistolen, Minenwerfern und Munition die Rede, aber auch von Unterseeboot-Empfangsstationen, Ferngläsern und Entfernungsmeßgeräten ${ }^{66}$. Es war Werber offenbar gelungen, nicht nur Marineoffiziere seinen Plänen zur Hinterziehung eines Teils der zur Vernichtung bestimmten Waffen gewogen zu machen, sondern auch Vertraucnsleute in die entsprechenden Abwicklungsstellen der Reichswehr zu plazicren ${ }^{67}$. Ein Großteil dieser militärischen Geräte war allerdings für die Aktivitäten der O.C. selbst gänzlich unbrauchbar und sollte teils nach Irland und Finnland verkauft, teils in geheimen Depots gelagert werden ${ }^{68}$, was es immerhin denkbar erscheinen läßt, daß der O.C. tatsächlich „vaterländische Interessen " vorschwebten, die die Regierung nicht verfolgen konnte ${ }^{69}$.

Doch in Wahrheit betrieb Werber den Waffenschmuggel nach Irland und Finnland primär, um der O.C. Einnahmen zu sichern ${ }^{70}$. Offensichtlich war Ehrhardt auf die erhofften Gewinne dringend angewiesen, denn Werber sah sich angesichts einer Zahlungsverzögerung in einer der in Aussicht genommenen Transaktionen zu der Bemerkung veranlaßt: „Der Chef hat in seinem Aufbau der Organisation seiner Firma mit unserem Geschäft gercchnet und ist

${ }^{62}$ BA/P, 15.07-560, Aussage Killinger, 20. 10. 1921.

${ }^{63}$ Fragebogen, S. 394.

${ }^{64}$ StAF, Nr. 183.

${ }^{65}$ Ebenda, Bericht vom 27. 4. 1921.

${ }^{66}$ Ebenda, Bericht vom 30. 4., 9. 5., 7. 6., 22. 8. 1921; Aussage Werber, 16. 1. 1923, in: Ebenda, Nr. $168 /$ 178.

${ }^{67}$ Ebenda, Nr. 183, Bericht Werber, 23. 2. 1921.

${ }^{68}$ Ebenda, Aussage Hoffmann, 31. 10. 1921.

${ }^{69} \mathrm{BA}, \mathrm{NL} 150,110$, Aussage Werber, 3.12.1921. Die Reichsregierung setzte allerdings unverzüglich den englischen Botschafter d'Abernon in Kenntnis, nachdem sie von den Waffenschiebungen der Ehrhardt-Organisation erfahren hatte (StAF, Nr. 183, Der RKO an die Staatsanwaltschaft Offenburg, 25. 11. 1921).

70 StAF, Nr. 168/178, Aussagen Werber, 3. 12. 1921 und 15. 2. 1922. 
nun seincrseits in gewisse Schwierigkeiten geraten. “71 Ungeachtet dieser Mahnung erwiesen sich die Waffenschiebungen als langwierig und risikoreich, so daß neben dem tatsächlichen Umfang auch unklar bleibt, ob die O.C. ihre Absicht überhaupt verwirklichen konnte, nur ein Drittel der Waffen zu verkaufen und den Rest in eigener Verfügungsgewalt zu behalten ${ }^{72}$.

Hoffmanns Aussagen zu diesem Komplex lassen vermuten, daß die O.C. mit dem finnischen Waffengeschäft noch sehr viel weitergehende Hoffnungen verband: „Wir rechneten dabei in der Weise, daß, wenn der Bolschewismus in Deutschland um sich gegriffen hätte, es immerhin beherzigten Leuten gelingen könne, sich dorthin durchzuschlagen und [sie] zusammen mit ehemaligen, dort angesiedelten Deutschen (Frontkämpfern) die Wiederherstellung der Ordnung in Deutschland versuchen könnten. " 73 Diese Überlegung wirkt weniger verstiegen, wenn man berücksichtigt, daß die O.C. sich auch in Deutschland um Zugang zu geheimen Waffenlagern bemüht hatte. Zwar wurde von den Funktionären in München bestritten, daß die O.C. eigene Waffen besitze; andere O.C.-Leute hingegen gaben $\mathrm{zu}$, daß ihre Organisation in Grafenwöhr - offenbar auf dem dortigen Truppenübungsplatz - ein Waffenlager unterhalte. Vor allem abcr hoffte die O.C., bei einer Erhebung unter Beteiligung anderer Organisationen Zugriff auf deren Waffendepots zu erhalten ${ }^{74}$. Gerät, das zur Abwehr eines inneren Aufstandes oder zur militärischen Absicherung eines eigenen Staatsstreichs nützlich sein konnte, gab die O.C.-Führung erst gar nicht aus der Hand, wie etwa eine Reihe auf M.G.-Wagen fahrbarer Funktelegraphen-Stationen: „Es war bei uns immer dic Rede davon, in wclcher Weise wir für den Fall eines Aufstandes, wenn wir marschieren würden, gegenseitig eine Verbindung herstellen könnten. "Der Sammclort sollte in Mitteldeutschland liegen, wobei Werber mit seinen Leuten von der Nordsee über Hannover durch das Leinetal hätte ziehen sollen, während die Münchener ihm mit weiteren in Bayern aufgestellten Verbänden dorthin entgegenzukommen versucht hätten ${ }^{75}$. Diese Äußerung legt freilich den Verdacht nahe, daß die Absichten der O.C. durchaus nicht auf die verdeckte Unterstützung der Reichsregierung gerichtet waren. Unter der Vorspicgelung, daß die eigenen Aktivitäten wegen des stets drohenden Eingreifens der Alliierten verdeckt betrieben werden müßten, suchte die O.C. im Frühjahr 1921 vielmehr zu einer schlagkräftigen Einheit zu werden, die auf Befehl ihre Kräfte in der strategisch günstig gelegenen Mitte Deutschlands zusammenziehen könnte, um sie auch gegen einen inneren Feind zu führen.

Wohl spätestens im Juni 1921, mit dem Ausscheiden der meisten seiner Leute aus der Marine, wurde diese von Ehrhardt selbst anscheinend immer mit Skepsis verfolgte Strategie aufgegeben. Dennoch beleuchtet sie die Janusköpfigkeit des von ihm geschaffenen Wehrverbandes, der gleichermaßen zur Unterstützung der Regierung an den Grenzen eingesetzt werden konnte wic zu ihrem Sturz im Inneren. Die militärische Stärke, über die Ehrhardt bis zur Enttarnung seines Bundes gebot, war jedenfalls beachtlich: Die O.C. konnte neben den eigenen Mannschaften, deren Zahl im September bei mindestens $5000 \mathrm{Mann} \mathrm{lag}^{76}$, möglicherweise aber sogar um ein Vier- oder Fünffaches höher war, bei einem Einsatz auch die

71 Ebenda, Nr. 183, Brief Werber, 29. 7. 1921.

${ }^{72}$ So meldete Werber am 6. 9. 1921 eine „Beschlagnahme in Finnland auf Veranlassung der Franzosen“ (ebenda); BA, NL 150, 110, Aussage Werber, 16. 1. 1921.

73 StAF, Nr. 183, Aussage Hoffmann, 31. 10. 1921.

74 Ebenda, Aussage H. Müller, 5. 11. 1921, und Aussage Hoffmann, 31. 10. 1921. Besonders zur Orgesch suchte die im Aufbau befindliche O.C. den Kontakt, vor allem, um an Waffen heranzukommen: „Heute haben wir mit der Einwohnerwehr Fühlung genommen und hoffen nun, durch die Orgesch Waffen und alles, was wir brauchen, zu bekommen." NL Plaas, Tagebuch, Eintrag vom 6. 2. 1921.

75 Aussage Hoffmann, 31. 10. 1921, und Aussage Werber, 3. 12. 1921, in: StAF, Nr. 183 bzw. 168/178.

76 Vgl. Diehl, Paramilitary Politics, S. 108. 
Angehörigen der ihr unterstellten Freikorps aufbieten, also möglicherweise bis zu 120000 Mann, womit sie personell stärker gewesen wäre als die Reichswehr ${ }^{77}$. Die Vermutung, daß die Führung dieses enormen militärischen Potentials ihre Loyalität nur vortäuschte, in Wirklichkeit aber auf den Staatsstreich hinzielte, war nicht aus der Luft gegriffen. Nur gegenüber offiziellen Stellen beharrten ihre Mitglieder darauf, daß sie nicht gegen, sondern für die Regierung hätten tätig sein wollen. Interne Äußerungen und Aufzeichnungen der Geheimbündler sprechen hingegen eine andere Sprache: In der Arbeitsgemeinschaft am Ammersee hoffte Hartmut Plaas seinem Tagebuch zufolge Anfang 1921 fast wöchentlich, daß der Putsch endlich stattfinde, auf den seit fast einem Jahr hingearbeitet werde ${ }^{78}$. Auch dem preußischen Staatskommissar Weismann waren wohl entsprechende Warnungen zugegangen, die er freilich zu zerstreuen trachtete: „Putschgedanken sind anscheinend auch in den Kreisen um Ehrhardt zurzeit nicht vorhanden. Immerhin bedarf auch diese Bewegung der Beobachtung."79

Die der Geheimbündelei Beschuldigten leugneten in ihren Vernehmungen zumeist gar nicht, daß ihre Organisation nicht zuletzt innenpolitische Ziele verfolgte. Doch weit entfernt davon, selbst einen Putsch zu inszenieren, hätten sie einzig angestrebt, „eine Stütze zu sein für den Fall, daß auf gesetzlichem Wege eine neue rechtsgerichtete Regierung ans Ruder käme " 80 . Nur einer von ihnen gestand ein, daß die O.C. sich durchaus nicht auf den Aufbau einer erst späteren Rechtsregierungen nützlichen Hilfspolizei, sondern auf einen nahen Bürgerkrieg vorbereitete, in dessen Verlauf sie selbst die Macht zu erobern hoffte: „Die Initiative für einen Rechtsputsch wird verworfen oder aber nur dann ergriffen werden, wenn mit $99 \%$ ein gesicherter Erfolg vorauszusehen ist. Die Führer haben erklärt, einen Mißerfolg wie in den Kapptagen ein zweitesmal nicht erleben zu wollen. Darum soll die Gelegenheit eines Linksputsches abgewartet und ergriffen werden." Der Anklageentwurf der Offenburger Staatsanwaltschaft von 1922 tat diese Äußerung als belangloses Zeugnis eines einzelnen $\mathrm{ab}^{81}$, - zu Unrecht. Selbst Hoffmann als organisatorischer Kopf wehrte den Vorwurf, einen Putsch gegen die Regierung vorbereitet zu haben, mit einer Aussage ab, die erkennen läßt, daß die O.C. sehr wohl eine Rechtsregierung an die Macht zu bringen plante: „Wir wollen keine

77 Dafür, daß die O.C. über weit mehr als 5000 Mann gebot, spricht die Stammrollennummer 7723, die dem Leipziger O.C.-Mann Herbert Lauch nach eigenem Geständnis von der Zentrale zugeteilt worden war (StAF, Nr. 180, Aussage Lauch, 1. 10. 1921). Für Breslau konnten Stammrollennummern von 8401 bis 8500 festgestellt werden (ebenda, Nr. 179, Entwurf der Geheimbündelei-Anklage, S. 43). Die Auflage der Ehrhardt-Zeitung Wiking überschritt hingegen wohl 2500 Exemplare nicht (ebenda, Nr. 109, Aussage Henrich, 17. 9. 1921). Der Geheimbündelei-Anklageentwurf gegen die O.C. von 1922 schätzte für den September 1921 die Zahl aller O.C.-Mitglieder auf 20 000-25 000 (ebenda, Nr. 179, S. 16). Ein in der Zentrale angefertigter Entwurf vom September 1921 sah neben der Bezirkseinteilung eine selbständige Organisation der der O.C. angeschlossenen Freikorps und eine zusätzliche Zeitfreiwilligen-Organisation in Deutsch-Österreich vor (ebenda, Nr. 89). Einfachen O.C.-Angehörigen wurden von ihren Ortsgruppenführern wie etwa in Leipzig versichert, daß die O.C. etwa 500000 Personen umfasse (ebenda, Nr. 179, Entwurf der Geheimbündelei-Anklage, S. 13 f.).

78 Allein im Januar 1921 kam Plaas dreimal auf dieses Ziel zu sprechen; NL Plaas, Tagebuch, Einträge vom 8., 13., 17. 1. 1921.

79 Bericht des preußischen Staatskommissars für Überwachung der öffentlichen Ordnung, 1. 7. 1921, zit. nach StAF, Nr. 179, Entwurf der Geheimbündelei-Anklage, S. 59. An die „alten Putschisten der O.C.“ erinnerten sich auch Salomon und Plaas rückblickend; Fragebogen, S. 115.

${ }^{80}$ Aussage Krebs, 7. 11. 1921, und Aussage von Seffner, 17. 10. 1921, in: BA, NL 150, 114 bzw.110.

${ }^{81}$ Aussage Lauch, 1. 10. 1921, und der Anklageentwurf in: StAF, Nr. 180 bzw. 179, S. 31. 
Revolution von rechts gegen die Verfassung und Regierung hervorrufen, sondern dann erst eingreifen und eine andere Verfassung herbeiführen, wenn die von uns erwartete Revolution von links kommt. " ${ }^{82}$ Von hier war es nur noch ein Schritt bis zu der Überlegung, daß die O.C. diesem revolutionären Aufstand der Linken ja keineswegs tatenlos. entgegensehen müsse, sondern seine Auslösung durch eigene Aktivitäten beschleunigen könne. Es ist nicht verwunderlich, daß Hoffmann die defensive Hilfestellung für die Regierung, die die O.C. angeblich leisten wollte, nur mühsam vom offensiven Kampf gegen sie abzugrenzen vermochte: „Die Organisation ist gedacht als eine Sicherheits- und Abwehrorganisation für den von uns noch immer erwarteten großen Aufstand von links; sie sollte in diesem Falle als eine Verstärkung und Unterstützung der Reichswehr und der Sicherheitspolizei eingesetzt werden [...]. Das Bestreben ging dahin, zu dem Zeitpunkt, der durch die Linksbewegung ausgelöst wird, materiell so stark und geistig von solchem Einfluß zu sein, daß dann allerdings mit unserer Hilfe in Verbindung mit anderen Organisationen eine Regierung eingesetzt würde, die für sich das Prädikat ,national' in Anspruch nehmen kann. “83

Die Identifizierung der O.C. mit dieser Provokationsstrategie ist keine neue Behauptung. Sie wurde bereits von zeitgenössischen Politikern wie Hoegner und Scheidemann ausgesprochen und auch in der jüngeren Literatur vielfach angeführt ${ }^{84}$. Mit ihr wurde als Lehre aus dem gescheiterten März-Putsch 1920 abgeleitet, daß eine erfolgreiche Unternehmung zur Zerschlagung des „Weimarer Systems" ohne den Beistand der Reichswehr oder gar gegen sie aussichtslos sei. Die Reichswehrspitzen aber hatten sich in den Märztagen 1920 weitgehend neutral verhalten, auch wenn diese Neutralität in der Mehrheit der Reichswehrkommandos mit wenig verhüllter Sympathie für die Putschisten einherging. Reinhardts Nachfolger als Chef der Heeresleitung, Seeckt, hatte es sich zum Ziel gesetzt, die Truppe auf eine abstrakte Staatsidee zu verpflichten, die zu jeder Regierungsform, also auch zur bestehenden Republik, gleiche Distanz wahrte. Die Reichswehr würde aber jede gewaltsame Absetzung der verfassungsmäßigen Regierung bekämpfen, gleichviel, ob von links oder rechts. Da die Ehrhardt zur Verfügung stehenden Kräfte unter diesen Umständen für einen frontalen Angriff auf die Republik zu schwach waren, konnte der gegenrevolutionäre Staatsstreich nur im Gefolge einer vermeintlichen Verteidigung des Staates gegen einen gemeinsamen Feind erreicht werden. Es kam also darauf an, das Gewaltpotential der Linken in Deutschland zu einem Aufstand zu reizen, um unter Zustimmung großer Teile des die Bolschewisierung fürchtenden Bürgertums und zusammen mit der Reichswehr durchzusetzen, was während der Freikorpskämpfe 1919 und 1920 versäumt worden war: die Zerschlagung des Weimarer Verfassungsstaates und die Diktatur von rechts ${ }^{85}$.

Allem Anschein nach wurde die Provokationsstrategie in der O.C. über die Münchener Zentrale hinaus bis in die einzelnen Bezirke als brauchbares Drehbuch für den kommenden

82 Ebenda, Nr. 105, Aussage Hoffmann, 24. 9. 1921.

83 Ebenda. Wie sorgfältig Hoffmann die Verteidigungslinie abstimmte, zeigt die Abschrift eines offenbar von ihm verfaßten Papiers im Nachlaß Luetgebrune, in dem darauf hingewiesen wird, daß die Untersuchungsbehörden die Ausdehnung der O.C. nach Sachsen ermittelt hätten: Es sei aber „noch nicht festgestellt, daß es sich um die Organisation Westsachsen handelt. [...] Um Weiterungen aus dem Weg zu gehen, müssen auch wir jegliche Verbindung mit den Westsachsen ableugnen. Da weder Ort noch irgendwelche Personen dieser sächsischen Organisation dem Richter bekannt sind, bitte jegliche Erklärung hierüber verweigern." BA, NL 150, 113.

${ }^{84}$ Vgl. Scheidemann, Memoiren, Bd. 2, S. 417; Hoegner, Verratene Republik, S. 100; Stern, Political Crime, S. 260 f., und ders., Organisation Consul, S. 22 f.; Krüger, Brigade Ehrhardt, S. 87 f.; Heydeloff, Political-Judicial Career, S. 248 ff.; Mauch, Wehrorganisationen, S. 57.

${ }^{85}$ Vgl. Freksa, Kapitän Ehrhardt, S. 194 f. 
Umsturz angesehen, wobei die eigene Fixierung auf den Staatsstreich zu dem taktischen Kurzschluß verführte, dem politischen Gegner auf der Linken dieselbe Absicht zu unterstellen: „Ein Linksputsch solle durch Anhänger der Organisation,C.' agitatorisch und provokatorisch vorbereitet und unterstützt werden. Nach Ausbruch eines Linksputsches sollte sich die Organisation ,C.' angeblich in den Dienst der Regierung stellen und staatserhaltend eingreifen. Nach Niederwerfen des Linksputsches war es Aufgabe der Führer der Gruppe C., ihre Macht zur Erreichung der herrschenden Staatsgewalt einzusetzen und somit die bestehende Regierung, wie auch die Verfassung von Weimar, umzustoßen.“ 86

In den organisatorischen Vorbereitungen dieser Bestrebungen war die O.C. 1921 offensichtlich weit vorangeschritten. Ein in der Münchener Zentrale hergestelltes, auf den 17. April 1921 datiertes und als "ganz geheim“ eingestuftes Dokument „Die militärische Organisation“, das nur den Vertrauensleuten zugänglich gemacht und nicht vervielfältigt werden durfte, befaßte sich mit der „Erhaltung ciner zuverlässigen Truppe in Brigadestärke“, die bei Links-Aufständen, lokalen Unruhen und außenpolitischen Verwicklungen einsetzbar war, um so allmählich „ein Machtfaktor [zu] werden, mit dem alles andere zu rechnen hat ${ }^{\text {" } 87}$. Die Brigade sollte von cincm in Permanenz arbeitenden Stab geleitet werden, der über den Einsatz zu entscheiden hätte und von dem - in Absprache mit der Reichsregierung - der Aufruf zum Sammeln ausgehen würdc. Auf diese Weise hoffte die O.C. sich als militärische Armeereserve unentbehrlich zu machen, um zu gecigneter Zeit ihre Macht auch gegen die Regierung ins Feld führen zu können. Daneben aber plante sie, ihre kaltblütigsten und todesmutigsten Männer zu einem Elitekommando zusammenzufassen, das durch blitzartige Mordüberfälle und terroristische Anschläge das politische Klima zu beeinflussen geeignet war: „Es können Fälle eintreten, wo einige Hundert oder weniger entschlossene Männer vorübergehend gebraucht werden. Die Fälle können schr vielfältig sein, sei es, um eine Sache in Gang, ins Rollen zu bringen, sei es, um eine rasche Tat zu vollbringen. Solche Fälle können z.B. sein: Die Frechheiten der Franzosen gehen ins grenzenlose, alles nachgeben hat keinen Sinn, man ermordet organisiert dicse Hunde durch Schuß oder Gift, jedes Mittel ist recht. [...] Rote Teilaufstände stehen mit Sicherheit vor der Tür. Stoßgruppen sammeln sich unter irgend einer Maske an bedrohtem Ort, greifen führend ein, sobald die Roten zur Gewalt übergehen, reißen dadurch Ordnungselemente mit sich, stärken Widerstandswillen. Sache dieser Gruppen ist es, den Führern und Hetzern ihr Handwerk für alle Zukunft unauffällig zu legen. Leitung hierbei besonders veranlagter Offiziere, die der Führung jederzeit zur Verfügung stchen. Eine Reihe weiterer Fälle sind denkbar." 88

Aber auch die Orientierung auf einen Einsatz in Oberschlesien war mehr als nur ein taktisches Mittel, um der eigenen, ungeduldig werdenden Anhängerschaft ein konkretes Zicl zu geben. Die Zwangslage der Regierung, die in Oberschlesien angesichts der restriktiven Haltung der Alliierten auf militärische Hilfe von außen angewiesen war und diese doch verleugnen mußte, eröffnete der O.C. eine bequeme Möglichkeit, unter den Augen der Reichsregierung, ja sogar mit ihrer Unterstützung, zu einem Verband heranzureifen, der nur darauf wartete, die Waffen gegen Berlin zu kehren. Welchc Gelegenheit hätte geeigneter sein können als ein Aufstand polnischer Freiwilligenverbände in Oberschlesien, der die ganze Ohnmacht der verfassungsmäßigen Reichsregierung offenbaren würde? In diese Lücke hättc dann die O.C. stoßen können, deren Männer unter der Führung Ehrhardts die Integrität des Staates gegen den äußeren Feind sichern würden, wie sie es Anfang 1919 gegen den inneren

\footnotetext{
${ }^{86}$ StAF, Nr. 180, Aussage Lauch, 1. 10. 1921.

87 Ebenda.

${ }^{88}$ Ebenda.
} 
getan hatten - ohne aber noch einmal zu vergessen, daß der Weg zum nationalen Wiederaufstieg über die Eroberung der Macht in Berlin führe.

Im Frühjahr 1921 war dies offensichtlich auch die Ansicht Ehrhardts. In seinem Tagebuch legte Plaas die Inhalte ciner Lagebesprechung in München Mitte April 1921 nieder, zu der die Vertrauensleute aus dem ganzen Reich gerufen worden waren. Plaas notierte als Leitgedanken Ehrhardts, der trotz des gegen ihn bestehenden Haftbefehls anwesend war, „daß mit einer Erhebung von innen heraus nicht zu rechnen sei und daß das Volk durch cine militärische Aktion, voraussichtlich über den Osten, emporgerissen werden müßte. Ehrhardt braucht jeden Offizier und uns Arbeitsgemeinschaftler nicht zuletzt. Wir stehen wirklich im Brennpunkt." 89

Um so verwunderlicher erscheint, daß Ehrhardt kaum einen Monat später, als O.C.Männer ohne Befehl nach Oberschlesien strömten, es zur Pflicht aller Mitglieder erklärte, "diese Werbungen zu sabotieren"90. Das ausschlaggebende Moment für diesen taktischen Richtungswechsel war sicherlich in der Auflösung der bayerischen Einwohnerwchr zu schen, die nach der Annahme des Londoner Ultimatums durch die neue Regierung Wirth am 11. Mai 1921 unvermeidlich wurde. Daß Kahr trotz seiner bisher demonstrierten Härte in der Frage der Wehrverbände sich daraufhin mit Escherich über die Selbstauflösung der bayerischen Einwohnerwehr verständigte" ${ }^{\text {}}$, fand allerdings bei Ehrhardt überraschenderweise volle Zustimmung: In cinem „Lagebericht“ vom 2. Juni nahm er den baycrischen Ministerpräsidenten gegen Klagen aus dem nationalen Lager in Schutz; nur durch momentanes Nachgeben sei die Ordnungszelle Bayern und damit die letzte Keimzelle nationaler Gesundung vor alliierter Intervention zu retten gewesen ${ }^{92}$. "Jeder Widerstand gegen den äußeren Feind“, so betonte Ehrhardt, „hat zur Voraussetzung ein sich einigendes Deutschland. Diesem steht Weimar im Wege." Also wäre zum gegenwärtigen Zeitpunkt ein Engagement in Oberschlesien nichts als nutzlose Opferung von Menschen, die Ehrhardt lieber für die Bekämpfung des Grundübels geschont sehen wollte: des Weimarer Systems ${ }^{93}$.

Die Frage, ob der angestrebte Staatsstreich eher über eine innen- oder über eine außenpolitische Aktion einzuleiten sei, blieb nun bis zur Verhaftung der Münchener Mitarbeiter Ehrhardts im Herbst 1921 in der Schwebe. Nach Auffassung der O.C.-Leitung mußte die Entscheidung, ob „Kricgsfall A oder B“94 zum Zuge käme, von der politischen Situation abhängig gemacht werden. Im Frühjahr 1921 schienen infolge des kommunistischen Aufstands in Mitteldeutschland und der beginnenden Unruhen in Oberschlesien beide Varianten gleich aussichtsreich, während im Mai 1921 Ehrhardt seine Leute zuerst von einem Eingreifen in Oberschlesien abhalten wollte ${ }^{95}$, dann aber doch seinen militärischen Leiter Killinger in das Kampfgebiet entsandte, damit dic O.C.-Männer nicht vom Oberschlesischen Selbstschutz

89 NL Plaas, Tagebuch, Eintrag vom 18. 4. 1921.

${ }^{90} \mathrm{StAF}, \mathrm{Nr}$. 149, Befehl Ehrhardts vom 31. 5. 1921. Zu diesem Zeitpunkt hatte Killinger bereits im Kampfgebiet den Befehl über die bisherige Sturmkompanie Koppe übernommen, um ihren weiteren Einsatz im Sinne der O.C.-Führung zu lenken.

$91 \mathrm{Vgl}$. Thoß, Ludendorff-Kreis, S. $160 \mathrm{f}$.

92 StAF, Nr. 149, Hermann Ehrhardt, Zur Lage, 2. 6. 1921.

93 „Die Oberschles. Frage ist vorläufig für uns erledigt. [...] Die Leitung beabsichtigt nicht, unser wertvolles Menschen-Material, das zu höheren Zielen gebraucht werden wird, einem aussichtslosen Unternehmen hin zu opfern." Rundschreiben vom 18. 5. 1921, in: Ebenda.

94 NL Plaas, Tagebuch, Eintrag vom 24. 3. 1921.

95 Im Feme-Ausschuß des Preußischen Landtags berichtete ein ehemaliger O.C.-Mann später: „Kurz darauf brach der Aufstand in Oberschlesien aus und reiste ich am 9. Mai 21 zum Bataillon Wolf des Selbstschutzes. Vor meiner Abreise traf ich zufällig [Friedrich Wilhelm] Heinz [...]. Dieser erklärte 
aufgesogen würden. Der Ausgang dieses militärischen Abenteuers festigte in der O.C. die Überzeugung, daß der Weg, die Berliner Regierung über einen Sieg in Oberschlesien zu entmachten, in die Sackgasse führen müsse: „Dic Freikorps haben mit ihrer selbstlosen Arbeit seit der Revolution nur dieses jämmerliche System künstlich am Leben erhalten. Es war nur unter einer Bedingung zu rechtfertigen, ein Freikorps aufzustellen, nämlich unter der zielklaren Absicht, eines Tages damit die Regierung zu stürzen. Ehrhardt war der einzige, der darin den folgerichtigen Weg gegangen ist, wenn auch ohne Erfolg. [...] Was ist erreicht? Wir haben die Regierung aus einem Dilemma befreit und sie dadurch gestärkt. Das Volk ist dadurch beruhigt, daß es in Oberschlesien Taten gesehen hat, die es verlangte; die Entente wird aber dadurch befriedigt, daß die Regierung mit salbungsvollem Ton den Freikorps in den Rücken fällt und womöglich noch die Waffen abliefert. ${ }^{\text {"96 }}$ Die Aufstellung eines eigenen „Regiments Süd“ konnte unter diesen Umständen kaum mehr als den Zweck haben, eine Abwanderung der eigenen Leute zu anderen Verbänden zu verhindern ${ }^{97}$.

Noch in anderer Hinsicht konnte sich Ehrhardt durch die Entwicklung im Frühjahr 1921 bestätigt sehen. Das Schicksal der unter alliiertem Druck aufgelösten bayerischen Einwohnerwehr und der Orgesch mußte der Einschätzung Auftrieb geben, daß angesichts der alliierten Überwachung eine Organisation wie die O.C. nicht offen operieren könne: „Nur nationale Geheimorganisationen können heute bestehen bleiben. " 98 Konsequenterweise suchte Ehrhardt sich im März 1921 auch einen neuen Finanzier. Waren bisher vor allem Gelder aus Kreisen von Industrie und Handel geworben worden, so ergriff Ehrhardt nun bald die Gelegenheit, mit dem Sanitätsrat Otto Pittinger in Verbindung zu treten, der als Vertrauensmann Kahrs die aufgelösten bayerischen Einwohnerwehren in eine geheime Nachfolgeorganisation überführt hatte und eng mit der bayerischen Reichswehr zusammenarbeitete ${ }^{99}$. Pittinger verfügte über das millionenschwere Konto der aufgelösten Einwohnerwehr ${ }^{100}$ und versuchte die bayerischen Wehrverbände unter seiner radikalen Flagge zu einer rechten Einheitsfront zu einigen - ein Vorhaben, das auch Ehrhardt für seine Organisation verfolgte. Offenbar im August 1921 trafen Ehrhardt und Pittinger eine Absprache, die Pittinger als Unterstellung der O.C. unter seine Oberleitung und Ehrhardt als "gemeinsames Arbeitsverhältnis“ interpretieren mochte, aus der jedenfalls aber eine weitgchende Finanzierung der O.C. durch Pittinger erwuchs ${ }^{101}$. Spätestens jetzt war der Republik ein gefährlicher Gegner entstanden, der nach Stärke und Taktik für einen neuen Putschversuch ungleich besser gerüstet war als im März 1920.

mir auf dem Bahnhof, daß mein Schritt zu voreilig sei, da von München aus noch keinerlei Anweisungen vorlägen, sich an den Kämpfen in Oberschlesien zu beteiligen [...]. Er begründete diesen Standpunkt damit, daß er gerade aus München komme und daß die innerpolitischen Verhältnisse für unsere Ziele günstig ständen und in Kürze Maßnahmen der Organisation zur Ausnützung dieser Situation folgen würden." StAF, Nr. 32, Aussage K. Schmidt, 5. 1. 1927.

${ }^{96}$ NL Plaas, Tagebuch, Eintrag vom 27. 5. 1921.

${ }^{97}$ StAF, Nr. 179, Entwurf der Geheimbündelei-Anklage, S. 54.

${ }_{98}$ Ebenda, Nr. 149, Ehrhardt, Zur Lage, 2. 6. 1921.

${ }^{99} \mathrm{Vgl}$. Thoß, Ludendorff-Kreis, S. $174 \mathrm{ff}$.

100 Nußer, Konservative Wehrverbände, S. 217.

${ }^{101}$ Datierung nach der Aussage Eberhard Kautters vom 29. 3. 1922, in: StAF, Nr. 106; vgl. Thoß, Ludendorff-Kreis, S. 177; BA/P, 30.03, 12 J 190/22, Bd. 9, Ehrhardt an den Regierungspräsidenten von Regensburg, 26.11. 1921. 


\section{Der Germanenorden}

Anders als die O.C. operierte der Germanenorden nicht im Zwielicht zwischen Tarnung und kalkulierter Öffentlichkeit, sondern gänzlich klandestin. Sein Wirken ist aus den der zeitgeschichtlichen Forschung zur Verfügung stehenden Quellen nur so unscharf crschließbar, daß seine bloße Existenz bis heute umstritten ist ${ }^{1}$. Die Unsicherheit beruht nicht zuletzt darauf, daß der Germanenorden in der Öffentlichkeit erst durch die Aussagen der Erzbergermörder 1947 und 1950 bekannt wurde, denn angesichts des Kontextes bestand der Verdacht, daß sie mit einem möglicherweise nur vorgetäuschten Geheimbund lediglich die eigentlichen Drahtzieher vor der Strafverfolgung schützen wollten². Tatsächlich aber war bereits 1921 die Polizei im Zug der Fahndung nach Schulz und Tillessen auf den geheimnisvollen Orden gestoßen ${ }^{3}$; Haussuchungen in Regensburg hatten bei dem Architekten Lorenz Mesch und seinem Sekretär Ludwig Seidl Satzungen und Mitgliedslisten zutage gefördert, die auf etwa 1500 Mitglieder schließen ließen ${ }^{4}$ und die Ziele des Bundes zu erkennen gaben: „Alle Ringe müssen aus dem Willen schaffen, das deutsche Wesen, den deutschen Menschen, deutsches Recht und deutschen Geist zu fördern. Alle Mächte des Umsturzes, der Dämonie sind zu bekämpfen, sowie die Vermischung mit Fremdrassen zu verhindern. " ${ }^{5}$ Trotz seiner völkischaggressiven Ausrichtung und der praktizierten Geheimhaltungsvorschriften erblickten dic Ermittlungsbehörden in ihm seinerzeit nur einen harmlosen Sektierbund: „Überhaupt macht die Gehcimniskrämerei, mit der sich der Orden umgibt, und die gekünstelte Sucht, altdeutsche Worte, Namen und Benennungen anzuwenden, mehr einen lächerlichen als einen gefährlichen Eindruck." ${ }^{6}$

In Wahrheit war der Orden, der sich zusammen mit dem Hammerbund 1912 in Leipzig als Geheimverband konstituiert hatte ${ }^{7}$, weit weniger harmlos. Aber er verbarg seine wahre Absichten zunehmend vor der Öffentlichkeit - und auch vor der Mehrzahl seiner Mitglieder. Nur anfangs tritt aus den erhaltenen Unterlagen das Bild von Sektierern hervor, die ganz auf dem Rassegedanken aufbauten und ihre Vereinigung nur für „germanische Naturen “ öffneten $^{8}$. Der Aufnahmewillige hatte in einem „Blutbekenntnis“ zu versichern, „daß in seinen Adern nur arisches Blut fließt und sich auch unter seinen und seiner Frau Eltern und Vorfahren keine Angehörigen der farbigen oder hebräischen Rassen befinden". Zu dieser Zeit

1 Jasper geht davon aus, daß "die O.C. und der Germanenorden [...] im wesentlichen identisch waren“ (Akten, S. 434); Langemann „erscheint die ganze Angelegenheit ,Germanenorden' nicht besonders überzeugend“ (Attentat, S. 153, Anm. 129), und Epstein spricht gar von einem „mysteriösen, Germanenorden', auch unter dem Namen, Organisation Consul' (O.C.) bekannt" (Erzberger, S. 434). Die vom RKO geführten Akten mit den Betreffen „Germanenorden“ und "Welsungenorden“ wurden durch Kriegseinwirkung vernichtet; BA/P, 15.07, Findbuch.

2 So vermutet Stern, Political Crime, S. 257.

3 HStA Düsseldorf, Reg. Düsseldorf, 15638, Schreiben des Staatskommissars für öffentliche Ordnung, Nebenstelle Essen, 10. 12. 1921.

4 Ebenda, Schreiben der Meldestelle für den Regierungsbezirk Düsseldorf, 31. 1. 1922.

5 Ebenda, 15639, Schreiben des Württ. Landespolizeiamtes, 22. 11. 1921.

6 Ebenda und Schreiben vom 27. 2. 1922, in: Ebenda, 15638.

7 Lohalm, Völkischer Radikalismus, S. 60 f. Logen, die aus Hammerbundgruppen heraus entstanden, nutzten den Hammerbund auch weiterhin noch als Tarnung nach außen, wic die Einladung der Berliner Loge des Germanenordens zu einer Weihefeier vom „29. Julmond“ [Dezember] 1913 zeigt, in der cs heißt: „Dic Tagung ist als ,Hammerbundsitzung' angemeldet, da der G.O. öffentlich nicht erwähnt werden darf."IfZ, MA 740.

${ }^{8}$ IfZ, ebenda, Einladungsschreiben vom 29. 12. 1913. 
verstand sich der Germanenorden als ein Elitebund zur Wahrung und Veredlung eines mythisierten Germanentums, das die Grundlage zur „Wiedererreichung und Befestigung der germanischen Herrenstellung über die anderen Menschenrassen "9 bilden sollte. In einer dem Freimaurertum nachgebildeten Ordensverfassung wurden neugeworbene Mitglieder nach Ablegung eines Treue-, Gehorsams- und Schweigegelübdes dem Lehrlingsgrad zugeteilt und konnten dann stufenweise in den Gesellen- und Meistergrad aufsteigen. Der Orden gliederte sich in Gaulogen, die je nach Stärke weitere Tochterlogen ins Leben riefen und unter der Führung einer Großloge standen. Zu ihr, die das eigentliche Herz und die alleinige Entscheidungsinstanz des Ordens bildete, hatten die als „Meister vom Stuhle“ bezeichneten Leiter der Gaulogen zwar Zutritt; Stimmrecht in der Großloge und damit die Herrschaft über den Orden besaß nur der aus wenigen Großmeistern gebildete „Großlogenkopf “. Dieser bestand, gemäß einer auf der Zahl ,drei“ aufgebauten Zahlenmystik, aus dem „Ordenskanzler“, dem „Schatzkanzler" und dem „Großsippenwahrer", die den Orden über die nur ihnen verantwortlichen „Stuhlherren“ der Gau- bzw. Tochterlogen beherrschten ${ }^{10}$.

In diesen örtlichen Logen spielte sich das durch feierliche Rituale geprägte Logenleben ab, von dem im Verständnis der Ordensmitglieder der völkische Wiederaufstieg ausgehen sollte ${ }^{11}$. Daneben plante der Orden auch in diesem frühen Stadium bereits, seine Ziele in die weitere Öffentlichkeit zu tragen. In einem Schreiben der Gauloge Berlin finden sich Überlegungen, zusammen mit anderen gleichgerichteten Bünden völkische Lehrer-, Juristen- und Ärztevereinigungen zu bilden, zielbewußte Werbung zu treiben und mit Presseausschüssen „nach festen Plänen an der Beeinflussung der öffentlichen Meinung“ zu arbeiten ${ }^{12}$. In allen Orten, in denen der Orden bereits Mitglieder hat, sei ein Abkommen mit einem geeigneten Buchhändler zu schließen, um den Bezug völkischer Schriften zu propagieren ${ }^{13}$.

Leitendes Prinzip war die Bekämpfung des angeblichen jüdischen Einflusses auf das deutsche Volk. Ähnlich dem Deutschvölkischen Schutz- und Trutzbund schürte der Orden in Flugschriften die Empörung darüber, „daß cin Fremdvolk es wagt, sein Wirtsvolk im eigenen Lande zu besudeln und in seinen heiligsten Empfindungen zu verletzen“, propagierte den Zusammenschluß, „um unser Volk aus der jüdischen Zinsknechtschaft wieder zu befreien“, und warb für ein „Schutz- und Trutzbündnis [... ], um den hypnotischen Einfluß der Hebräer allmählich zu überwinden und auszuschalten "14. Mit der zunehmenden Aggressivität der antisemitischen Propaganda veränderte der Orden seinen Charakter. Die Ordensführung umgab ihre eigentlichen Aktivitäten mit einer immer undurchdringlicheren Geheimhaltung, die mit der angeblichen Notwendigkeit begründet wurde, sich vor jüdischer Rache zu schützen, und pflegte glcichzeitig enge Kontakte mit anderen völkischen und

9 "Muster für eine schriftliche Beitrittserklärung“ und „Ausführungsbestimmungen zu den Satzungen des G.O.“, in: Ebenda.

${ }^{10}$ Die Ordensleitung an die Ordensbrüder, 20. 10. 1916, und Mitteilung des „Germanen-Orden Großloge“, 1. 1. 1916, in: Ebenda.

${ }^{11}$ Ebenda, „Ausführungsbestimmungen zu den Satzungen des G.O.“. „Die,Loge“ ist und bleibt die beste und vornehmste Form der Gesinnungsgemeinschaft und Disziplin unter Männern. Der feierliche Ernst, das stille geheimnisvolle Wirken, das feierliche Brauchtum (Ritual) bewirkt erst das Wunder, die Deutschen zu geschlossenem Vorgehen zu einigen." Ebenda, Werbeschreiben vom 30. 9. 1915.

12 Ebenda, Die Gauloge Berlin an ihre Mitglieder, ohne Datum.

${ }^{13}$ Ebenda, Niederschrift des Vereins für Gewinnung einer Organisation der Gauloge Franken, September 1915.

${ }^{14}$ Ebenda, Flugblatt „Gedenke, daß Du ein Deutscher bist“, ohne Datum. 
nationalistischen Vereinigungen ${ }^{15}$. Nach der Spaltung im Oktober 1916 erneuerte und verschärfte die neue Ordensleitung die bisher gültigen Geheimhaltungsvorschriften. Diese bestanden darin, daß Mitglieder innerhalb der Gaulogen nur mit ihrem Ordensnamen bekannt sein durften, der Name „Germanenorden“ geheimzuhalten und jede Gauloge unter harmlosem Namen als Verein gerichtlich einzutragen war ${ }^{16}$. Auch die Namen der Ordensleitung und besonders des Ordenskanzlers waren fortan nicht nur vor der Öffentlichkeit, sondern auch vor den Ordensmitgliedern selbst zu verbergen.

In den folgenden Jahren entwickelte der Germanenorden sich zu einer terroristischen Vereinigung, die sich selbst als „Kampfverband“ verstand ${ }^{17}$. Aktenkundig wird dieser Charakterwandel erst 1921, als der Germanenorden sich mit dem Wälsungenorden vereinigte. Die Diskussionsbeiträge auf dem sogenannten Septemberthing der Ordensleitung 1921 lassen aber erkennen, daß dieser Wandel schon lange zuvor cingesetzt und zu einer neuen Struktur der Organisation geführt hatte: Dic nun „Burgen“ genannten lokalcn Vereinigungen von einfachen Ordensmitgliedern „müssen [...] als Vereine eingetragen und in einem Verbande zusammengefaßt werden. Diese Form ist für die Verschleierung unserer weiteren Ziele [... ] vonnöten. "Bemängelt wurde besonders, daß die angestrebte völkische Erziehung in den einzelnen Logen von der politischen Betätigung - die der Ordensleitung vorbehalten blieb - bisher nicht getrennt worden und daher verratsanfällig gewesen sei ${ }^{18}$. Als eine Konsequenz wurden die monatlichen Beiträge der Ordensmitglieder fortan unterteilt in ordnungsgemäß abgerechnete und den Behörden offenzulegende und in geheime Zahlungen an die Leitung. Die einzelnen „Burgen“ korrespondierten mit der Ordensleitung nur mehr über Deckadresse, um die Anonymität der Führer des nun konspirativ verfaßten Verbandes zu wahren ${ }^{19}$. Der neue Orden verstand sich als Kern einer politischen Elite, die das „Gegenwartsziel“ erreichen könnte: „Aufrichtung eines großdeutschen Reiches unter Ausschaltung des Judentums und Niederwerfung der internationalen Freimaurerei. " ${ }^{20}$ Auf eine Erörterung der einzelnen politischen Schritte und einzusetzenden Machtmittel wurde aus Geheimhaltungsgründen verzichtet. Als auf dem Leitungstreffen im September $1921 \mathrm{der}$ neugewählte Vorsitzende Brockhusen erklärte, daß zur Bekämpfung des politischen Gegners jedes Mittel recht sei, mochte dies nach bloßer Rhetorik klingen. Aus anderen überlieferten Aufzeichnungen ist aber zu entnehmen, daß die hinter der harmloseren „Erziehungsaufgabe“ verborgene und nirgendwo eindeutig formulierte "Tataufgabe" 21 politische Gewalttaten keineswegs ausklammerte. Den Verrat in den eigenen Reihen bedrohte der Orden sogar ganz unverhüllt mit der Todesstrafe ${ }^{22}$. Zu ihrer Verhängung hatte man den Grad eines „Femerit-

15 Ebenda, „Aufgabenbeschreibung der neuzuschaffenden Gauloge Franken“ vom September 1915. Beispielsweise wurde das Verbot des Alldeutschen Verbandes nach dem Rathenaumord nicht zuletzt damit begründet, daß führende Verbandsmitglieder mit dem als Gründer des Germanenordens angesehenen Philipp Stauff in regem Gedankenaustausch gestanden hätten; BA/P, 30.09-43, Bericht des Thüringischen Ministeriums des Innern, 5. 9. 1922.

16 IfZ, MA 740, Schreiben der neuen Ordensleitung, 20. 10. 1916. Der wirkliche Name sollte in der Regel nur dem dreiköpfigen Vorstand der jeweiligen Loge bekannt sein; für exponierte Mitglieder galt eine Sonderregclung: „Herren in hohen sozialen gefährdeten Stellungen [sic!] können von vornherein unter Ortsnamen, der nur dem Stuhlherrn bekannt sein darf, eingeführt werden."

17 Ebenda, „Protokoll des Mihilathings“, 29. 9. 1921.

${ }^{18}$ Ebenda, „Der Mihilathing. Ergänzungen zur bekannt gegebenen Nicderschrift“, 3. 11. 1921.

19 Ebenda, Verfügung der Ordensleitung vom Dezember 1921.

20 Ebenda, „Protokoll des Mihilathings“, 29. 9. 1921.

${ }^{21}$ Ebenda, „Der Mihilathing. Ergänzungen zur bekannt gegebenen Niederschrift“, 3. 11. 1921.

22 Ebenda, Schreiben Brockhusen, 13. 6. 1921. 
ters“ eingeführt ${ }^{23}$; als Vorsitzender der Femeritter und damit der „Gerichtsstelle des Ordens für innere und äußere Streitigkeiten“ wurde nach der Vereinigung von Germanen- und Wälsungsorden der Berliner Ludwig Müller von Hausen berufen ${ }^{24}$.

Müller, Gründer und Leiter des 1912 von führenden Alldeutschen und Völkischen ins Leben gerufenen „Verbandes gegen die Überhebung des Judentums“ ${ }^{25}$ und Herausgeber der Zeitschrift Auf Vorposten, entfaltete seine verhängnisvollste Wirkung durch die von ihm besorgte deutsche Ausgabe der „Zionistischen Protokolle" ${ }^{26}$. Kein Machwerk hat mehr zur Popularisierung des Antisemitismus in Deutschland nach 1918 beigetragen als diese Fälschung der zaristischen Geheimpolizei, die bald in 8 . Auflage erschien und der Wahnvorstellung einer jüdischen Weltverschwörung das gedankliche Rüstzeug lieferte. Gegen eine ihrer am meisten verbreiteten Verunglimpfungen hatte Walther Rathenau, der das besondere Ziel der aus den „Protokollen“ erwachsenden Agitation wurde, sich mit einer gerichtlichen Klage zu wehren versucht. Es handelte sich um die Behauptung, der Fries des von Emil Rathenau erbauten Hauses in der Berliner Viktoriastraße zeige 60 abgeschnittene Königsköpfe auf Opferschalen und sei von Emil Rathenau, der auf den Sturz der Hohenzollern hingearbeitet habe, über der Eingangstür angebracht worden ${ }^{27}$. Allerdings starb Walther Rathenau unter den Kugeln seiner Mörder, bevor die Klage verhandelt wurde, so daß das von seiner Mutter fortgeführte Verfahren erst 1923 ausgetragen wurde. Es endete mit einem Freispruch Müllers von Hausen ${ }^{28}$.

$\mathrm{Daß}$ es sich bei der geheimnisumwitterten Bestellung eines Femegerichtes nicht um ein leeres Ritual handelte, belegen Feststellungen der badischen Staatsanwaltschaft, nach denen Müller für überführt galt, die Ermordung des sozialdemokratischen Publizisten Alexander Parvus-Helphand in Auftrag gegeben zu haben: Der in mehreren Rechtsverbänden aktive Ernst Krull, der sein Wissen auch in dieser Angelegenheit an die Polizei verkauft hatte, konnte glaubhaft machen, daß Müller von Hausen ihm eine Reihe von Handgranaten übergeben hatte, dic für das Attentat auf Parvus-Helphand bestimmt waren ${ }^{29}$. Bei einer Hausdurchsuchung der Charlottenburger Wohnung Müllers erwiesen sich die Angaben Krulls als zutreffend. Müller leugnete die Bekanntschaft mit Krull auch gar nicht, und gab ebenso zu, sich über Parvus-Helphand äußerst abfällig geäußert zu haben, bestritt natürlich aber, Krull zu einem Tötungsdelikt angestiftet zu haben, und wurde 1925 unbeschadet der Tatsache freigesprochen, daß Krull bei seinen belastenden Angaben blieb ${ }^{30}$.

Müller von Hausen war nicht der einzige Funktionär, über den der Germanenorden mit den rechtsterroristischen Anschlägen der frühen Weimarer Republik in Verbindung stand. Wenn auch die zur Kenntnis der Bchörden gelangten Mitgliederlisten mit Sicherheit unvollständig sind ${ }^{31}$ und die erhaltenen Thingprotokolle der Ordensleitung zum Teil nur Decknamen aufführen, so tauchen doch in ihnen mehrere Personen auf, die mit den hier zu untersuchenden Anschlägen in engster Verbindung standen. So war der Regensburger

23 Ebenda, Verfügung der Ordensleitung vom Dezember 1921.

${ }^{24}$ Ebenda, „Berufungsschreiben der Ordensleitung der Vereinigten G.O. und ehemaligen W.O.“, 5. 7. 1921.

${ }^{25}$ Lohalm, Völkischer Radikalismus, S. 30.

26 Erschienen 1919 unter dem Pseudonym Gottfried zur Beek als „Geheimnisse der Weisen von Zion“; vgl. zu Müller auch die vom RKO angelegte Akte, in: BA/P, 15.07-574/22.

$27 \mathrm{Vgl}$. Berliner Tageblatt vom 24. 2. 1924.

28 Vgl. ebenda, 19. 3. 1924; BA/P, 15.07-574/22.

${ }^{29}$ StAF, Nr. 50, Auszug aus den Akten des Polizei-Präsidiums Berlin, Abt. I A, Tagebuch Nr. 276.

$30 \mathrm{Vgl}$. Rote Fahne vom 30. 7. 1925.

31 BA/P, 30.01-5053/1, Mesch an Staatsanwaltschaft Offenburg, 5. 10. 1921. 
Architekt Lorenz Mesch, mit dem Tillessen und Schulz vor ihrer Abkommandierung in die Münchener O.C.-Zentrale in enger Verbindung gestanden hatten, ausweislich der bei ihm selbst sichergestellten Mitgliederlisten Leiter der Regensburger Ortsloge und darüber hinaus vermutlich einer der leitenden Männer des Geheimbundes ${ }^{32}$. Tätige Mitglieder des Germanenordens waren auch der Heidelberger Privatdozent Arnold Ruge, der Anfang 1922 mit einem Plan zur Ermordung Rathenaus umging, und der Oldenburger Buchhändler Albert Grenz $^{33}$, der später wegen seiner Beteiligung an dem Plan, Maximilian Harden zu ermorden, vor Gericht stehen sollte. So fragmentarisch diese Quellenübcrlieferung auch ist, erlaubt sie doch die Feststellung, daß die Aussagen der nach 1945 angeklagten Erzbergermörder, in denen der Germanenorden für den Mordauftrag verantwortlich gemacht wurde, durchaus nicht von vornherein als abwegig abgetan zu werden verdient. Unzweifelhaft war neben der ungleich größeren, militärisch aufgebauten Organisation Consul auch der hinsichtlich seiner Mitgliederzahl eher unbedeutende Germanenorden nach Struktur und terroristischem Potential zur Beteiligung an dem Anschlag auf Erzberger durchaus in der Lage gewesen.

\section{Die Auftraggeber des Erzbergermordes}

Innerer Aufbau und politische Ziele lassen sowohl für die O.C. wie für den Germanenorden auf eine starke Affinität zu politischen Gewaltverbrechen schließen, was die Entschcidung erschwert, für welche der beiden Organisationen der von Tillessen und Schulz als Anstifter angegebene Killinger das Verbrechen eigentlich vorbereitet hatte. Tillessens Aussagen zufolge lag die Verantwortung ganz beim Germanenorden und war Ehrhardts O.C. zumindest in dieses Attentat überhaupt nicht verwickelt. Doch gegen diese Darstellung sprechen schon die von Tillessen selbst beschriebenen Umstände, unter denen sich im September 1921 die von Killinger organisierte Flucht der beiden Täter vollzog: Über cinen Mittelsmann ausreichend mit Geld versehen, wurden sie von Kern - dem späteren Rathenaumörder - nach Berchtesgaden gefahren und von einem Ortskundigen über die österreichische Grenze gelotst ${ }^{1}$, reisten dann mit Hilfe anderer nationaler Verbände via Salzburg nach Ungarn und fanden in Budapest Unterstützung ausgerechnet auf dem Polizeipräsidium. Drei Jahre nach der Vcrurteilung seines Komplicen Tillessen bestätigte 1950 Schulz vor Gericht die Vermutung, daß sie beide seinerzeit nur mit Hilfe der O.C. ins Ausland entkommen waren. Die Offenburger Staatsanwaltschaft wäre ihrer damals in München mit Sicherheit habhaft geworden, wenn Ehrhardts Leute nicht unter dem besonderen Schutz des Polizeipräsidiums gestanden hätten: „Mitten in der Nacht kam ein gewisser Dr. Müller zu mir, der sagte, ich müsse sofort verschwinden. [...] Der Block sei bereits von der Polizei umstellt. Die Organisation C hatte gute Verbindung zur Polizei. Dr. Müller half mir, durch die Polizeisperre hindurchzukommen. Ich wurde mit einem Pkw nach der Ramsau bei Berchtesgaden gebracht. Dort traf ich mit Tillessen zusammen. Später wurden wir von geländekundigen Leuten über die Grenze nach Österreich gebracht. [...] Der Polizcipräsident von Salzburg brachte uns mit dem Kraftwagen an die österreichisch-ungarische Grenze. “2

32 HStA Düsseldorf, Reg. Düsseldorf, 15638, Bericht des Württembergischen Landespolizeiamtes, 22. 11. 1921, Anlage 2. Mesch hatte maßgeblich an der Vereinigung von Wälsungen- und Germanenorden mitgewirkt; IfZ, MA 740, „Der Mihilathing. Ergänzungen zur bekannt gegebenen Niederschrift", 3. 11. 1921; vgl. zu Mesch, der auch im DVSTB aktiv war: Lohalm, Völkischer Radikalismus, S. 228.

${ }^{33}$ HStA Düsseldorf, ebenda, Anlage 2; Lohalm, ebenda.

${ }^{1}$ Diese und die folgenden Angaben nach: StAF, Nr. 6, Urteil gegen H. Tillessen, 28. 2. 1947, S. 7 f.

2 Ebenda, Nr. 7, Aussage Schulz, 23. 1. 1950. 
Bereits vor dem Anschlag hatten die Attentäter auch zu Ehrhardt selbst in engen Beziehungen gestanden: Schulz zufolge waren Tillessen und er nach dem mißlungenen KappLüttwitz-Putsch auf Ehrhardts Befehl in Regensburg beim einflußreichen bayerischen Bauernpolitiker Heim angestellt worden und im Frühjahr 1921 wiederum von Ehrhardt „nach München zur Organisation Consul befohlen“" worden ${ }^{3}$. Nach dem Anschlag war es Ehrhardts Kontakten zu verdanken, daß die Münchener Polizei die Gesuchten erst warnen licß, bevor sie zu ihrer Verhaftung schritt, und der Münchener Polizeipräsident sclbst für die Ausstellung der zur Flucht notwendigen Pässe sorgte ${ }^{4}$. Ehrhardt kümmerte sich nach dem Bekunden von Schulz darum, daß die beiden Attentäter in Ungarn „laufend mit Nachrichten versehen und finanziell unterstützt" wurden ${ }^{5}$, und er sorgte dafür, daß der zwei Jahre nach dem Anschlag in Ungarn festgenommene Schulz dank „der Unterstützung einflußreicher Persönlichkeiten " wieder freikam. Schulz wurde nun nach Marburg an der Drau und von dort nach Triest weitergeleitet. Er erfuhr nicht, von wem diese Weisungen im einzelnen stammten, und konnte die Hilfe der O.C. nur vermuten. Daß Ehrhardt sich aber persönlich weiterhin für ihn verantwortlich fühlte, crfuhr Schulz, als er von Triest „durch Einschreibebrief mit getarntem Absender und besonderem Erkennungszeichen nach Trient gewicsen" und anschließend nach Bozen gebracht wurde. Dort betrieb Ehrhardt zu dieser Zeit einc optische Werkstätte, in die Schulz als Buchhalter eintrat. Als die Firma jedoch Pleite machte und der Teilhaber sich an die Münchener Polizei wandte, um ihr den Aufenthaltsort des gesuchten Erzbergcrmörders zu nennen, mußte Schulz abermals untertauchen. Ehrhardt beschützte seinen Mann auch jetzt. Schulz wurde von einem Mann gewarnt, „der sich mir gegenüber auswies [...] durch eine zerschnittenc Visitenkarte. Die beiden Hälften, die gezackt abgeschnitten waren, mußten genau ineinander passen. Ich hatte immer meine Hälfte der so präparierten Visitenkarte bei mir. Die andere Hälfte hatte Erhardt, der sie jeweils dem Kurier gab oder geben ließ, den er an mich schickte. Der junge Mann, der somit ein Kurier von Ehrhardt war, sagte mir, ich solle auf dem schnellsten Wege verschwinden; die Berliner Kriminalpolizci werde schon mit dem nächsten Zug eintreffen. "6 Ehrhardt hattc für einen neuen $\mathrm{Paß}$ mit allen erforderlichen Visa ebenso gesorgt wie für Geld und Schiffspassagen. Am Ziel, bei Kapstadt, wurde Schulz von instruierten Deutschen erwartet, die ihm cine neue Existenzgrundlage als Mitarbeiter einer Holzfirma in den Tropen verschafften. Bei ihr blicb Schulz einige Jahre. Doch als er 1933 wiederum in Schwierigkeiten geriet und Ehrhardt von seiner durch das ungewohnte Klima zerrütteten Gesundheit berichtete, befahl ihm dieser, nach Deutschland zurückzukehren; Schulz wurde dann bei Himmler als Adjutant untergebracht ${ }^{7}$.

Aus alledem erhellt, daß Ehrhardt sich tatsächlich in der Rolle eines Dienstvorgesctzten empfand, der seincm in Not geratenen Untergebenen Schulz Hilfe schuldete, sich aber auch auf dessen bedingungslosen Gehorsam noch Jahre nach dem crzwungenen Ende des Arbeitsverhältnisses verlassen konnte. Schulz' Aussage bestätigt, wie verfehlt die Vermutung wäre, daß Ehrhardt als Kopf einer militärisch geführten Organisation von einem vor scinen Augen vorbereiteten Attentat nichts gewußt und es im nachhinein gar scharf mißbilligt haben könnte. Wohl kaum hätte er sich persönlich für Schulz nach 1921 derart engagiert, wenn

3 Ebenda, Nr. 8, Aussage Schulz, 9. 9. 1949.

4 Ebenda, Nr. 13, Bcricht des Offenburger Untersuchungsrichters und des Offenburger Staatsanwaltes, 22. 6. 1922; vgl. Epstein, Erzberger, S. $436 \mathrm{f}$.

5 StAF, Nr. 7, Urteil gegen Schulz, 19. 7. 1950, S. 15.

6 Ebcnda, Aussage Schulz, 26. 1. 1950.

7 Ebenda, Aussage Schulz, 30. 1. 1950. 
dieser durch seine Tat die Politik Ehrhardts mutwillig so gefährdet hätte, wie Salomon seine Leser glauben machen will ${ }^{8}$.

Tatsächlich konnte Schulz selbst sich 1950 trotz aller Geständnisfreudigkeit an Vorwürfe Ehrhardts nicht erinnern, wohl aber an dessen Bestreben, eine mögliche Kompromittierung als Komplice oder gar Auftraggeber tunlichst zu vermeiden. So habe Ehrhardt Tillessen und ihm bei ihrer Abmeldung vor der Ausführung der Mordtat nur einen guten Urlaub gewünscht, zugleich aber den Eindruck vermittelt, durchaus zu wissen, zu welchem $Z$ weck die beiden in die Ferien fahren wollten ${ }^{9}$. „Als Ehrhardt uns begegnete, sagte er uns, wie er gehört habe, wollen wir in Urlaub fahren. Er wünschte uns recht gute Erholung und baldige gesunde Heimkehr. Ausdrücklich gab er also nicht zu erkennen, daß er um den Befehl, den wir erhalten hatten, und um unser Vorhaben nach Maßgabe dieses Befehls wisse. Aus seinem ganzen Verhalten gewannen wir aber den Eindruck, daß dies der Fall sei." Dieselbe Taktik beachtete der O.C.-Chef, als Schulz und Tillessen ihrem Vorgesetzten Killinger die Ausführung des Mordauftrags gemeldet hatten: „Am selben Tag haben wir auch noch Corvettenkapitän a. D. Ehrhardt getroffen, und zwar haben wir in einem alten schönen Münchener Weinrestaurant mit ihm zu Nacht gegessen. [...] Gemeldet haben wir Ehrhardt nichts, wir merkten jedoch, daß er im Bilde war."10

Danach steht fest, daß der Auftrag, Erzberger zu töten, von eincm Mitglied der engsten O.C.-Führung, Manfred von Killinger, unter Wissen und Billigung Ehrhardts erteilt wurde. Intern übernahm Ehrhardt die Verantwortung für das Schicksal seiner Männer und versorgte die Attentäter ${ }^{11}$; nach außen aber stritt er jede Verantwortung ab, schon um nicht der angestrebten Sammlung einer schlagkräftigen Bewegung mit der eigenen Kompromittierung durch ein Gewaltverbrechen stärker zu schaden, als der Anschlag ihr politisch nutzen konnte ${ }^{12}$. Aus diesem Grund war für Ehrhardts Leute Verschwiegenheit über die Rolle ihres Leiters höchstes Gebot, und Ehrhardt konnte in seiner Autobiographie stolz feststellen, daß nicht einer seiner Männer in der Untersuchungshaft „Verrat" begangen hätte ${ }^{13}$. Dicse Verschwiegenheit, die 1922 im Prozeß gegen Killinger die Aufdeckung der Wahrheit verhinderte, bestimmte über den Zweiten Weltkrieg hinaus auch die Haltung Tillessens, der zunächst in seinem ersten Prozeß jede Anstiftung zur Tat durch Dritte abstritt und es auch noch nach seinem Teilgeständnis als Zeuge im Prozeß gegen Schulz 1950 peinlich vermied, Ehrhardt oder ehemalige Mitverschworene in irgendeiner Form zu belasten ${ }^{14}$.

So unzweifelhaft aber Ehrhardt billigender Mitwisser bei dem geplanten Mord an Erzberger war, so wenig war er sicherlich auf der anderen Seite sein eigentlicher geistiger Urheber. Dafür spricht bereits das Zeugnis des späteren Ehrhardt-Adjutanten Hartmut Plaas, der im

${ }^{8}$ Fragebogen, S. 396.

9 StAF, Nr. 7, Aussage Schulz, 10. 3. 1950.

10 Ebenda, Aussage Schulz, 11. 5. 1950.

${ }^{11}$ Aussage des ehemaligen O.C.-Angehörigen Karl Schmidt-Halbschuh 1926, in: StAF, Nr. 31, Mittcilung des RKO an den Offenburger Untersuchungsrichter, 23. 12. 1926.

12 Ganz im Einklang mit dieser Taktik teilte der immer noch steckbrieflich gesuchte Ehrhardt nach dem Attentat in einer Erklärung mit, daß allein der Verdacht, er könne „irgendwie mit der Sache in Verbindung “ stehen, ihn ,auf eine Stufe mit Raubmördern, Bankräubern und ähnlichen Verbrechern“ stelle, weshalb er es ablehne, sich zu stellen; Münchner Neueste Nachrichten vom 31. 10. 1921.

${ }_{13}$ Freksa, Kapitän Ehrhardt, S. 219.

${ }^{14}$ Auf die Frage, ob er sich auch jetzt noch an seinen Eid gebunden fühle, gab Tillessen die aufschlußreiche Antwort: „Nein, ich möchte nur nicht, daß jetzt auch noch andere Leute hineingezogen werden, da man nie weiß, ob diesc eines Tages nicht doch zur Verantwortung gezogen werden. "Offenburger Tageblatt vom 20. 7. 1950; vgl. Langemann, Attentat, S. 153, Anm. 129. 
August 1921 noch in einer der als Auffanglager gebildeten Arbeitsgemeinschaften in Bayern landwirtschaftlich tätig war. Am Tage nach dem Anschlag begrüßte Plaas in einer Tagebuchnotiz den Tod des „Unhold[s] unseres Unglückes und unserer Zerrissenheit" und bedauerte nur, daß Erzberger nun nicht mehr vor einem deutschen Volksgerichtshof angeklagt werden könne ${ }^{15}$. Offenbar aber kannte Plaas die Identität der Täter nicht und vermutete sie nicht in den eigenen Reihen ${ }^{16}$. Erst als am 15. September 1921 die Personalien der Mörder veröffentlicht wurden, erkannte Plaas seinen Irrtum, beurteilte gleichwohl aber die Folgen des Attentats weiterhin als verhängnisvoll. Offenkundig war die Kenntnis über das gegen Erzberger geschmiedete Mordkomplott auch innerhalb der O.C. nicht über einen kleinen Kreis hinausgelangt und hatten terroristische Anschläge für die bisherige politische Ausrichtung des Geheimbundes keine Rolle gespielt. Schwerlich kann demnach das ErzbergerAttentat Teil einer politischen Strategie gewesen sein, die den Einsatz oder auch nur die vorbereitende Orientierung der insgeheim fortbestehenden Brigade erfordert hätte. Es trägt ersichtlich die Merkmale eines isoliert in der Münchener O.C.-Zentrale verabredeten Fememordes, der dann das Bestehen der ganzen Organisation aufs Spiel setzte. Die Schuld für diese Kurzsichtigkeit suchte Plaas aufgrund seines unzureichenden Kenntnisstandes nicht bei Ehrhardt, sondern bei Killinger, der „durch die eigenmächtige Tat vorläufig alles zuschanden

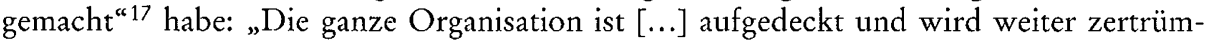
mert. " ${ }^{18}$ Falsch wäre es freilich, in dieser Schelte eine grundsätzliche Distanz zum politischen Terror innerhalb der O.C. suchen zu wollen. Plaas' Kritik an Killinger war allein taktisch gemeint ${ }^{19}$ und hinderte ihren Autor nicht daran, Pläne zur Befreiung Killingers aus der Münchener Untersuchungshaft zu schmieden, die dann durch Ehrhardt unterbunden wurden, weil zwischenzeitlich Killingers Chancen auf einen Freispruch erheblich gestiegen zu sein schienen.

Die Tatsache, daß die außerhalb des Führungszirkels stehenden Mitglieder der Organisation Consul vom Anschlag völlig überrascht wurden, läßt das von Schulz wie Tillessen behauptete Mitwirken des Germanenordens doch sehr viel plausibler erscheinen, als bislang übcrwiegend angenommen wurde ${ }^{20}$. Beide waren mit dem Germanenorden in Regensburg bekannt geworden, wo Heinrich Schulz, durch die Schriften des Hammerverlages angezogen, über den Architekten Mesch nähere Verbindung zu dem Bund angeknüpft haben wollte. Schulz meinte sich zu erinnern, daß sie beide erst in München, kurz vor der Tat, formell in den Orden aufgenommen worden seien ${ }^{21}$, was allerdings dem in der Mitgliedsliste festgehaltenen Wohnort Regensburg widerspricht, den sie bereits im Mai 1921 auf Ehrhardts Geheiß mit München vertauscht hatten. Dennoch muß die Erinnerung von Schulz nicht trügen, denn in einem der von der Polizei bei Mesch gefundenen Schreiben beklagt sich der Regensburger Architekt am 19. März 1921 darüber, daß ihm die Ausweise von Schulz und Tillessen noch

15 NL Plaas, Tagebuch, Eintrag vom 27. 8. 1921.

16 „Wirth schreit gegen die Reaktion, dabei ist überhaupt noch nicht bekannt, wer Erzberger überhaupt erschossen hat. [...] Wahrscheinlich scheint es, daß die Freimaurer die Urheber des Mordes sind.“ Ebenda.

17 Ebenda, Eintrag vom 15. 9. 1921.

18 Ebenda, Eintrag vom 21. 9. 1921.

19 „Daß eine Leichtsinnigkeit, wahrscheinlich Killingers, diesc Folgen gehabt hat! Trotz aller Eigenmächtigkeit wäre die Sache an sich Ehrensache gewesen. "Ebenda, Eintrag vom 28. 9. 1921.

${ }^{20}$ Der These einer Täterschaft des Germanenordens folgt nur Goodrick-Clarke vorbehaltlos, ignoriert dabei aber die O.C. gänzlich (Occult Roots of Nazism, S. 133).

21 StAF, Nr. 7, Aussage Schulz, 2. 3. 1950. Daß diese Angaben zutreffen, belegen die 1921 bei Mesch beschlagnahmten Mitgliedslisten. Unter „+ [Loge] 6 ,Zur Treue“ “ werden neben Mesch (Nr. 1) auch H. Tillessen (Nr.11) und Schulz (Nr. 12) angeführt; HStA Düsscldorf, Reg. Düsseldorf, 15639. 
nicht zugesandt worden seien ${ }^{22}$. Offenbar zog das Aufnahmeritual sich dann über den Wohnsitzwechsel der beiden hinaus hin und wurde - anders als in der im Orden sonst üblichen Form ${ }^{23}$ - abgehalten, ohne die örtliche Loge einzuschalten und die beiden Novizen dort einzuführen: „Vor der Aufnahme in den Germanenorden mußten Tillessen und ich cine Art von Eid leisten. [...] Diesen Eid haben Tillessen und ich geleistet und zwar auf dem Büro des Kapitänleutnants a. D. von Killinger. [...] Bei der Eidesleistung zugegen waren von Killinger und ein Herr aus Nord- oder Mitteldeutschland. " ${ }^{24}$ Dieser von auswärts kommende Herr, der sich „Rittmeister a. D. von Möhring“ nannte, ohne Näheres über seine Person und Funktion preiszugeben, war anscheinend ein Vertreter der Ordensleitung, denn ihm gegenüber legten Schulz und Tillessen ihren Eid ab: „Von Killinger ist gewissermaßen als Zeuge zugegen gewesen. Die Eidesleistung von Tillessen und mir crfolgte wenige Tage, bevor wir den Auftrag zur Tat erhielten." 25

Der enge zeitliche Konnex zwischen Ordenseintritt und Mordauftrag läßt vermuten, daß Tillessen und Schulz, die zuvor häufig und lautstark Erzberger als „den gefährlichsten Schädling des deutschen Volkes" verurteilt hatten, von Mesch oder anderen Führern des Ordens bei Aufnahme bereits als Werkzeuge des Verbrechens in Aussicht genommen worden waren. Dieser Verdacht, den Schulz rückblickend selbst äußerte, wird durch die Formulierung des von den beiden verlangten Schwurs noch verstärkt: „Die Eidesformel ist mir nicht mehr erinnerlich. Ich weiß aber noch, daß wir uns verpflichten mußten, jeden von unseren Vorgesetzten gegebenen Bcfehl bedingungslos auszuführen. In der Eidesformel war auch gesagt, daß wir uns darüber klar sein müßten, daß jeder, der Verrat übe, sein Leben verwirkt habe. Jeder Verrat werde unweigerlich aufgedeckt." 26

Ohne es zu wissen, hatten die beiden Neumitglieder sich mit ihrem Eid dem Willen einer Ordensführung ausgeliefert, die sich beeiltc, ihre gefügigen Werkzeuge als Fememörder zu verwenden, und dazu auf dasselbe konspirative Ritual zurückgriff, das bei der Ordensaufnahme verwendet worden war: „Drei Wochen vor der Tat fand eine Besprechung mit v. Möhring in München statt. Dieser eröffnete dem Angeklagten [Tillessen] und Schulz, daß in der Zentrale des Germanenordens in Jena das Los darüber gezogen sei, wer Erzberger zu beseitigen habe. Das Los sei auf sie gefallen. "27 Genauer noch erinnerte sich Schulz, daß Tillessen und er eines Tages in Killingers Büro gerufen worden waren, wo ihnen in einem verschlossenen Umschlag „ein mit Schreibmaschinenschrift geschriebener Zettel überreicht [wurde]. Der Zettel hatte etwa folgenden Inhalt: Gemäß der in der Leitung stattgefundenen Auslosung wurden Sie - es folgten dann unsere beiden Namen - dazu bestimmt, den Reichsfinanzminster a. D. Erzberger zu beseitigen. Die Art der Ausführung bleibt Ihnen überlassen. Vollzugsmeldung ist nicht zu erstatten. Wenn ich mich richtig erinnere, stand auch noch eine Wendung etwa des Inhalts in dem Zettel: Brüder, Ihr könnt der Unterstützung

22 StAF, Nr. 50, Interner Bericht des Offenburger Staatsanwalts, 26. 12. 1921. Erst für den „18. Osters 2034“ [18. 4. 1921] findet sich die Notiz: „Die Ausweise Schulz und Tillessen sind an HM [Hochmeister] + 6 [Loge Regensburg] zur Unterzeichnung gegangen.“ Ebenda. Hochmeister der Ortsloge war in Regensburg Mesch selbst.

${ }^{23}$ Die „Ausführungsbestimmungen zur Satzungen des G.O.“ schrieben für die Behandlung von Aufnahmegesuchen ein genaues Prozedere vor, das von dem Nachweis rassischer Eignung über dic per „Kugelung“vollzogene Aufnahmeentscheidung bis zur weihevollen Einführung reichte; IfZ, MA 740.

${ }^{24}$ StAF, Nr. 7, Aussage Schulz, 2. 3. 1950.

${ }^{25}$ Ebenda, Nr. 6, Urteil gegen H. Tillessen, 28. 2. 1947.

26 Ebenda, Nr. 7, Aussage Schulz, 2. 3. 1950.

27 Ebenda, Nr. 6, Urteil gegen H. Tillessen, 28. 2. 1947, S. 6. 
des Ordens im Fall einer Entdeckung gewiß sein. ${ }^{28 “}$ Es gibt um so weniger Grund, diese von beiden Tätern vorgebrachte Darstellung in Zweifel zu ziehen, als sie in einer entscheidenden Hinsicht aktenkundige Bestätigung findet: Killinger als Vorgesetzter von Schulz und Tillessen war tatsächlich Mitglied des Germanenordens. Er hatte seine Aufnahme offenbar bereits 1920 als noch aktiver Marineoffizier in Wilhelmshaven beantragt, denn in einem Schreiben vom 25. Januar 1921 an den, liebwerten Herrn Ordensbruder wurde der frisch aufgenommene Killinger der Gauburg Dresden überwiesen ${ }^{29}$.

In ein kaum aufzuhellendes Dunkel getaucht bleibt allerdings das Verhältnis von Germanenorden und O.C. Wenn Tillessen behauptete, daß Killinger, Schulz und er durch ihre Mitgliedschaft in dem Orden ihre Verpflichtung gegenüber der O.C. verletzt hätten, so ist hinter dieser durchsichtigen Konstruktion das Bemühen unverkennbar, Ehrhardt zu entlasten. Sie wird auch von seinem Komplicen Schulz nicht gestützt, der es für möglich hielt, daß Ehrhardt den Attentatsplan viclleicht sogar initiiert hatte ${ }^{30}$. Allem Anschein nach entsprach das Verhältnis Ehrhardts zum Orden dem zu vielen anderen Organisationen, die der Kapitän an sich band, um in ihnen Kräfte für seinen Wehrverband und den erhofften gewaltsamen Regierungssturz zu rekrutieren. Diese Interpretation findet ihre Bestätigung in einem Schreiben, mit dem Schulz im Germanenorden kurz nach seinem Beitritt wehrtaugliche Männer für die O.C. und ihren Einsatz in Oberschlesien zu werben versuchte: „Alle Brüder, die in der Lage sind, zu kämpfen und notfalls auch marschieren, wollen sich melden unter Angabe ihres früheren Ranges bei Herrn Schulz, stud. jur., München. “31

Hinsichtlich des Erzbergermordes läßt sich ein Zusammenspiel beider Organisationen nicht nur bei der Befehlsübermittlung, sondern auch bei der Durchführung feststellen, deren Art die Auftraggeber offengelassen hatten. Tatsächlich operierten Schulz und Tillessen von nun an bis zu ihrer Rückkehr nach München selbständig, wurden aber von ihrem O.C.Vorgesetzten mit ausreichenden Barmitteln und einigen Verhaltensmaßregeln versehen ${ }^{32}$. Um den Aufenthaltsort Erzbergers auszukundschaften, reisten sie zunächst nach Berlin, dann über Kassel nach Stuttgart, als sie erfuhren, daß der Politiker sich in Süddeutschland aufhalte, und konnten schließlich die Spur ihres Opfers über Biberach am Riß und Beuron nach Bad Griesbach verfolgen. Ihr immerhin fünftägiger Aufenthalt in Berlin erschien schon

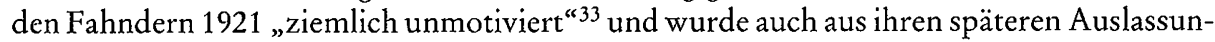
gen nicht recht einsichtig. Denn nach Tillessens Darlegung hatten sie in Berlin unverzüglich beim Portier des Reichstages, Schulz zufolge sogar durch einfachen Telefonanruf im Reichstag bzw. in der Zentrumsfraktion erfahren, daß Erzberger sich gar nicht in Berlin aufhalte ${ }^{34}$. Die Offenburger Ermittlungsbehörden gewannen die Überzeugung, daß Tillessen und Schulz wohl nicht zuletzt deshalb nach Berlin gekommen seien, um hier mit Ludwig Müller von Hausen in Kontakt zu treten, dem „Femeritter" im Germanenorden und mutmaßlichen Anstifter des Mordkomplotts gegen Alexander Parvus-Helphand. Auf diese Verbindung

${ }^{28}$ Ebenda, Nr. 7, Aussage Schulz, 2. 3. 1950.

29 BA/P, 15.07-341, Schreiben der Gauburg Dresden, 25. 1. 1921.

30 StAF, Nr. 7, Aussage Schulz, 2. 3. 1950.

31 Ebenda, Nr. 50, Interner Bericht des Offenburger Staatsanwalts, 26. 12. 1921.

32 Urteil gegen H. Tillessen, 28. 2. 1947, und Aussage Schulz, 17. und 10. 3. 1950, in: Ebenda, Nr. 6 bzw. 7. Tillessen hingegen bchauptete, daß ihnen das Geld vom Abgesandten des Germanenordens ausgehändigt worden sei; ebenda, Nr. 6, Urteil gegen H. Tillessen, 28. 2. 1947.

${ }^{33}$ Ebenda, Nr. 13, Die Offenburger Staatsanwaltschaft an den Generalstaatsanwalt in Karlsruhe, 24. 6. 1922.

${ }^{34}$ Urteil gegen H. Tillessen, 28. 2. 1947, und Aussage Schulz, 10. 3. 1950, in: Ebenda, Nr. 6 bzw. 7. 
wurde die Staatsanwaltschaft durch die Aussage des Zeugen Krull gelenkt ${ }^{35}$. Ihr Verdacht wurde gestützt durch den Fund eines von Schulz und Tillessen stammenden Papierschnitzels hinter dem Gasthof in Oppenau, in dem die beiden vor Ausführung des Attentats logiert hatten. Die auf diesem Zettel erhaltenen Wortstücke „Charlo ..." und „Kantst ..." paßten zu der Adresse Müllers in Charlottenburg, Neue Kantstraße $125^{36}$, so daß der Offenburger Staatsanwalt Burger die Politische Polizei in Berlin, die gegen Müller von Hausen wegen des geplanten Anschlags auf Parvus-Helphand ermittelte, auf die „Zusammenhänge offensichtlicher Natur zwischen Ihrer Untersuchung und der Morduntersuchung Erzberger" aufmerksam machte und es für sicher hielt, „daß Schulz und Tillessen während ihrer Anwesenheit in Spandau vom 6. -10. August mit Müller von Hausen bzw. anderen Mitgliedern des völkischen

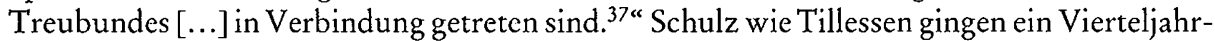
hundert später in ihren Aussagen auf Müller von Hausen nicht ein. Sie wurden allerdings auch nicht nach ihm befragt. Legt man jedoch ihr Geständnis zugrunde, nach dem der Befehl zur Ermordung Erzbergers vom Germanenorden ausgegangen war, liegt die Folgerung auf der Hand, daß Müller von Hausen als Vorsitzender des „Femegerichtes“ an einem Beschluß der Ordensleitung zur Tötung des Reichsministers mitgewirkt haben muß, ihn vielleicht sogar herbeigeführt hat. Dazu paßt eine auffällige zeitliche Koinzidenz: Ausweislich der Korrespondenz der Ordensleitung wurde das Femegericht in der ersten Julihälfte 1921 neu gebildet und Müller von Hausen zu seinem Vorsitzenden bestimmt ${ }^{38}$. In den ersten Augusttagen erfolgte der Mordauftrag an Schulz und Tillessen.

Trotz mancher fortbestehenden Unsicherheit im cinzelnen läßt die Rckonstruktion des Tathintergrundes im ganzen keine andere Deutung zu, als daß die Ermordung des ehemaligen Reichsfinanzministers von führenden Kräften des Germanenordens und der O.C. gemeinsam vorbereitet worden ist. Das verbrämende Ritual vor dem Verbrechen trägt die Handschrift des völkischen Ordens, während die Versorgung der Täter nach seiner Ausführung Sache der O.C. war und das Interesse an der Beseitigung Erzbergers von den Spitzen beider Organisationen geteilt wurde. Ein über die Mordtat hinausweisendes politisches Konzept ist bei diesem Verbrechen nicht zu erkennen; das die Tatverantwortlichen wie ihre Werkzeuge leitende Motiv war Haß gegenüber einem mißliebigen Politiker, der auf der Rechten einhellig mit der verachteten Republik identifiziert wurde und dessen Rückkehr in das politische Leben unmittelbar bevorzustehen schien. Unzweideutig erklärt sich von seiten der O.C. der Mordbefehl aus einer schrankenlosen Verteufelung des Zentrumspolitikers, der als „Jesuitenzögling“ der „schwarzen Internationale“ zuzurechnen sei und damit eben den Verrat begangen habe, der nach dem Femeparagraphen des Ehrhardtbundes mit dem Tode bedroht war. Als Fememord wurde der Anschlag aber auch im Germanenorden verstanden; die als Ritual inszenierte Übergabe des Mordbefehls in einem verschlossenen Umschlag deutet dies ebenso an wie die mutmaßliche Beteiligung seines Femegerichtsvorsitzenden Müllers von Hausen. Auf derselben Ebene gezielten Terrors lag es, wenn wenige Wochen nach dem Mord auf eincr geheimen Sitzung der "Großmeister" des Germanenordens das Studium der feindlichen Kräfte zur dringlichen Aufgabe erklärt wurde, „um sie in richtiger Weise angreifen und ausmerzen zu können “39.

${ }^{35}$ Ebenda, Nr. 50, Aussage Krull, 23. 11. 1921.

${ }^{36}$ Ebenda, Nr. 13, Die Staatsanwaltschaft Offenburg an den Generalstaatsanwalt in Karlsruhe, 24.6.1922.

${ }^{37}$ Ebenda, Staatsanwalt Burger an Regierungsrat Weiß in Berlin, 26. 12. 1921.

38 IfZ, MA 740, Schreiben der Ordensleitung des vereinigten Germanen- und Wälsungenorden, 5. 7. 1921.

39) Ebenda, „Protokoll des Mihilathings“, 29. 9. 1921. 
Mag zumindest für die O.C. auch der Gedanke eine Rolle gespielt haben, durch den Mord die Republik zu destabilisieren ${ }^{40}$, so ist aus der geteilten Verantwortung zweier Geheimorganisationen für den Anschlag, aus der nur indirekten Einflußnahme Ehrhardts auf seine Planung und aus der Irritation in der O.C. nach seiner Durchführung zu entnehmen, daß die Leitung der O.C. Erzbergers Ermordung nur mitbetrieb, um sein weiteres politisches Wirken zu unterbinden und seinen vermeintlichen Vaterlandsverrat zu richten. Kein Anhaltspunkt aber spricht dafür, daß mit Hilfe des Anschlags das Land zur Umsturzreife aufgereizt werden sollte; zur Verwirklichung eines solchen Vorhabens wäre die bis weit in republikanische Kreise auf wenig Sympathie stoßende Person Erzbergers auch kaum geeignet gewesen.

\section{Der Anschlag auf Philipp Scheidemann am 4. Juni 1922}

Die Fahndung nach den Mördern Erzbergers hatte im Herbst 1921 nicht nur zur überraschenden Entdeckung der O.C. geführt, sondern der Öffentlichkeit auch den Eindruck vermittelt, daß der Staat mit dieser Bedrohung aus dem Untergrund rasch und entschlossen fertig geworden war. Mochten die Mörder auch noch flüchtig sein, so waren doch dic O.C.Führer mit Ausnahme Fhrhardts fast geschlossen verhaftet und die Münchener Zentralc gänzlich zerschlagen worden. Vor allem aber lag nun die ausgeklügelte Struktur dieser Organisation, deren besondere Gefährlichkeit in der Heimlichkeit ihres Tuns gelegen hatte, offen zutage. So mußte es als ausgeschlossen erscheinen, daß die O.C. sich von diesem vernichtenden Schlag je erholen oder gar abermals politische Terroranschläge organisieren könnte - bis im Frühsommer 1922 innerhalb eines Monats gleich drei politische Anschläge die Furcht wiederbelebten, daß der Weimarer Staat von einem nicht zu greifenden Gegner aus dem Hinterhalt sturmreif geschossen werden solle und daß dieser Gegner die wider Erwarten doch nicht aufgelöste Organisation „Consul“ Hermann Ehrhardts sei.

Zum ersten Ziel dieser Angriffsserie wurde am Pfingstsonntag 1922 der sozialdemokratische Kasseler Oberbürgermeister Philipp Scheidemann. Auch nach scinem Rücktritt als erster Ministerpräsident der Weimarer Republik war er eines der hervorragenden Angriffsziele der nationalistischen Rechten geblieben. Nach seiner flammenden, aber letztlich wirkungslosen Ablehnung der Versailler Friedensbedingungen als „Philipp mit der verdorrten Hand" verspottet und als eitler Vielredner geschmäht, mußte der Politiker dulden, daß die Rechtspresse in ihm die verhaßte Republik personifizierte, ihm Selbstsucht, Landesverrat und Korruption vorwarf. Hoegner zufolge war Scheidemann über Jahre hinweg zermürbendsten Angriffen und Verleumdungen ausgesetzt, bei denen seine Gegner mit gekauften Zeugen, gefälschten Urkunden und Drohbriefkampagnen arbeiteten, sein Haus in Kassel mit Wandparolen beschmierten, seine Wohnung vernagelten und ihn öffentlich in gröbster Weise belästigten ${ }^{1}$. Wie sehr Scheidemann von diesen Angriffen trotz zur Schau getragener Gelassenheit getroffen wurde, läßt ein „An meine Herren Mörder" betitelter Artikel erahnen, den er in seine lange vor dem Attentat veröffentlichten Betrachtungen "Zwischen den Gefechten“ aufnahm. In dieser fast makabren Adresse an seine Feinde listete Scheidemann gegen ihn gerichtete Morddrohungen auf, die an die Äußerungen erinnern, mit denen später der tatsächliche Anschlag auf ihn motiviert wurde ${ }^{2}$. Nachdem nämlich die zunächst entkommenen Angreifer als zwei völkische Nationalisten namens Hans Hustert und Karl Oehlschläger identifiziert und verhaftet worden waren, rechtfertigten sie ihren Mordversuch mit den

${ }^{40}$ Dies behauptete einige Jahre später zumindest Schmidt-Halbschuh; StAF, Nr. 32, Mitteilung des RKO an den Offenburger Untersuchungsrichter, 23. 12. 1926.

${ }^{1}$ Hoegner, Verratene Republik, S. 102.

${ }^{2}$ Scheidemann, Zwischen den Gefechten, S. $108 \mathrm{ff}$. 
altbekannten Vorwürfen und bericfen sich dabei besonders auf eine Schmähschrift des Ludendorff-Adjutanten Bauer. Hustert führte während seines Prozesses vor dem Staatsgerichtshof aus: „Ich habe in Scheidemann den Mann gesehen, der vom Jahre 1918 an die Revolution vorbereitet hat, der die Meuterei der Marine selbst eingeleitet hat, der sich in Berlin an die Spitze stellte und sich so zum Nutznießer der Revolution aufschwang und der dann schließlich später aus Angst vor der eigenen Verantwortung zurücktrat. "3 Scheidemann, als Nebenkläger zugelassen, wehrte sich zwar entschlossen gegen die Unterstellung, er habe die Revolution vorbereitet und somit Landesverrat betrieben, konnte aber nicht verhindern, daß die Angeklagten selbstbewußt auf ihrem Standpunkt beharrten und ihr Opfer sogar beschuldigten, sich als Oberbürgermeister in Kassel dem Kaiser gehörende Möbel angeeignet zu haben ${ }^{4}$.

Die deutschnationale und namentlich die völkische Presse benutzte selbst den Mordanschlag zur Herabsetzung von Scheidemanns Ansehen. Ohne daß die Tatumstände überhaupt näher geklärt oder die Täter bekannt waren, fand die Deutsche Tageszeitung, daß „bei ruhiger Betrachtung dic Komik bereits überwiegt“, und verharmloste das „Klistierspritzenattentat" zu einem „Dummenjungenstreich“; das Verhalten des Opfers, das die Angreifer mit Revolverschüssen zu vertreiben gesucht hatte, verdiene hingegen durchaus als Totschlagsversuch qualifiziert zu werden ${ }^{5}$. Für die Hamburger Nachrichten handelte es sich bei der zum Überfall verwendeten Substanz um eine „Flüssigkeit, dic sich allmählich als Himbeerlimonade zu entpuppen scheint "6 . Der Schlesischen Tagespost zufolge hatte nur ein Zufall verhindert, daß Scheidemann für ein „Blutvergießen“ in einer angeblich „viclhundertköpfige(n) Menge von Spaziergängern“ verantwortlich wurde: „Wahrhaftig, die rote deutsche Republik kann stolz sein auf ihre Führer! Tapfer ist ja der wackere Scheidemann nie gewesen, das wissen die, die ihn bei den Spartakusunruhen in Berlin gesehen haben. Aber von der weibischen Angst um das eigene behagliche Leben bis zur Veranstaltung von Schießübungen auf harmlose Bürger ist doch ein weiter Schritt, mit dem sich der Herr Oberbürgermeister auf die Stufe seines röteren Genossen Hölz stellt."7

Zwar war der Kasseler Oberbürgermeister tatsächlich glimpflich davongekommen, doch konnte an der Mordabsicht der zwei Männer, die ihm an diesem Pfingstsonntag 1922 während eines Waldspaziergangs in Kassel aufgelauert hatten, kein Zweifel bestehen. Nach der Erinnerung seiner Tochter, die ihn begleitete, wurde Schcidemann von einem sportlich gekleideten Wanderer eingeholt, der in der linken Hand einen Bergstock trug, die rechte Hand aber in der Tasche verborgen hielt. Sobald er sein ahnungsloses Opfer erreicht hatte, „zog er plötzlich mit der rechten Hand einen roten Spritzball aus Gummi aus der Tasche, richtete diesen, indem er auf der linken Seite an Scheidemann vorüberging, wiederholt gegen dessen Gesicht und drückte los"8. Scheidemann sank, von einer später als Blausäure identifizierten Flüssigkcit an Unterkiefer und Nase getroffen, mit Verkrampfungen an Oberkörper und Beinen zu Boden, konnte aber noch seinen Revolver ziehen und einen allerdings ungerichteten Schuß abgeben, bevor cr für fünfzehn Minuten bewußtlos wurde ${ }^{9}$. Aufgrund

3 Zit. nach Vorwärts vom 4.12.1922; vgl. BA/P 30.01-5055, Anklageschrift gegen Hustert und Oelschläger, S. 7.

4 Ebenda, Urteil gegen Hustert und Oehlschläger.

5 Deutsche Tageszeitung vom 6.6.1922.

6 Hamburger Nachrichten vom 9. 6. 1922; zitiert nach Werthauer, Blausäure-Attentat, S. 44.

7 Schlesische Tagespost vom 6.6. 1922; zit. nach Werthauer, ebenda, S. 45.

8 BA/P, 30.01-5055, Anklageschrift gegen Hustert und Oehlschläger, S. 2.

9 Die folgenden Angaben nach dem Urteil gegen Hustert und Oehlschläger in: Ebenda; vgl, auch Scheidemann, Memoiren, Bd. 2, S. 416. 
seiner beherzten Abwehr, die den Angreifer in die Flucht schlug, und eines glücklichen Zufalls entging Scheidemann dem Tod, den die auf ihn gespritzte Blausäure in gasförmigem Zustand gewöhnlich schon in der weit geringeren Dosis von 60 Milligramm herbeiführt: „Nur dem Umstande, daß die bei der Tat angewandte Blausäure im Freien den Verletzten getroffen hat und an jenem Nachmittag ein starker Luftzug gerade an dem fraglichen Bergabhange herrschte, ist es zu verdanken gewesen, daß eine tödliche Wirkung nicht eingetreten ist." 10

Seine Angreifer konnten bald als der 1893 geborene Karl Oehlschläger und der 1900 geborene Hans Hustert identifiziert und Anfang August 1922 in einem oberschlesischen Waldgut gefaßt werden, wo sie unter den Namen „Halber“ und „Wurm“ als Waldarbeiter untergeschlüpft waren, sich dann aber durch unvorsichtige Redereien verdächtig gemacht hatten. Beide wurden vom Staatsgerichtshof zum Schutz der Republik am 6. Dezember 1922 des Mordversuchs für schuldig befunden und zu zehn Jahren Zuchthaus verurteilt ${ }^{11}$. Nach Auffassung des Oberreichsanwaltes lag die Sache „tatsächlich und rechtlich sehr einfach“12, denn die Täter zeigten sich geständig und gaben ihre Tötungsabsicht durchaus zu; auch konnten die zur Tat führenden Umstände in großen Zügen erhellt werden. Den Feststellungen des Gerichts zufolge war Oehlschläger der geistige Urheber der Tat gewesen und wollte die Idee, Scheidemann als einen der Hauptschuldigen am Umsturz 1918 zur Rechenschaft zu ziehen, bereits im November 1918 entwickelt haben. Angeblich um Weihnachten 1921 hatte Oehlschläger, der die Bekanntschaft mit Hustert auf eine gemeinsame Tätigkeit beim Oberschlesischen Selbstschutz zurückführte, seinem Tatgenossen die Vorstellung nahegebracht, daß „man republikanische Führer beseitigen müsse“, und ihn im April 1922 in Köln dafür gewonnen, mit nach Kassel zu fahren, um Scheidemann zu töten. Am 26. April jedenfalls reisten beide - reichlich mit Geld versehen - nach Kassel, mieteten sich ein und verbrachten anschließend Wochen damit, ihr Opfer in seinen Lebensgewohnheiten auszuspähen. Die Gummispritze mit Blausäurefüllung hatte Oehlschläger nach übereinstimmender Bckundung der Angeklagten von einem Ungarn aus der rechtsradikalen Organisation „Erwachende Magyaren“ am 14. April 1922 auf dem Bahnhof von Karlsruhe erhalten ${ }^{13}$.

Diese Spritze führte Hustert am Nachmittag des 4. Juni 1922 in einem Rucksack mit sich, als er mit Oehlschläger die Verfolgung des Kasseler Oberbürgermeisters aufnahm, der seine Wohnung zusammen mit Tochter und Enkelin verlassen hatte, um mit der Straßenbahn nach Wilhelmshöhe zu fahren. Sich etwa 150 Meter hinter den dreien haltend, folgten ihnen die Täter eine Stunde lang durch den Wald, bis schließlich Oehlschläger Hustert den Anschlag befahl. Oehlschläger hielt sich eingriffsbereit in der Nähe: „Ich hätte Scheidemann ohne weiteres niedergeschossen, wenn ich im letzten Augenblick nicht noch gesehen hätte, daß die Wirkung der Gasspritze in Kraft tritt und Scheidemann zusammenbricht. Ich habe die Schußwaffe schußbereit in der Tasche gehabt und bin dann, als ich Scheidemann zusammenbrechen sah, mit weggelaufen. “14

${ }^{10}$ BA/P, 30.01-5055, Urteil gegen Hustert und Oehlschläger, S. 3.

11 Weder Hustert noch Oehlschläger mußten ihre volle Strafe abbüßen; beide wurden 1927 im Rahmen einer allgemeinen Amnestie begnadigt; ebenda, 15.07-698, Vermerk des RKO, 5. 11. 1927.

12 Ebermayer, Dienst am Recht, S. 175.

${ }^{13}$ Die Umstände dieser Verbindung blieben allerdings mysteriös, da Oehlschläger den Namen seines ungarischen Bekannten angeblich nic erfahren, sondern „ihm unter der Chiffre PA 366 postlagernd Passau geschrieben“ hatte; BA/P, 30.01-5055, Urteil gegen Hustert und Oehlschläger, S. 5.

${ }^{14}$ Ebenda, 15.07-340, Aussagc Häncl, 7. 11. 1922. Während der Verhandlung zog Oehlschläger dieses einem Zeugen mitgeteilte Geständnis allerdings zurück. 
Anders als der vor einem badischen Geschworenengericht angeklagte Killinger konnten Hustert und Oehlschläger ein halbes Jahr später nicht auf die Milde der Justiz zu hoffen. Der Staatsgerichtshof war unter Vorsitz des Senatspräsidenten Dr. Schmidt nahezu ebenso zusammengesetzt wie schon beim vorangegangenen Prozeß gegen die Mörder Rathenaus ${ }^{15}$, und er ließ keinen Zweifel daran, daß er den Angriff für ein unnachsichtig zu verfolgendes Verbrechen hielt ${ }^{16}$. Dennoch gelang es auch in diesem Fall nicht, die Hintergründe befriedigend aufzuhellen; unbeantwortet stand vor allem die die Öffentlichkeit bewegende Frage im Raum, ob die Angeklagten nicht als Werkzeuge noch unerkannter Auftraggeber, ja vielleicht sogar der nur vermeintlich ausgeschalteten O.C. fungiert haben könnten. Doch weder Hustert noch Oehlschläger vermochte das Gericht ein entsprechendes Geständnis zu entlokken, so daß das Ergebnis in der republikfreundlichen Publizistik enttäuscht kommentiert wurde: „Der Wunsch, die Fäden aufgedeckt zu sehen, die von den Tätern zu ihren Auftraggebern und Geldmännern führen, wurde auch im Scheidemann-Prozeß nicht erfüllt. Daß sie vorhanden sind, kann als festgestellt angesehen werden." 17

Hatte das Berliner Tageblatt wirklich recht? In der Literatur zum Scheidemann-Attentat wird die Frage nach möglichen Drahtzichern wenn nicht überhaupt ausgeklammert ${ }^{18}$, so doch für nicht beantwortbar erklärt ${ }^{19}$ oder mit wenigen, empirisch zudem unzureichend belegten Andeutungen abgetan ${ }^{20}$. Auch spätere Zeugnisse Eingeweihter ergeben kein klares Bild: Während Salomon kurz vor seinem Tod die Zugehörigkeit der Scheidemann-Attentäter zur Organisation „Consul“ andeutete ${ }^{21}$ und bereits in den „Geächteten“ die Beteiligung des späteren Rathenaumörders Erwin Kern auch am Scheidemann-Anschlag hatte anklingen lassen ${ }^{22}$, focht Heinz auch in der NS-Zeit energisch gegen die Ansicht, das Attentat sei von der O.C. gesteuert worden, und behauptete, Hustert und Oehlschläger hätten auf eigene Faust gehandelt ${ }^{23}$. Hartmut Plaas, der wegen des Verdachts auf Mittäterschaft zeitwcilig in Untersuchungshaft saß, kommentierte den Anschlag nur mit der maliziösen Formulierung: „Inzwischen hat man Scheidemann in Wilhelmshöhe beattentatet, angeblich mit Blausäure. Er ist aber nicht gestorben. " ${ }^{24}$ Die Bemühungen um eine nachträgliche Klärung des Sachverhalts sind daher ganz auf verstreute Indizien angewiesen.

Ein solches Indiz bildet bereits der Tathergang. Es war schon in der zeitgenössischen Berichterstattung aufmerksam registriert worden, daß das „Zweimännersystem“ ganz den

15 Ursprünglich war mit Hagens auch derselbc Vorsitzende vorgesehen wie im Rathenaumord-Prozeß. Er mußte aber infolge Erkrankung durch scinen Kollegen ersetzt wcrden; vgl. Vossische Zeitung vom 5. 12.1922.

${ }^{16}$ Mit einer auf dic politische Haltung der Angeklagten zielenden Stellungnahme, nach der „Lügen und Quengeln [...] deutschvölkisch sein [mag], niemals aber war es deutsche Art“, provozicrte der Vorsitzende sogar eine Kleine Anfrage im Reichstag; BA/P, 30.01-5055, Reichstag, 1. Wahlperiode, Anfrage Nr. 1937 vom 11. 12. 1922.

17 Berliner Tageblatt vom 6. 12. 1922, Morgen-Ausgabe.

18 So bei Langemann, Attentat, S. $237 \mathrm{ff}$.

19 Vgl. Meinl, Revolutionär, S. 92.

20 Vgl. Hannover/Hannover-Drück, Politische Justiz, S. $126 \mathrm{ff}$.

21 Salomon crwähnte beiläufig im Zusammenhang mit den Mördern Rathenaus auch „die Attentäter auf Erzberger, die Attentäter auf Scheidemann. Wir haben ja eine Reihe von Attentaten verübt. NL von Salomon, Jean José Marchand, Interview mit Salomon, 1./2. 7. 1972.

22 Die Geächteten, S. 353.

${ }^{23} \mathrm{Vgl}$. Heinz, Ministermorde, S. 849 f.; ders., Sprengstoff, S. $121 \mathrm{ff}$.

${ }^{24}$ NL Plaas, Tagebuch, Eintrag vom 7. 6. 1922. 
Anschlägen auf Erzberger und Rathenau ähnelte ${ }^{25}$. Wie die Erzbergermörder waren auch hier die Täter Wochen vorher angereist und hatten ihr Verbrechen sorgfältig vorbereitet. Sie fielen in Kassel durch ihre beträchtlichen Geldmittel auf, obwohl sic keiner Beschäftigung nachgingen. Eine Zeugin bekundete, „daß sie regelmäßig mit Tausendmarkscheinen bezahlten, von denen jeder ein ganzes Päckchen bei sich hatte"; die Miete für ihr Zimmer entrichteten sie pünktlich und im voraus, um es dann doch vorzeitig aufzugeben; zudem unternahmen sie während der Tatvorbereitungen weitere Bahnreisen, dic ebenfalls nicht unerhebliche Summen verschlangen ${ }^{26}$. Dieses Verhalten ließ nur den Schluß zu, daß die Täter von Dritten finanziert worden waren. Tatsächlich hatte Oehlschläger noch am Vorabend des Anschlags den Besuch eines Unbekannten empfangen, behauptete vor Gericht aber unwiderlegt, er selbst habe diesem Unbekannten Geld gegeben und nicht umgekehrt ${ }^{27}$.

Wiesen schon diese Auffälligkeiten auf eine Außensteuerung des Mordversuchs, so gilt dies um so mehr für das Verhalten der Angeklagten vor Gericht. In seinem Plädoyer betonte der Oberreichsanwalt, „daß wir in den Prozessen dieser Art ganz ungeheuerlich angelogen werden", und der Prozeßbeobachter des Vorwärts sah die Gemeinsamkcit dieses Verfahrens mit dem zwei Monate zuvor durchgeführten Prozeß gegen die Rathenaumörder in einem Befehl, der „allen Angcklagten dieser Mordprozesse den Mund verschließt. [...] Alle benehmen sich etwa so, wie sich Kriegsgefangene bei der Vernehmung durch den Feind vorschriftsmäßig benehmen müssen. "28 Werthauer, im Prozeß Rechtsbeistand des Nebenklägers Scheidemanns, fiel auf, daß der Angeklagte Oehlschläger sich grundsätzlich über alle relevanten Tatumstände ausschwieg, die Beschaffung der Mordwaffe durch den ominösen Ungarn aber in epischer Breite schilderte, was wiederum den Schluß nahelegte, „daß eine Organisation gedeckt werden sollte, denn wenn eine solche nicht bestanden hättc, so war es nicht erforderlich, über alles die Aussage zu verweigern mit Ausnahme der unwahren Vorschiebung des Ungarn. Diese Vorschiebung geschah gleichfalls, um die Fährte von der Mordorganisation abzulenken. "29 Tatsächlich waren in Budapest, wo der angebliche Ungar nach den Auslassungen Oehlschlägers „wiederholt Juden mit Blausäure bescitigt" ${ }^{30}$ haben sollte, Nachforschungen nach einem Blausäureattentat völlig ergebnislos geblieben ${ }^{31}$.

Bei dieser Sachlage war das Gericht sich selbst bewußt, daß es sein Urteil über zwei Angeklagte in einem Fall sprach, der nur unzureichend aufgeklärt war: „Darüber, ob hinter ihnen gewisse Organisationen oder Persönlichkeiten stehen, die sie mit der Ermordung Scheidemanns beauftragt oder unter deren Einfluß sie die Tat begangen haben, hat die

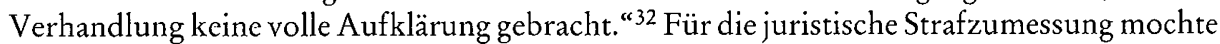
dieser Umstand zweitrangig sein, wie der Vorsitzende ausführte, für die Feststellung der historischen Wahrheit ist er zentral ${ }^{33}$. Daß das Verfahren übcrhaupt eröffnet wurde, obwohl

${ }^{25} \mathrm{Vgl}$. Vorwärts vom 6. 12. 1922.

${ }^{26}$ BA/P, 30.01-5055, Anklageschrift gegen Hustert und Oehlschläger, S. $14 \mathrm{f}$.

$27 \mathrm{Vgl}$. Wcrthauer, Blausäure-Attentat, S. $23 \mathrm{f}$.

28 Vorwärts vom 6. 12. 1922.

29 Werthauer, Blausäure-Attentat, S. 22 f.

${ }^{30}$ BA/P, 30.01-5055, Anklageschrift gegen Hustert und Oelschläger, S. 6.

$31 \mathrm{Vgl}$. Werthauer, Blausäure-Attentat, S. 23.

32 BA/P, 30.01-5055, Urteil gegen Hustert und Ochlschläger, S. $10 \mathrm{f}$.

${ }^{33}$ Mit Recht kommentierte der Vorwärts vom 6. 12. 1922: „Für uns ist die Frage, ob die Angeklagten einer dieser Prozesse ein paar Jahre Zuchthaus mehr oder weniger crhalten haben, nicht entscheidend. Entscheidend ist, ob es gelingt, den Kopf der Verschwörung zu cntdecken und dic Hauptschuldigen zu entdecken." 
„die Ermittlungen nach etwaigen Gehilfen noch nicht abgeschlossen waren “34, war auf das Drängen des Oberreichsanwaltes zurückzuführen, der schon Ende September 1922 bei einer wciter hinausgeschobenen Aburteilung des im Juni verübten Deliktes und angesichts des mit dem Rathenaumord noch fortgesetzten politischen Terrors fürchtete, daß die Justiz sich in der Öffentlichkeit gegenüber der Bedrohung des Staates als ohnmächtig präsentiere ${ }^{35}$.

So fiel der Versuch, tiefere Zusammenhänge der Tat aufzuklären, prozeßtaktischen Rücksichten zum Opfer, ohne daß der Oberreichsanwalt die von Hustert und Oehlschläger beharrlich behauptete Alleintäterschaft für sehr überzcugend hielt ${ }^{36}$. Für die Annahme eines organisierten Hintergrundes sprach zum Beispiel die Zufallsbeobachtung der Frau eines ostdeutschen Polizeipräsidenten, die auf eincr Zugfahrt von einer mit Oehlschläger befreundeten Mitreisenden erfahren hatte, daß dieser am Himmelfahrtstag 1922 - zehn Tage vor dem Anschlag - ganz verstört zu ihr gekommen sei und erklärt habe, „er müsse die Bezichungen zu ihr abbrechen, er könne nur noch dem Vaterland dienen“. Auf ihre verwunderte Frage, was denn geschehen sei, habe Ochlschläger nur gesagt: „Das Los ist auf mich gefallen. “ ${ }^{37}$ Nicht weniger bezeichnend war der Umstand, daß die Attentäter Scheidemanns im Zuge der Fahndung nach den Mördern Rathenaus ermittelt wurden: Nach der Ermordung des Außenministers crfuhr die Polizei bei Nachforschungen in Elberfeld durch einen Spitzel, daß cin Mitglied der O.C. in Elberfeld, Alfred Günther, geäußert haben solle, „Hustert habe das Attentat auf Scheidemann ausgeführt und zwar auf Veranlassung des früheren Kapitänleutnants Karl Tillessen "38. Günther koordinierte in Elberfeld die Aktivitäten der O.C. in den von den Franzosen besetzten Gebieten. Daß die Hintermänner des Anschlags aus der O.C. stammten, legten auch andere Indizien nahe: Hustert bekannte ohne Umschweife, ihr anzugehören ${ }^{39}$, während Oehlschläger anfangs nur die Mitgliedschaft in der Brigade Ehrhardt zugab, in der Verhandlung aber ein gewundenes Teilgeständnis ablegte: „Wir waren beide Mitglieder der Sturmkompagnie von Killinger. Nach dem Erzbergermord hörten wir von der Organisation C. Da wir Ehrhardt-Leute waren, dachten wir, auch Mitglieder der Organisation C. zu sein. "40 In Wahrheit hatte Oehlschläger zu den landwirtschaftlichen Arbeitsgemeinschaften gehört, die Ehrhardt in Oberbaycrn untergebracht hatte ${ }^{41}$ und aus denen auch Schulz und Hcinrich Tillessen stammten. Mehrfach wird Oehlschläger im Tagebuch von Hartmut Plaas erwähnt; und er war, wie Plaas überliefert, im September 1921 an den ersten Plänen zur Befreiung Killingers aus der Münchener Untersuchungshaft

${ }^{34}$ BA/P, 30.01-5055, Anklage gegen Hustert und Oehlschläger, S. 14.

${ }^{35}$ Nach seiner Auffassung hieß die Alternative, „Anklage gegen Hustert und Oehlschläger schon jetzt zu erheben, oder eine Ergänzung der Voruntersuchung nach der Richtung zu beantragen, daß der Versuch gemacht wird, die tieferen Zusammenhänge der Tat nach Möglichkeit aufzuklären. [...] Ich möchte der ersteren Ansicht zuneigen in der Erwartung, daß eine möglichst rasche Aburteilung der bciden Attentäter durch den Staatsgerichtshof dem Ansehen der Rechtspflege nur förderlich sein kann." Ebenda, Der ORA an den RMJ, 27. 9. 1922.

36 Ebenda.

${ }^{37}$ Vorwärts vom 6. 12. 1922. Oehlschläger bestritt übrigens zwar die ihm zugeschriebene Äußerung, nicht aber, daß er am Himmelfahrtstag tatsächlich nach Wiesbaden zu der betreffenden Dame gefahren sei; BA/P, 30.01-5055, Anklageschrift gegen Hustert und Oehlschläger, S. 15.

${ }^{38}$ Ebenda, S. 4. Da der zuständige Kriminalist keine Aussagegenehmigung erhielt, um seinen Gewährsmann nicht zu gefährden, konnte der Hinweis zwar bei der Fahndung, nicht aber vor Gericht verwendet werden; ebenda, Der ORA an den RMJ, 27. 9. 1922.

${ }^{39}$ Vorwärts vom 4. 12. 1922.

${ }^{10}$ Zit. nach Werthauer, Blausäurc-Attentat, S. 28.

${ }^{41}$ BA/P, 30.01-5055, Anklageschrift gegen Hustert und Oehlschläger, S. 5. 
beteiligt ${ }^{42}$. Unter dem 28. September 1921 aber notierte Plaas am Ammersee: „Oehlschläger ist abgereist. " ${ }^{43}$ Wenige Wochen später trat Oehlschläger in Elberfeld eine Tätigkeit als Sicherheitsbeamter an, die Günther vermittelt hatte ${ }^{44}$. Günther bereitete zu dieser Zeit die Befreiung des mittlerweile in Offenburg einsitzenden Killinger vor. ${ }^{45} \mathrm{Zu}$ einer geheimen Konferenz in Elberfeld am 12. November 1921 erschien dann aber aus München mit Paul Werber ein Abgeordneter der O.C.-Zentrale, der in Absprache mit Killinger ein gewaltsames Vorgehen untersagte, um seine Freilassung auf rechtlichem Wege erwirken zu können. Der später festgenommene Werber räumte ein, daß an dieser Konferenz neben Alfred Günther auch Oehlschläger teilgenommen habe ${ }^{46}$. Die Vermutung erscheint nicht abwegig, daß Oehlschläger im Auftrag der O.C. von Oberbayern nach Elberfeld beordert worden war, um an der dann abgesagten Befreiung Killingers mitzuwirken.

Auch Hustert war an dem geplanten Befreiungsversuch beteiligt, wie ein Gewährsmann der Polizci in Elberfeld am 12. Dezember 1921 mitteilte ${ }^{47}$. Die Spuren sciner Tätigkeit für die O.C. lassen sich noch sehr viel deutlicher erkennen als die Oehlschlägers. Bei der Fahndung nach den Erzbergermördern fand sich bei cinem Regensburger O.C.-Mitglied neben der Satzung des Geheimverbandes auch ein Organisationsschema der „Oberbezirks- und Bezirksleitungen“, in dem es unter dem „Oberbezirk II Korv. K. Werber, Hannover" für den Bezirk W (Essen) heißt: „Umfangreiche Post ist zu senden an Hanns Hustert, Elbcrfeld, Charlottenstr. 32. “48 Demnach zählten Hustert wie Oehlschläger zu dem mit besonderen Aufgaben betrauten Stamm von O.C. -Aktivisten, die - ähnlich wie Heinrich Tillessen und Schulz - schon vor dem Attentat auf Scheidemann in der Organisation zusammengearbeitet hatten, und zwar an demselben Ort, von dem aus sie aufbrachen, um ihren Mordplan an Scheidemann auszuführen ${ }^{49}$. Es bedarf nicht des Hinweises auf die innerhalb der O.C. übliche Disziplin, um nachzuvollziehen, daß die beiden unmöglich ein solches Verbrechen ohne Auftrag vorbereitet haben könnten. Zur Gewißheit wird diese Vermutung durch weitere Indizien: So stammte die bei dem Überfall verwendete Spritze aus München ${ }^{50}$, was die Angabe Oehlschlägers über deren Budapester Herkunft noch unglaubwürdiger, die Verbindung zur O.C.-Zentrale hingegen um so wahrscheinlicher macht. Hustert hatte überdies vor seiner Festnahme einer Bekannten gegenüber erklärt, daß Blausäure und Gummiballon in einer Apotheke besorgt worden seien und 25000 Mark gekostet hätten ${ }^{51}$. Ein anderer Zeuge konnte diese Angaben konkretisieren; ihm hatte Hustert anvertraut, „cs habe sich um

42 NL Plaas, Tagebuch, Eintrag vom 20. 9. 1921.

43 Ebenda.

44 BA/P, 30.01-5055, Anklageschrift gegen Hustert und Oehlschläger, S. 5. In derselben Firma arbeitete als Heizer auch Hustert; Vorwärts vom 4. 12. 1922.

${ }^{45}$ StAF, Nr. 12, Mitteilung der Kriminalpolizei Elberfeld, 14. 11. 1921.

${ }^{46} \mathrm{Vgl}$. hierzu den Auszug aus den Akten „Fahndungsmaßnahmen“ in: Ebenda, Nr. 66.

47 Ebenda.

48 Ebenda, Nr. 183.

${ }^{49}$ Hustert galt allerdings in der O.C. offenbar auch für unzuverlässig; BA/P, 15.07-327, Auszug eincs Briefes von Wehrmann an Siebel, 2. 8. 1921. Auch Oehlschläger vertraute einem Zeugen an, daß mindestens einmal jemand aus der Brigade Ehrhardt „Hustert als ungeeignet für Attentatsausführungen mir gegenüber bezcichnet hatte. [...] Der Hustert sauft und plaudert in seinem Suff und macht Quatschereien, die dann auch mir gefährlich werden. "Ebenda, 15.07-340, Aussage Häncl, 7. 11. 1922; vgl. Werthauer, Blausäure-Attentat, S. 22.

50 Sie war ein Produkt der Firma Metzeler; SAM, 567-1-2648, Bericht Oberstaatsanwalt Dr. Noctzel an den ORA, 10. 7. 1922.

51 Vorwärts vom 6. 12. 1922. 
pulverisierte Blausäure gehandelt. Sie stamme aus Bayern von einem Apotheker und kostete inclusive Spritze 20000 Mark. Es seien 20 Stück vorhanden gewesen, und zwar hätte er selbst 20 solche Spritzen gesehen, in der Wohnung bei Killinger. Der Apotheker, von dem die Blausäure stammte, sei ein Mitglied der Ehrhardt-Brigade gewesen. Er fügte noch weiter an, die Spritzen seien in Blechdosen untergebracht gewesen. " 52

Auf die O. C. führen auch die Äußerungen Oehlschlägers gegenüber demselben Zeugen: „Die Aufsicht über die Ausführung des Attentats auf Scheidemann stand unter Kontrolle der Brigade Ehrhardt. " ${ }^{53}$ Für die konspirative Organisation der Erhardt-Leute war, wie sich in den Ermittlungen immer wieder ergab, cine durch Reisen und Kuriere ständig aufrechterhaltene Verbindung typisch. Offenbar war dieses Vorgehen auch für das Scheidemann-Attentat gewählt worden, denn während ihres Kasseler Aufenthaltes unternahmen Hustert und Oehlschläger mehrfach Reisen, die sie nach Köln und Wiesbaden führten und deren Zweck sic nicht einleuchtend begründen konnten ${ }^{54}$. In Kassel wiederum erhielten sie häufiger Besuch durch einen oder mehrere Unbekannte: So bekundete ihr Zimmermädchen, daß Oehlschläger mehrere Tage hindurch Besuch eines Herrn empfangen hatte. Ein anderer Zeuge, der die beiden drei Tage vor dem Anschlag besucht hatte, sagte aus, daß plötzlich in der Wohnung ein Mann erschienen sei, mit dem Oehlschläger sich sofort zurückgezogen habe $^{55}$. Die Identität des Besuchers ließ sich nicht aufklären ${ }^{56}$. Doch wird man mit der Annahme nicht fehlgehen, daß es sich um Kuriere der O.C. handelte, die Geld und Befehle überbrachten. Sie wird durch einc Äußerung Oehlschlägers bestärkt, der im oberschlesischen Klein-Althammer erklärtc, er warte nur noch darauf, daß ihm ein Mittelsmann Geld aus Deutschland überbringe, um endgültig ins Ausland fliehen zu können ${ }^{57}$. Ebenso crweckte das wochenlange Herumlungern von Ochlschläger und Hustert in Kassel vor dem Hause Scheidemanns den Eindruck, als hätten die beiden nur auf ein Kommando gewartet, um dann das verabredetc Verbrechen auszuführen, und obendrein sprach nach der Beweisaufnahme vieles für die Vermutung, daß sich den eigentlichen Tätern für den Tag des Anschlags „noch eine dritte Kontrollperson hinzugesellt" 58 hatte.

Den entscheidenden Beweis jedoch, daß das Komplott gegen den Kasseler Oberbürgermeister tatsächlich von der O.C. geschmicdet worden war, licferte ein stellungsloser Gärtner namens Theodor Brüdigam, der sich im Frühjahr 1922 als Spitzel in die Frankfurter O.C.Gruppe um Karl Tillessen eingeschlichen hatte. Sechs Tage nach dem Überfall auf Scheidemann erschien der in Frankfurt wohnhafte Brüdigam auf dem Kasseler Polizeipräsidium und gab zu Protokoll, er habe durch Kontakte zur O.C. herausgefunden, daß diese Organisation Scheidemannund Rathenau zu töten planc ${ }^{59}$. Der zunächst skeptische Kasseler Oberstaatsanwalt beantragte am 19. Juni 1922, fünf Tage vor der Ermordung Rathenaus, Haftbefehl gegen die von Brüdigam des Mordkomplotts beschuldigten O.C.-Funktionäre Alfred Hoffmann, Karl Tillessen und Friedrich Wilhelm Heinz. Seine geänderte Haltung beruhte darauf, daß sich Brüdigams zunächst unwahrscheinlich klingende Behauptung, er habe den Überfall auf Scheidemann zu verhindern gesucht, zwischenzeitlich als zutreffend herausgestellt hatte ${ }^{60}$ :

52 BA/P, 15.07-370, Aussage Hänel, 7. 11. 1922.

53 Ebenda.

${ }^{54}$ Ebenda, 30.01-5055, Anklageschrift gegen Hustert und Oehlschläger, S. 15.

55 Vorwärts vom 5. 12. 1922; BA/P, 30.01-5055, Der ORA an den Staatsgerichtshof zum Schutze der Republik, 11. 6. 1923.

56 SAM, 567-1-2648, Bericht Oberstaatsanwalt Dr. Noetzel an den ORA, 13. 7. 1922.

57 BA/P, 15.07-340, Aussage Hänel, 7. 11. 1922.

58 Werthauer, Blausäure-Attentat, S. 18.

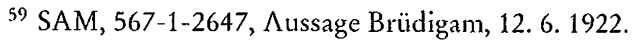

60 Ebenda, Verfügung Oberstaatsanwalt Dr. Noctzel, 19. 6. 1922. 
Nachweislich hatte Brüdigam seine Beobachtungen über die offenkundig terroristischen Absichten der O.C. bereits in der letzten Maiwoche an den Chefredakteur der Frankfurter Volksstimme und an den Frankfurter Polizeipräsidenten Ehrler weitergegeben. „Er hat damals unter Anderen erklärt, daß ihm auf seine Frage, ob Rathenau daran glauben müsse, geantwortet worden sei: ,Gewiß, aber zuerst muß Scheidemann daran glauben.“

Im Lichte dieser Aussage gewann der Angriff auf Scheidemann plötzlich mehr Bedeutung, als der Dilettantismus seiner Ausführung die Behörden ursprünglich hatte vermuten lassen, und der Oberstaatsanwalt äußerte nun selbst den „Verdacht, daß es sich bei dem zweifellos ernstgemeinten Anschlag nicht um die Tat eines einzelnen Feindes des Überfallenen, sondern um das Komplott eines Geheimbundes [...] handeln könne"61. Was der Informant zu Protokoll gegeben hatte, schien dennoch fast zu abenteuerlich, um glaubhaft zu sein: Brüdigam, ein durch den Krieg entwurzelter Soldat, der offenbar in der Revolutionszeit zwischen der Linken und der Rechten hin- und hergeschwankt hatte, war im April 1921 nach eigenen Angaben gebeten worden, für deutschvölkische Kreise zu arbeiten, und hatte sich daraufhin zwei Redakteuren der sozialdemokratischen Volksstimme gegen entsprechende Bezahlung als Spitzel angeboten. Mit deren Zustimmung und unter Rückversicherung beim Frankfurter Polizeipräsidenten ging Brüdigam auf das Angebot seines Kontaktmannes ein und wurde von dem am 3. Mai 1922 mit einem Empfehlungsschreiben zu Karl Tillessen geschickt. Dieser erläuterte seine politischen Absichten, indem er Brüdigam ein Foto seines Bruders Heinrich mit dem Bemerken zeigte: „Das ist mein Brüderchen, der hat das erste Schwein gckillt!“ Karl Tillessen beorderte Brüdigam anschließend zusammen mit einem Unbekannten nach München und stellte ihm am Bahnhof auch seinen Mitarbeiter Hartmut Plaas vor. In München wurde Brüdigam mit Ehrhardts Stellvertreter Alfred Hoffmann bekanntgemacht, der ihn in seine Wohnung in der Franz-Josef-Straße mit der Erläuterung einlud, „daß in diesen Räumen schon allerhand ausgekocht worden sei“. Hoffmann eröffnete dem neuen Mann, daß er von nun an für die O.C. gegnerische Gruppierungen zu bespitzeln habe. Tags darauf empfing Brüdigam Geld zur Deckung seiner Unkosten und cine Ansichtskarte von München als Erkennungszeichen für eventuell notwendige schriftliche Mitteilungen. Bei dieser Gelegenheit kam Hoffmann auch auf Attentate zu sprechen und „meinte, nachdem nun Erzberger erledigt sei, käme vielleicht Walther Rathenau und Scheidemann in Betracht "62. Brüdigam gewann aus den Beobachtungen der nächsten Tage „den Eindruck, daß hier etwas Ernstes im Werke sei“. Am 27. Mai 1922 wurde er befragt, ob er in Kassel das Gewerkschaftshaus kenne und ob ihm Scheidemann bekannt sei. Als er beides bejahte, wurde er beauftragt, einen Berliner Herrn unbekannten Namens nach Kassel „zu begleiten und ihn dort über die Verhältnisse bei den Linksparteien zu orientieren“. Obwohl immer noch von keinem bestimmten Vorhaben die Rede war, hielt es Brüdigam nun für richtiger, Scheidemann zu warnen. Er verließ seinen O.C.-Begleiter in Kassel unter einem Vorwand und informierte noch am selben Tag das Kasseler Parteisekretariat der SPD sowie am Morgen darauf seine Auftraggeber bei der Frankfurter Volksstimme, nachdem er zunächst vergeblich Scheidemann telefonisch zu warnen versucht hatte ${ }^{63}$.

Brüdigams Beschreibungen waren nicht aus der Luft gegriffen. Die von ihm namentlich bezeichneten Personen gab es tatsächlich, sie arbeiteten für die O.C. - und sie waren großteils

${ }^{61}$ Ebenda, Bericht Oberstaatsanwalt Dr. Noetzel an den RMJ, 22. 6. 1922.

62 Ebcnda, Aussage Brüdigam, 12. 6. 1922.

${ }^{63}$ Bericht Oberstaatsanwalt Dr. Noetzel an den RMJ, 22. 6. 1922. Scheidemann erinnerte sich später daran, „daß in der Nacht des 27. Mai aus dem Gewerkschaftshause bei ihm angerufen und er um eine sofortige dringende Unterredung mit cinem Fremden gebeten worden sci, daß cr aber, da er cinen Schabcrnack seiner Gegner vermutet hätte, den Hörer eingehängt habe“. Ebenda. 
bereits im Zusammenhang mit der Untersuchung des Mordfalles Erzbergers aktenkundig geworden. Auch die überprüfbaren äußeren Details erwiesen sich als korrekt. Schließlich konnte Brüdigam glaubhaft machen, nur aus eigener Beobachtung zu schöpfen, da er zum Beispiel nicht wußte, wer sich hinter dem Namen „Consul“ verberge. Wären seine Mitteilungen ernster genommen worden, hätte womöglich bereits der Anschlag auf Scheidemann, mit Sicherheit aber der auf Rathenau verhindert werden können. Aber es war der Informant selbst, der seine eigene Glaubwürdigkeit untergrub. Nachdem er nämlich vom 10. bis zum 12. Juni 1922 im Kasseler Gewerkschaftshaus gewohnt hatte, um sich dort in Anwesenheit Scheidemanns vernehmen zu lassen, kehrte er nach Frankfurt zurück und verlor offenbar die Nerven, als die weitere Untersuchung sich infolge einer Behördenpanne mehr und mehr verzögcrte ${ }^{64}$. Am 19. Juni wartete der Richter vergebens, um den Zeugen zu vercidigen: Brüdigam war untergetaucht. Die uncrwartete Wendung machte die Kasseler Ermittlungsbehörden orientierungslos. War Brüdigam nicht vielleicht doch nur ein berufsmäßiger Schwindler, der sich von zwei Seiten bezahlen ließ und sie beide verriet? Oder, schlimmer noch, ein Spitzel der Rechten, der die Arbeitsweise der Polizeibehörde ausspionieren sollte und dafür von einer SPD-Zeitung auch noch beträchtliche Zuwendungen kassierte? Jedenfalls hielt der Kasseler Oberstaatsanwalt die Glaubwürdigkeit Brüdigams nun für zu erschüttert, „um auf Grund dieser Aussage die öffentliche Klage gegen die von ihm Beschuldigten zu erheben“. Angesichts der undurchsichtigen Umstände schien Abwarten vorerst das Gebotene; die schon beantragten Haftbefehle gegen Hoffmann, Heinz und Karl'Tillessen wurden zurückgezogen, und die neue Direktive lautete: „Gegenüber den von Brüdigam beschuldigten Personen muß sich das Ermittelungsverfahren zur Zeit wesentlich auf eine sorgfältige Überwachung beschränken." ${ }^{65}$

Fünf Tage später war Rathenau tot und auch Brüdigams zweite Prophezeiung traurige Wirklichkeit geworden. Seine nun offenkundige Schlüsselrolle in der Vorgeschichte beider Attentate verstärkte den Druck auf die Ermittlungsbehörden, den Flüchtigen zur Stelle zu schaffen. Noch am Tage der Ermordung Rathenaus erklärte der Kasseler Oberstaatsanwalt dem Reichskommissar für Überwachung der öffentlichen Ordnung, daß Brüdigam „als äußerst wichtiger Zeuge " in Betracht komme $e^{66}$, und zwei Tage später war er in den Augen der Anklagebchörde gar zum Kronzeugen einer organisierten Mordverschwörung gegen Rathenau und Scheidemann avanciert ${ }^{67}$. Doch ungeachtet eines am 27. Juni 1922 erlassenen Haftbefehls blieb der Gesuchte wochenlang verschwunden, bis cr seinen Aufenthaltsort in einem Schreiben an den Frankfurter Polizeipräsidenten selbst anzeigte. Als er daraufhin verhaftet werden konnte, war aus dem Informanten ein Tatverdächtiger geworden, der

${ }^{64}$ Am 16. 6. 1922, einem Freitag, hatte es der zuständige Amtsrichter in Frankfurt abgelehnt, sich mit Brüdigam ausführlich zu befassen, und ihn nach kurzer Vernehmung für den darauffolgenden Montag wieder zu sich bestellt, was zu einer sofortigen Beschwerde Oberstaatsanwalt Dr. Noctzels beim aufsichtsführenden Richter am Amtsgericht Frankfurt/Main führte: „Die Vernehmung und Beeidigung ist von ausschlaggebender Bcdeutung für die Fortführung des Verfahrens in der Attentatssache [Scheidemann]. Brüdigam bclastet mehrere genau bekannte Personen so erheblich, daß im Falle seiner Beeidigung die Voruntersuchung gegen diese Personen und ihre alsbaldige Verhaftung geboten sein würde." BA/P, 30.01-5055, Oberstaatsanwalt Dr. Noetzel an den aufsichtsführenden Richter beim Amtsgericht Frankfurt/M., 20. 6.1922 (Hervorhebung im Orig.). Dieser räumte in seiner Stellungnahme das Fehlverhalten des Amtsrichters ein; SAM 567-1-2649, Bericht Mittag an den Oberlandesgerichtspräsidenten, 3. 7. 1922.

${ }^{65}$ Ebenda, 567-1-2647, Bericht Oberstaatsanwalt Dr. Noetzel an den RMJ, 22. 6. 1922.

${ }^{66} \mathrm{~B} \Lambda / \mathrm{P}, 15.07-698$, Oberstaatsanwalt Dr. Noetzel an den RKO, 24. 6. 1922.

${ }^{67}$ SAM, 567-1-2647, Oberstaatsanwalt Dr. Noetzel an den RKO, 26. 6. 1922. 
zunächst nur unter dem Verdacht der „gewinnsüchtigen Begünstigung der von ihm Angeschuldigten "68, dann aber auch wegen mutmaßlicher Beihilfe zum Rathenaumord ${ }^{69}$ in der Untersuchungshaft festgehalten und erst Ende August 1922 entlassen wurde, nachdem die gegen ihn erhobenen Vorwürfe fallengelassen worden waren.

Unterdessen war der mehrfach vorbestrafte Brüdigam $^{70}$ für die mittlerweile an den Oberreichsanwalt abgetretene Anklage als Zeuge uninteressant geworden; zu deutlich schien seine Flucht im Juni gezeigt zu haben, daß er eine Beeidigung seiner damaligen Anschuldigungen scheuen mußte oder gar von KarlTillessen und Hoffmann gegen Entgelt zum Verschwinden bewegt worden war. Nur beiläufig erwog der Oberstaatsanwalt in Kassel ein drittes Fluchtmotiv: „die Furcht Brüdigams vor einer Rache der von ihm Beschuldigten“" ${ }^{\text {" Daß er }}$ gerade mit dieser für unwahrscheinlich erachteten Hypothese das Richtige getroffen hatte, zeigte die später beschlagnahmte Korrespondenz Brüdigams. Aus ihr geht hervor, daß sein überstürztes Verlassen Frankfurts im Juni 1922 einzig auf „Furcht vor der ,Fehme““72 zurückzuführen war: Ihn hatte plötzlich die Angst überfallen, von der Polizei nicht ausreichend geschützt zu werden ${ }^{73}$. Brüdigams Furcht fand kein Gehör; vor dem Staatsgerichtshof galt er als käuflicher Spitzel ${ }^{74}$ und seine Aussage als wertlos. Um das Gericht von seinen lauteren politischen Absichten zu überzeugen, reichte jetzt nicht einmal mehr Brüdigams Berufung auf einen offiziellen Auftrag des Frankfurter Polizeipräsidenten ${ }^{75}$.Zudem litt seine Darstellung nach Auffassung des Oberreichsanwalts „an innerer Unwahrscheinlichkeit, da nicht anzunehmen ist, daß, wie er behauptet, die von ihm bezichtigten Personen ihn, den Wildfremden, bei der ersten Begegnung in von ihnen gehegte Mordpläne eingeweiht haben sollten "76. Der Oberreichsanwalt übersah allerdings, daß von einem wirklichen Mordkom-

${ }^{68} \mathrm{BA} / \mathrm{P}, 30.01-5053 / 1$, Mitteilung des ORA an den RMJ, 18. 7. 1922.

${ }^{69} \mathrm{BA}$, NL 150, 10, Beiakten, H. 18. Diese Wendung hatte Brüdigam allerdings nicht zuletzt insofern wieder selbst verschuldet, als er nach seiner Festnahme auf dem Transport nach Kassel gesprächsweise verlauten ließ, daß er O.C.-Mitglied und an den entscheidenden Attentatsvorbereitungen maßgeblich beteiligt gewesen sei; SAM, 567-1-2621, Bericht Kriminalsekretär Edelmann, 4. 7. 1922.

${ }^{70} \mathrm{Vgl}$. hierzu die Zusammenstellung in BA, NL 150, 10, H.18.

${ }^{71}$ SAM, 567-1-2647, Oberstaatsanwalt Dr. Noetzel an den RKO, 26. 6. 1922.

72 Ebenda, 567-1-2621, Bericht Kriminalsekretär Edelmann, 4. 7. 1922. Auch auf dem Rücktransport nach seiner Festnahme Anfang Juli 1922 wiederholte Brüdigam mehrfach, „daß er fürchtet, daß ihm die Mitglieder der Organisation eine Kugel geben, da die Fehme strenge sei und er sie fürchte, da alle Verräter der Fehme verfallen".

${ }^{73}$ BA/P, 15.07-698, Brüdigam an den Polizeipräsidenten von Kassel, 29. 6. 1922. Tatsächlich saß er wegen des Verdachts auf Beteiligung an den von ihm ausgekundschafteten Mordplänen nicht weniger lang in Untersuchungshaft als einige der von ihm Angeschuldigten.

${ }^{74}$ Auch Scheidemann wollte „mit dem Herrn [Brüdigam] nichts zu tun haben, da er ihn für nicht ganz aufrichtig hält“. BA, NL 150, 10, H.18, Notiz vom 30. 6. 1922. Der Redakteur der Volksstimme, der Brüdigam beauftragt und bezahlt hatte, trat allerdings für seinen Spitzel ein und wies in einem Schreiben an Scheidemann darauf hin, daß Brüdigam das von ihm empfangene Geld genutzt habe, um sofort weiterhin die O.C. auszukundschaften; BA/P, 15.07-698, Marckwald an Scheidemann, 3. 7. 1922.

75 „Unter Berufung auf die im Polizei-Präsidium Frankfurt a.M. am 2. Juni stattgefundene Besprechung betreffend meine Tätigkeit bei der Organisation $\mathrm{C}$ stelle ich mich Ihnen heute zur Verfügung. Ich muß Sie als Zeugen aufrufen, daß meine Tätigkeit bei der Organisation $C$ auf Ihren Rat hin aufgenommen wurde und daß Sie mir volle moralische Deckung zusicherten. Meine Rolle bei der O.C. scheint heute mißdeutet zu werden." Ebenda, Anlage: Brüdigam an Polizeipräsident Ehrler, 29. 6. 1922.

${ }^{76}$ Ebenda, 30.01-5055, Antrag des ORA an den Staatsgerichtshof zum Schutze der Republik, 11. 6. 1923. 
plott in Brüdigams Gegenwart nie die Rede gewesen war; vielmehr war eine entsprechende Äußerung von seinen Gesprächspartnern offenbar sorgfältig vermieden worden.

Entscheidend aber ist, daß die von Brüdigam Angezeigten weder ihre Bekanntschaft mit dem Belastungszeugen noch die ihm gegenüber getanen Äußcrungen abzustreiten vermochten. Karl Tillessen etwa gestand, Brüdigam tatsächlich mit dem Auftrag, Beweise für eine Zusammenarbeit Rathenaus mit den russischen Bolschewisten herbeizuschaffen, nach München zur O.C.-Zentrale geschickt zu haben ${ }^{77}$. Hoffmann wiederum gab zu, Brüdigam habe sich in Begleitung des O.C.-Mannes Liedig bei ihm auf Empfehlung Tillessens gemeldet. Ebenso bestätigte er, Brüdigam Geld gegeben zu haben, und er leugnete nicht einmal ab, ihn beim Betreten seiner Wohnung auf deren historische Bedeutung aufmerksam gemacht zu haben $^{78}$. Schließlich bestritt auch Plaas weder seine Kontakte zu Brüdigam noch die von diesem bezeugte Szene, in der Karl Tillessen stolz auf sein brüderliches Vorbild als Erzbergermörder verwiesen hatte ${ }^{79}$. Nach diesem Geständnis, das den personellen Zusammenhang der Attentate auf Erzberger, Scheidemann und Rathenau schlaglichtartig beleuchtet, mochte Plaas auch nicht mehr bestreiten, daß Tillcssen in anderem Zusammenhang davon gesprochen habe, Rathenau niederzuschießen, und hielt als letzte Rückzugslinie nur an der Behauptung fest: „Von einem bestimmten in Kürze auszuführenden Plan war dagegen keine Rede." Genau das hatte aber auch Brüdigam betont, und es besagte nicht zwingend, daß es keinen solchen Plan gegeben hatte, sondern nur, daß er Brüdigam gegenüber nicht offengelegt worden war. Wie triftig diese Vermutung zumindest in bezug auf eines der beiden Attentate war, zeigte sich im Rathenaumord-Prozeß, als eben den von Brüdigam beschuldigten Plaas und Tillessen ihre Verwicklung in das Komplott gegen das Leben Rathenaus gerichtlich nachgewiesen werden konnte. Offenbar hatten die O.C.-Verschwörer Brüdigam doch nicht in ihre geheimsten Pläne eingeweiht, was den Einwand des Oberreichsanwaltes gegen Brüdigams Glaubwürdigkeit auch dann entkräftet hättc, wenn die Angeschuldigten Brüdigams Aussagen materiell nicht ohnehin bestätigt hätten.

Damit zeigt sich, daß das Verbrechen an Scheidemann eben jener Organisation „Consul“ zuzuschreiben war, die nach ihrer Enttarnung im Herbst 1921 für ausgehoben gegolten hatte. Mit Hustert und Oehlschläger waren zwei seit Jahren unter Ehrhardt dienende Männer ausgesucht worden, in denen sich fanatischer $\mathrm{Haß}$ auf Scheidemann mit persönlicher Entwurzelung verband. Beide hatten ihre Arbcit wie ihren Wohnort über die O.C. zugewiesen bekommen und lcbten weitgehend isolicrt. Andererseits waren ihre Kontakte zur O.C.Spitze bislang so lose gewesen, daß bei Einhaltung grundlegender Vorsichtsmaßnahmen der Apparat des Geheimbundes voraussichtlich selbst dann ungestört weiterlaufen konnte, wenn die unmittelbaren Täter nach dem Anschlag gefaßt werden würden. In der letzten Aprilwoche 1922 wurden Hustert und Ochlschläger nach Kassel in Marsch gesetzt, um sich dort mit den örtlichen Umständen und den Lebensgewohnheiten ihres Opfers vertraut zu machen. Die Kommunikation zwischen ihnen und der Frankfurter Führung um Tillessen wurde im wesentlichen über Kuriere abgewickelt, die Geld und Weisungen überbrachten; direkte

77 SAM, 567-1-2621, Aussage K. Tillessen, 3. 7. 1922.

${ }^{78}$ Ebenda, 567-1-2588, Aussage Hoffmann, 10. 7. 1922.

79 Ebenda, Aussage Plaas, 3. 8. 1922.

${ }^{80}$ „Als Brüdigam die Lage als trostlos und dem Bolschewismus verfallen hinstellte, sagte bei einer anderen Gelegenheit Tillessen etwa: Wenn wir wirklich den Bolschewismus bekommen, ist es immer noch Zeit, Rathenau niederzuschießen und sich sclbst eine Kugel ins Herz zu jagen. “ Ebenda. 
Treffen fanden, wenn überhaupt, in entfernteren Städten wie Köln statt ${ }^{81}$. In Kassel warteten die beiden dann wochenlang, bis sie am Tage vor dem Anschlag über den unbekannt gebliebenen Verbindungsmann den Ausführungsbefehl und die Blausäurespritze erhielten.

Auch nach dem Attentat stand die O.C. hinter den Tätern, wie sich zeigte, als ihnen auf ihrer Flucht nach Oberschlesien das Geld ausging ${ }^{82}$. Oehlschläger nahm daraufhin Verbindung zu Ehrhardt-Leuten in Berlin auf und wurde einige Tage später an den Studenten Gerhard Hahn in Breslau verwiesen. Hahn, den Oehlschläger vom Oberschlesischen Selbstschutz her gekannt haben wollte, gab Oehlschläger Unterkunft und half ihm und Hustert, Arbeit auf einem Waldgut in Klein-Althammer zu finden ${ }^{83}$. Hahn stritt zwar jede Beziehung zur O.C. energisch ab, wurde aber durch Zeugenaussagen und einen Brief seines Vaters, der ihn als Mitglied der Organisation Ehrhardt bezeichnete, Lügen gestraft. In Oberschlesien sondierten Oehlschläger und Hustert die Möglichkeiten zur weiteren Flucht. Zu diesem Zeitpunkt war jedoch infolge der Verhaftungen nach dem Rathenau-Attentat der aktive Kern der O.C. ausgeschaltet, die Organisationszentrale in München über die Situation in den einzelnen Ortsgruppen desorientiert. Unter diesen Umständen weitgehend auf sich selbst gestellt, gelang auch Hustert und Oehlschläger das Entkommen nicht mehr ${ }^{84}$. Ein Versuch, Pässe für Budapest zu besorgen, scheiterte, und bevor weitere von Oehlschläger erhofftc Geldzahlungen eintrafen, wurden die beiden verhaftet ${ }^{85}$. So konnte Ehrhardt seinen Werkzeugen die gerichtliche Bestrafung für ihr Verbrechen nicht ersparen. Wohl aber wußte er die Standhaftigkeit zu honorieren, mit der sie sich weigerten, die hinter ihnen stehende Organisation preiszugeben: Die 1927 von Ehrhardt mitbegründete und kontrollierte „Nationale Nothilfe " führte Oehlschläger wie Hustert und deren Familien im stillen „namhafte Beträge" zu, obwohl Hustert zu diesem Zeitpunkt längt zur NSDAP gestoßen war ${ }^{86}$.

${ }^{81}$ Möglicherweise wurden diese Besprechungen tatsächlich in der „Deutschen Klause“ in Köln abgehalten, in der Hustert und Oehlschläger im April 1921 ihren gemeinsamen $\mathrm{Haß}$ auf den früheren Ministerpräsidenten entdeckt haben wollten; BA/P, 30.01-5055, Urteil gegen Hustert und Oehlschläger, S. 4.

82 Ebenda, 15.07-340, Aussage Hänel, 7. 11. 1922.

${ }^{83}$ Hahn wurde später ebenfalls vor dem Staatsgerichtshof zum Schutze der Republik angeklagt und am 26. 9.1923 zu sechs Monaten Gefängnis wegen Begünstigung eines Verbrechens verurteilt. Er wies allerdings jede Bekanntschaft zu Oehlschläger von sich und fand hiermit vor Gericht mehr Glauben als Oehlschläger. Urteil und Anklageschrift gegen Hahn, in: Ebenda, 30.01-5055.

${ }^{84}$ Dies hatte Oehlschläger selbst einem Zeugen anvertraut: „Wir wären schon längst in Sicherheit gewesen, wenn die Rathenaugeschichte uns nicht überrascht hätte und wir Verbindung durch Gerhard Hahn mit C. aufnehmen könnten." Ebenda, 15.07-698, Der RKO an den Oberstaatsanwalt in Kassel, 22. 10. 1922.

${ }^{85}$ BA/P, 15.07-340, Aussage Hänel, 7. 11. 1922.

${ }^{86}$ Ebenda, 15.07-698, Abschrift des RKO aus dem Lagebericht des Pol. Präs. Berlin vom April 1928. 